\title{
DEVELOPMENT AND VALIDATION OF THE COPING FUNCTION QUESTIONNAIRE FOR ADOLESCENTS IN SPORT
}

\author{
A Thesis Submitted to the College of \\ Graduate Studies and Research \\ in Partial Fulfilment of the Requirements \\ for the Degree of Doctor of Philosophy \\ University of Saskatchewan \\ Saskatoon
}

By

Kent C. Kowalski

Spring, 2000

O Copyright Kent C. Kowaiski, 2000. All rights reserved. 
National Library

of Canada

Acquisitions and Bibliographic Services

395 Wellington Streot Otrawa ON KIA ONA Canada
Bibliothèque nationale

du Canada

Acquisitions et

services bibliographiques

395, ne Wellington

Ottawa ON K1A ONA

Canada
The author has granted a nonexclusive licence allowing the National Library of Canada to reproduce, loan, distribute or sell copies of this thesis in microform, paper or electronic formats.
L'auteur a accordé une licence non exclusive permettant à la Bibliothèque nationale du Canada de reproduire, prêter, distribuer ou vendre des copies de cette thèse sous la forme de microfiche/film, de reproduction sur papier ou sur format électronique.

L'auteur conserve la propriété du droit d'auteur qui protège cette thèse. Ni la thèse ni des extraits substantiels de celle-ci ne doivent être imprimés ou autrement reproduits sans son autorisation.
The author retains ownership of the copyright in this thesis. Neither the thesis nor substantial extracts from it may be printed or otherwise reproduced without the author's permission. 


\title{
PERMISSION TO USE
}

In presenting this thesis in partial fulfilment of the requirements for a Postgraduate degree from the University of Saskatchewan, I agree that the Libraries of this University may make it freely available for inspection. I further agree that permission for copying of this thesis in any manner, in whole or in part, for scholarly purposes may be granted by the professor or professors who supervised my thesis work or, in their absence, by the Head of the Department or the Dean of the College in which my thesis work was done. It is understood that any copying or publication or use of this thesis or parts thereof for financial gain shall not be allowed without my written permission. It is also understood that due recognition shall be given to me and to the University of Saskatchewan in any scholarly use which may be made of any material in my thesis.

Requests for permission to copy or to make other use of material in this thesis in whole or part should be addressed to:

\author{
Dean of the College of Kinesiology \\ University of Saskatchewan \\ Saskatoon, Saskatchewan \\ STN 5C2
}




\begin{abstract}
Two studies reported the development and validation of the Coping Function Questionnaire (CFQ) for adolescent sport participants. The final 18-item CFQ assessed three coping functions: (a) problem-focused coping consisted of six items to assess an effort to actively change and remain in the situation that was causing the stress, (b) emotion-focused coping consisted of seven items and assessed an effort to control thoughts or emotions while remaining in the situation that was causing the stress, and (c) avoidance coping consisted of five items and assessed an effort to remove oneself either permanently or temporarily from the situation that was causing the stress. Confirmatory factor analysis with data from 344 male and 339 female adolescent sport participants showed the three coping function CFQ measurement model to be acceptable for males $(T L I=.898$, CFI $=.912)$ and females $(\mathrm{TLI}=.882, \mathrm{CFI}=.898)$. All item factor loadings were above .40 for each of the three coping function scales. Simultaneous group analysis demonstrated factor loading and factor variance gender invariance for the CFQ measurement model, suggesting the questionnaire is appropriate for both males and females. Convergent and divergent validity was supported by correlations between the CFQ and select coping scales from the COPE (Carver, Scheier, \& Weintrub, 1989), the sport modified COPE (Crocker \& Graham, 1995), and Life Situations Inventory (Feifel \& Strack, 1989). Respecifications to the CFQ measurement model which improved model fit were also discussed. The CFQ appears to be a promising step towards measurement of coping function in adolescent sport samples.
\end{abstract}




\section{ACKNOWLEDGEMINNTS}

I would like to take this opportunity to thank the many students, parents, guardians, teachers, and principals who helped make this project a success. As well, I would like to thank the Saskatoon Public and Catholic School Boards for generously allowing me into their schools to conduct this research project. Thank-you to the Social Sciences and Humanities Research Council of Canada for funding this research. Thank-you to all the content specialists in the areas of coping, emotion, and perceived control for providing feedback on the scale at various points throughout the project. Thankyou to my doctoral committee members Dr. M. L. Humbert, Dr. B. S. Randhawa, and Dr. K. S. Spink for their many contributions along the way. Thank-you to Dr. D. R. Gould who acted as my external examiner and whose work I enjoy and respect. Also, thank-you to Dr. R. A. Faulkner for serving as chair of the advisory committee.

A special thank-you to Dr. Peter Crocker who has been an amazing advisor over the past few years. It is his commitment to the process of science that, more than anything, encouraged and inspired me along the way. I would be remiss not to note my thanks for the help provided by Nanette Kowalski and Sharlene Hoar who were in the trenches with me during data collection and data entry.

However, none of this process would have been possible without the constant support of my family, especially my intelligent, understanding, caring, supportive, gifted, wonderful wife Nanette who is always beside me. Thank-you. 
DEDICATION

To Carl Sagan,

a candle in the dark. 
PERMISSION TO USE.

i

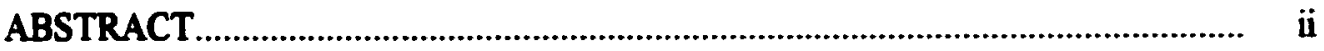

ACKNOWLEDGEMENTS........................................................................................ iii

DEDICATION................................................................................................ iv

TABLE OF CONTENTS

LIST OF TABLES

LIST OF FIGURES.

LIST OF APPENDICES.......................................................................................... x xiii

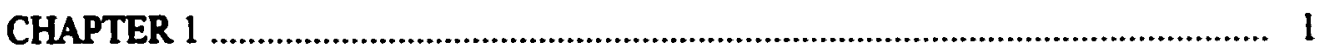

1.1 Introduction ....................................................................................................

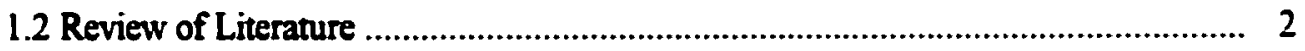

1.2.1 Cognitive-Motivational-Relational Theory ...................................................... 3

1.2.2 Measurement of Coping in Sport .................................................................... 9

1.2.3 Conceptual Issue of Assessing Coping Functions or Coping Strategies............... 15

1.2.4 Coping Dimensions on Existing Higher-order Coping Measures ........................ 17

1.2.5 Functional Themes for Coping .................................................................

1.2.6 Rationale for the Avoidance Coping Function ................................................... 23

1.2.7 Assessment of Avoidance in the Coping Literature ......................................... 25

1.2.8 Relationships Among Coping Functions ......................................................... 27

1.2.9 Gender Differences in Coping ........................................................................ 29

1.2.10 An Additional Measurement Issue: Time Frame for the Coping Recall Period... 31

1.2.11 Steps in Developing a Coping Instrument ....................................................... 36

1.2.12 Perceptions of Control and Coping ............................................................... 43 
1.2.13 Problem-Focused Coping, Emotion-Focused Coping, and Perceived Control.... 43

1.2.14 Avoidance and Perceived Control ........................................................... 45

1.2.15 Conceptualization of Perceived Control ..................................................... 47

1.2.16 Conclusion, Issues, and Hypotheses for Perceived Control and Coping ........... 51

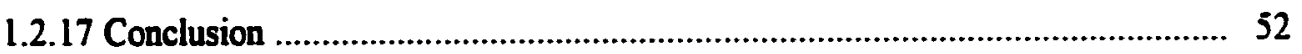

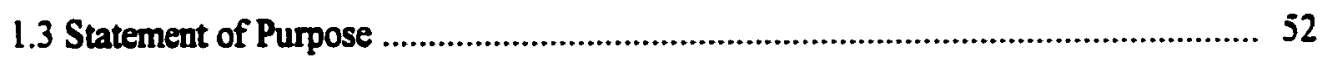

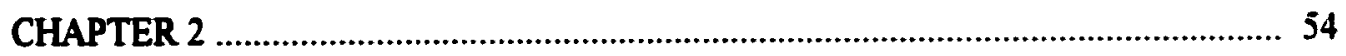

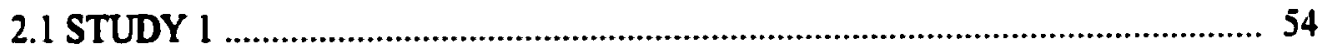

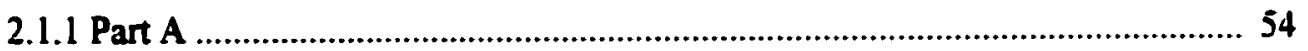

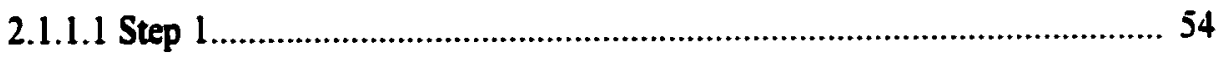

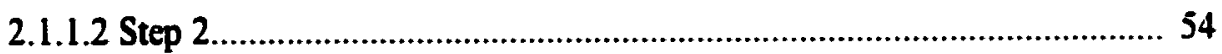

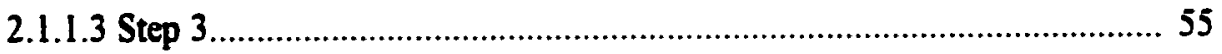

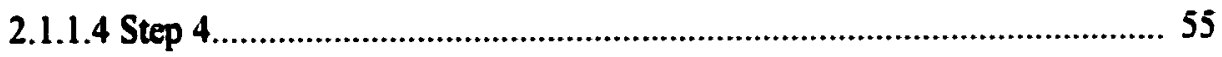

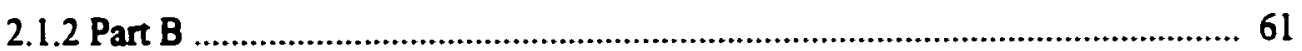

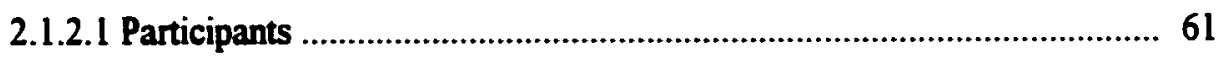

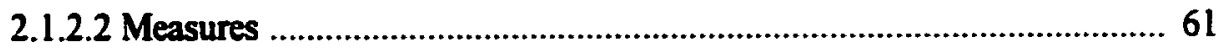

2.1.2.2.1 Demographics and Sport Participation Questionnaire (DSPQ).......... 61

2.1.2.2.2 Stress appraisal ............................................................... 62

2.1.2.2.3 Coping Function Questionnaire (CFQ) ........................................ 63

2.1.2.2.4 Perceived Control ........................................................................ 65

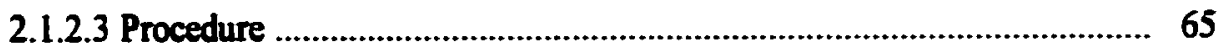

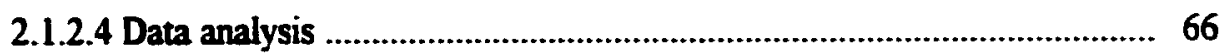

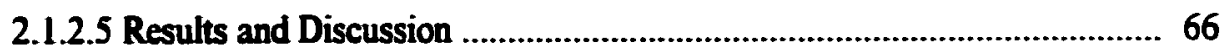

2.1.2.5.1 Descriptive Statistics............................................................... 66

$$
\text { vi }
$$


2.1.2.5.2 Relationships among items and scale reliability...........................67 67

2.1.2.5.3 Frequency, duration, and effort of coping functions ...................... 75

2.1.2.5.4 Relationships among scales .................................................... 77

2.1.2.5.5 Discussions with students ...................................................... 80

2.1.2.5.6 Scale modifications ............................................................. 81

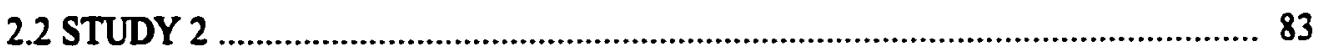

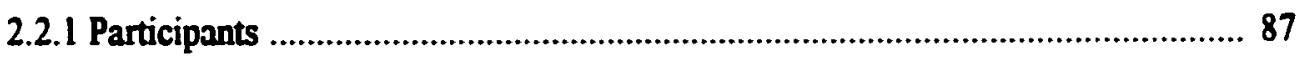

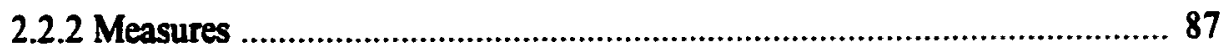

2.2.2.1 Demographics and Sport Participation Questionnaire (DSPQ)............... 87

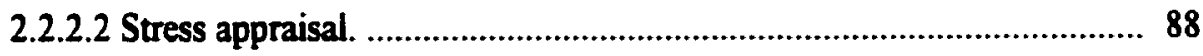

2.2.2.3 Coping Function Questionnaire (CFQ) ..................................... 88

2.2.2.4 Specific MCOPE and COPE coping scales................................. 88

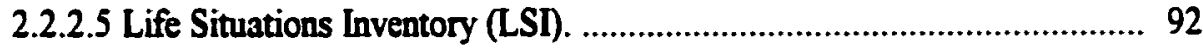

2.2.2.6 Perceived Control. ........................................................................ 93

2.2.2.7 Social Desirability Scale............................................................... 93

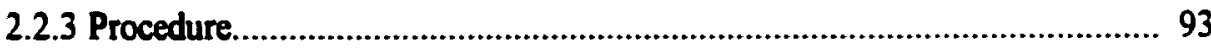

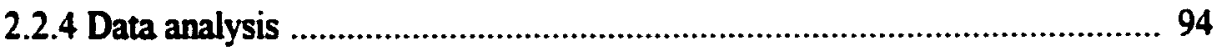

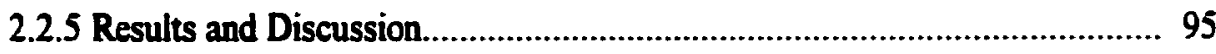

2.2.5.1 Descriptive Statistics. ................................................................. 95

2.2.5.2 Relationships among items and scale reliability................................. 102

2.2.5.3 Structural equation modeling. .......................................................... 106

2.2.5.4 Confirmatory Factor Analysis (CFA) for CFQ and other

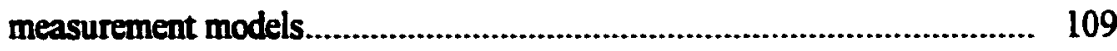

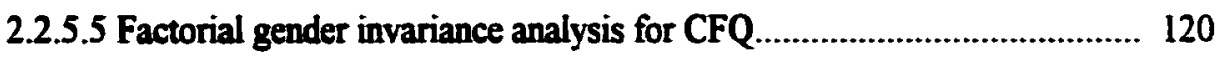


2.2.5.6 Relations between CFQ and other coping scales: Convergent

validity evidence..

2.2.5.7 Additional evidence of divergent validity.

2.2.5.8 CFQ model respecification.

2.2.5.9 Relations between coping function and perceived control

Construct validity evidence.. 132

2.2.5.10 Structural model for coping function and perceived control 134

CHIAPTER 3 144

3.1 General Discussion 144

CHAPTER 4 153

4.1 Conclusion 153

4.2 Recommendations for Future Research 154 REFERENCES. 159 APPENDICES. 171 


\section{LIST OF TABLES}

Table 2.1 Summary of Content Specialists' Item-Coping Function Matching Task. 56

Table 2.2 Summary of Content Specialists' Ratings of 22 Coping Items 58

Table 2.3 Items on the CFQ Used in Study 1 64

Table 2.4 Frequency Statistics for Age, Grade, How Long the Stressful Situation

Lasted, and When the Stressful Situation Occurred 68

Table 2.5 Descriptive Statistics for Items on the CFQ for Study 1 69

Table 2.6 Descriptive Statistics for Items on the Perceived Control Measure for Study 1 70

Table 2.7 Summary Variable Descriptive Statistics for Study 1 71

Table 2.8 Zero-order Correlations Among Items on the CFQ for Study 1 72

Table 2.9 Zero-order Correlations Among Items on the Perceived Control Measure for

Study 1 . 74

Table 2.10 Intemal Consistency Values for the CFQ and the Perceived Control Measure for Study 1 76

Table 2.11 Zero-order Correlations Among CFQ Frequency, Duration, and Effort Sub -scales 78

Table 2.12 Zero-order Correlations Among Scales for Study I 79

Table 2.13 Items on the CFQ Used in Study 2. 89

Table 2.14 Internal Consistency Values for the COPE and Modified COPE in Previous Research

Table 2.15 Frequency Statistics for Age, Grade, How Long the Stressful Situation

Lasted, and When the Stressful Situation Occurred for Males $(n=344)$ and 
Females $(\mathbf{n}=339)$ 96

Table 2.16 Descriptive Statistics for Items on the CFQ for Study 2 (Males, $n=344$;

Females, $\mathbf{n}=339$ )

Table 2.17 Descriptive Statistics for Items on the Perceived Control Measure for

Study 2 (Males, $n=344$; Females, $n=339$ ).

Table 2.18 Summary Variable Descriptive Statistics for Study 2 (Males, $\mathrm{n}=344$;

Females, $\mathrm{n}=339$ ).

Table 2.19 Zero-order Correlations Among Items on the CFQ for Study 2 (Males above diagonal, $n=344$; Females below diagonal, $n=339$ )

Table 2.20 Zero-order Correlations Among Items on the Perceived Control Measure

for Study 2 (Males above diagonal, $n=344$; Females below diagonal, $n=339$ ).

Table 2.21 Internal Consistency Values for the CFQ, Perceived Control Measure, COPE, and LSI (Males, $n=344$; Females, $n=339$ ).

Table 2.22 Scale Confirmatory Factor Analysis Results (Males, $n=344$ : Females, $n$

= 339)

Table 2.23 Factor Loading from CFQ Confirmatory Factor Analysis Results (Males, $\mathrm{n}=344$; Females, $\mathrm{n}=339$ ).

Table 2.24 Simultaneous Group Analysis for Males $(n=344)$ and Females $(n=339)$ :

Test of Factorial Invariance on the C.FQ

Table 2.25 Zero-order Correlations Among Scales for Study 2 (Males above diagonal, $\mathrm{n}=344$; Females below diagonal, $\mathrm{n}=339$ )

Table 2.26 Correlations Among Coping Latent Variables (Males above diagonal, $\mathbf{n}=$

344; Females below diagonal, $n=339$ ). 126

Table 2.27 Scale Confirmatory Factor Analysis Results for Modified CFQ Models 
(Males, $n=344$; Females, $n=339$ )

Table 2.28 Simultaneous Group Analysis for Males $(n=344)$ and Females

( $n=339)$ : Test of Factorial Invariance on the Modified CFQ (Ihem 4 Removed).

Table 2.29 Structural Model for Perceived Control Predicting Coping Function

(Males, $n=344$; Females, $n=339$ ).

136

Table 2.30 Nested Structural Models for Perceived Control Predicting Coping Function $(n=683)$. 


\section{LIST OF FIGURES}

Figure 1.1 Perceived control: Distinction among control, capacity, and control beliefs (Skinner, 1995).

Figure 2.1. Hypothesized relations between the CFQ and COPE and LSI coping scales.

Solid lines indicate expected bivariate correlations. Questionnaire source is indicated in parentheses.. 86

Figure 2.2. Hypothesized one-factor model of factorial structure for the CFQ. 112

Figure 2.3. Hypothesized three-factor model of factorial structure for the CFQ

Figure 2.4 Hypothesized five-factor model of factorial structure for the COPE

Figure 2.5. Hypothesized two-factor model of factorial structure for the LSI.

Figure 2.6. Hypothesized three-factor model of factorial structure for the perceived control measure

Figure 2.7. Hypothesized structural model for the relationship between coping

function and perceived control.

Figure 2.8. Male (top) and female (bottom) standardized path coefficients and perceived control latent factor correlations for the hypothesized structural model for the relationship between coping function and perceived control. 138 


\section{LIST OF APPENDICES}

Appendix A Demographics and Sports Participation Questionnaire

Appendix B Stress appraisal and Coping Function Questionnaire (CFQ) used in

Study 1

Appendix C Perceived control questionnaire used in Study 1

Appendix D Cover letter and consent form used in Study 1

Appendix E Research assistant confidentiality form

Appendix F Stress appraisal and Coping Function Questionnaire (CFQ) used in

Study 2 190

Appendix G COPE questionnaire

Appendix H Life Situations Inventory (LSI) questionnaire

Appendix I Perceived control questionnaire used in Study 2 199

Appendix J Social desirability questionnaire 202

Appendix K Cover letter and consent form used in Study 2 205

Appendix L Summary of results for non-sport participants in Study 2 208 


\section{CHAPTER 1}

\subsection{Introduction}

Adolescence can be very stressful as individuals confront and attempt to manage a number of demanding events (Hendren, 1990). This stress and coping process, however, is not well understood for adolescents involved in sport. There is limited stress research using adolescent sport participants, especially studies comparing males and females (Goyen \& Anshel, 1998). This lack of research is largely due to methodological and measurement problems in sport coping research (Crocker, Kowalski. \& Graham, 1998). Clearly the development and validation of coping instruments suitable for adolescent populations is critical to further our understanding of this area.

Lazarus (1990) emphasized the need for theory based instrument development in stress and coping research. He has outlined a cognitive-motivational-relational theory of emotion and coping which has contributed significantly to researchers' understanding of the stress and coping process in both sport and non-sport domains (Lazanus, 1991, 1993a, 1993b). An instrument developed from theory with strong measurement properties would provide a better understanding of how adolescent sport participants attempt to manage stress experienced in sport. The instrument must be appropriate for the demands of sport as well as an adolescent aged population.

The present study presents the development and validation of an instrument to assess three coping functions related to a self-indicated stressful situation in sport. These functions are (a) 
problem-focused coping to assess an effort to actively change and remain in the situation that was causing the stress, (b) emotion-focused coping assessing an effort to control thoughts or emotions while remaining in the situation that was causing the stress, and (c) avoidance coping assessing an effort to remove oneself either permanently or temporarily from the situation that was causing the stress. This dissertation will present research related to scale development, confirmatory factor analysis for the three factor measurement model, factorial gender invariance, and convergent and divergent validity. It was expected that the coping scale would be appropriate for an adolescent sport participant population.

\subsection{Review of Literature}

Youth experience a great number of stressors in their adolescent years that they need to manage in a functional way (Frydenberg \& Lewis, 1993; Hauser \& Bowlds, 1990; Hendren, 1990: Patterson \& McCubbin, 1987; Rice, Herman, \& Petersen, 1993). Potential stressors of youth include biological, psychological, and social forces such as the development of identity, physiological and cognitive developmental changes, social and gender role expectations, peer pressure, and heightened sexuality to name a few. The most significant factor in determining how adolescents manage a variety of stress experiences effectively is coping skills (Hendren, 1990). Coping is a person's constantly changing cognitive and behavioural efforts to manage specific demands that are appraised as taxing or exceeding a person's resources (Lazarus, 1993a, 1993b). Coping is an attempt to reduce this perceived discrepancy between situational demands and personal resources. Coping with stress varies across the age span as well as between genders (Boekaerts, 1996), and adolescence may be a critical stage in the development of coping skills (Aldwin, 1994). An individual's coping repertoire is expected to widen as he or she experiences a greater number of stressors and sees coping responses modeled by others (Boekaerts, 1996). In adolescence an individual is often confronted with life stressors for the first time, sometimes unexpectedly, but does not have the coping repertoire to deal with these new 
situations (Hauser \& Bowlds, 1990; Patterson \& McCubbin, 1987). Also, adolescence is a period in which there is increased gender intensification (sex-typed expectations become more pronounced) which shapes the way stress is experienced (Groer, Thomas, \& Shoffner, 1992).

Stress experienced by adolescent sport participants is associated with a wide variety of cognitive, behavioural, and affective factors (Gould \& Eklund, 1996). For example, excessive stress is expected to play a primary role in psychological, emotional, and physical withdrawal from a formerly enjoyable activity (Smith, 1986), a notion that has some support in youth sport research (Gould, Udry, Tuffey, \& Loehr, 1996). Specific sporting situations may be stressful depending on the specific situation and individual (Gould, Wilson, Tuffey, \& Lochbaum, 1993). Dimensions of stress identified in sport include physical demands, psychological demands, environmental demands, expectations and pressure to perform, life-direction concerns, and stressful situations that are more difficult to classify such as personal crisis and politics (Gould, Finch, \& Jackson, 1993). Specific sources of acute stress identified for adolescents include injury, coach and/or parental criticism, conflict with opponents and teammates, physical and mental errors, among others (Goyen \& Anshel, 1998). However, the stress and coping process is not well understood in youth sport because there is little systematic coping research. Our understanding of how coping influences adolescent athlete's emotional experience, as well as the link between coping and sporting performance is limited by a number of methodological and measurement problems (Crocker \& Graham, 1995; Crocker, et al., 1998). Measurement needs to consider the dimensions that are most relevant for sporting research and be appropriate for the intended population and purposes of a particular study. Therefore, a measure must be appropriate for adolescent sport participants in order to adequately assess coping with stress for this population. Lazarus (1990) emphasized the need for theory-based measurement in stress and coping research.

\subsubsection{Cognitive-Motivational-Relational Theory}


Lazarus (1991, 1993a, 1993b) developed a cognitive-motivational-relational theory which has contributed significantly to an understanding of the emotion and coping process in both sport and nonsport research. A cognitive-motivational-relational theory of emotion and coping is concemed with knowledge (a set of beliefs) and appraisals (evaluation of significance of what is happening in terms of one's well-being), as well as the individual's hierarchy of goals in situation (Lazanus, 1993a). This transaction between the individual and environment unfolds over time.

A cognitive-motivational-relational theory explains stress and emotional experience on the basis of cognitive appraisal and coping (Lazarus, 1991, 1993a, 1993b). Appraisal is a process of continuing evaluations of the significance of a person-environment relationship for one's well-being. A person will have an appraisal pattern which includes primary and secondary appraisal in a situation. Primary and secondary appraisal will determine the type and intensity of emotion.

Lazarus argued primary appraisal is concemed with what is at stake for personal well-being in a specific person-environment relationship. The key primary appraisal variables in emotion generation include goal relevance, goal congruence or incongruence, and the type of ego-involvement. Goal relevance concerns whether or not an individual's goals are involved in a situation. Emotions will be more intense if more important goals are at stake. If the situation does not involve personal goals, there will be no emotion. Goal congruence or incongruence refers to the extent to which a situation is consistent or inconsistent with an individual's goals. If the situation is one that facilitates personal goals, there will be positive emotions. If personal goals are thwarted, negative emotions will result. Type of ego-involvement refers to what aspects of ego-identity might be involved, including such aspects as self- and social-esteem, moral values, ego-ideals, persons and their well-being, meanings and ideas, and life goals. Different emotions will be associated with various aspects of egoidentity. Important secondary appraisal variables include attributions regarding blame and credit, coping potential, and future expectations regarding the person-environment relationship (Lazarus, 
1991). Blame or credit refers to who was responsible for the situation and whether or not it was controllable. Coping potential refers to whether or not one thinks adequate coping resources are available to deal with the situation. Future expectations refers to whether or not the current situation is expected to change. The primary and secondary appraisal processes occur simultaneously and are constantly changing.

The appraisal and emotion process can be further understood by providing an example from sport in which anger would likely occur. A female basketball player is playing a game in which she is unable to stop an opposing player who has just scored 30 points, mostly against her. The situation is one that is important to the individual (goal relevance) because her self-esteem is closely tied to her performance on the basketball court (type of ego-involvement). Because of her inability to stop the opposing player there is high goal incongruence, and hence, she is expected to experience an intense negative emotion. She also feels that the opposing player has intentionally scored many points on her to make her look bad in front of the fans. Therefore, she attributes blame to the other person and feels the opposing player did not have to run up the score like she did. Our player also feels there is little she could do to stop the other player (coping potential) and things were not going to change because the game was almost over and both players were now on the bench (future expectations). As a result of this appraisal process, the player would likely experience a high degree of anger towards the other player. Other emotions would be experienced if aspects of the appraisal process changed. For example, if the basketball player blamed herself for not being able to stop the opposing player, as opposed to feeling the other player was nunning up the score to make her look bad, then she would be more likely to experience guilt, shame, or anger towards herself. Only by understanding both primary and secondary appraisal can one understand the generation of emotion. For example, the basketball player described above would not experience as intense or very little negative emotion if she bad perceived there were a number of coping options (e.g. work harder, play a different defensive system) 
available to her. This may be in spite of the goal being important and having a large goal discrepancy.

Coping is proposed to be a mediator variable of the continuing appraisal and emotion process (Folkman \& Lazarus, 1988). A person-environment transaction is initially appraised as threatening, harmful, or challenging, which generates an emotional experience. This initial appraisal and emotion then influences the coping process, which then changes the nature of the person-environment relationship as well as subsequent appraisal, emotion, and coping. Thus, individuals will engage in coping efforts whenever they experience emotion in an effort to reduce the perceived demands versus perceived personal resources discrepancy. For example, the basketball player described above may confront the opponent following the game in an attempt to deal with the situation (possibly in an attempt to prevent it from happening again in the future or just to make herself feel better). As a result of the confrontation, the player will reappraise the situation and possibly experience other emotions. In her confrontation she may have verbally insulted the other player in front of all the fans in an attempt to rescue her social-esteem. Doing so could potentially create a situation in which she feels she has achieved her goal of being perceived by others as being tough, and hence she will experience positive emotions. Alternatively, she may find that although she attempted to enhance her socialesteem, the crowd instead reacts in a hostile manner towards her. She then may experience shame following the competition because she blames herself for acting immature.

Lazarus (1993a, 1993b) considers stress to be a subset of the emotions. Each of the emotions he identified arises from a different plot about the relationship between a person and the environment. By regarding stress as a subset of emotion, Lazarus does not suggest that the concept of stress is no longer important, but rather the concept of emotion includes that of stress, and both are subject to appraisal and coping. Although an understanding of how individuals manage specific emotions may tell us more about the coping process compared to general stress relations, it may be premature to proceed to the specific emotion level in sport given the present level of understanding. The strategies 
an individual uses to manage events characterized by different emotions might be quite unique. However, there is little theory specifying the specific relationships between each emotion and coping behaviour. It may be necessary to focus on the general area of stress at this point in time.

Within a cognitive-motivational-framework coping is expected to serve two primary functions, although Lazurus (1993a) has recognized coping may serve many functions. Problem-focused coping is an attempt to change the situation that is causing the stress. An individual attempts to directly act upon the environment or change his or her part in that environment. For example, the basketball player may have tried a number of problem-focused strategies throughout the course of the game to try to stop the opposing player from scoring. She may have tried different tactics to neutralize the scoring, tried talking to the referee to make calls against her opponent, or tried to increase her effort to make scoring more difficult. On the other hand, emotion-focused coping is an attempt to control the emotional experience, or produce a subjective change, in the stressful situation. For example, the basketball player may have shouted out in anger in an attempt for emotional release, or she may have engaged in self-talk to try to convince herself that it was only a game and was not really important in the big scheme of things. However, it is likely that many coping strategies serve multiple functions simultaneously. For example, yelling at the referee may have been an attempt to get more calls against the opposing player, but may also have acted as an emotional release.

An important aspect of coping is to manage action tendencies associated with emotional experience. An action tendency is a biological predisposition to act in a predetermined way that is associated with each particular emotion (Lazarus, 1993a). However, these action tendencies are often inconsistent with social regulations and need to be inhibited by coping processes. Thus, according to Lazarus, although each emotion is characterized by a specific action tendency, coping is a more deliberate, leamed, psychological, and complex process. For example, the action tendency associated with anger is to attack. However, given social rules governing the use of violence in sport, a basketball 
player may need to inhibit this action tendency to attack in order to prevent more severe consequences from occurring.

The model presented by Lazarus is useful for understanding coping by adolescents. Research with children and adolescents has supported the distinction between problem- and emotion-focused coping, and that these strategies vary as a function of cognitive appraisal and situational factors (Compas, Malcame, \& Banez, 1992). For example, in their study with adolescent sport participants, Goyen and Anshel (1998) categorized a list of coping responses as being either problem- or emotionfocused. They found different percentages of adolescents used problem- and emotion-focused coping strategies depending on the type of stressor.

Boekaerts (1996) has presented a model of children's and adolescent's coping process consistent with the framework presented by Lazarus (199l, 1993a, 1993b) in his cognitivemotivational-relational theory. She proposed that cognitive appraisal and subsequent emotions are based on an adolescent's perception of the situation, his or her coping repertoire, and coping goals. Cognitive appraisal may be age-dependent, as adolescents of various ages may perceive different situations to be stressful. They may also become more skillful at appraising factors such as the meaning of the situation, personal ability to control the situation, changeability of the situation on its own, possible recurrence of the situation, uncertainty created by the situation, and personal experiences with that type of situation. Based on cognitive appraisal, an adolescent will develop an intention to cope in a certain way. This intention will be the primary determinant of which coping strategies will be selected. As with cognitive-motivational-relational theory, each component of the coping process is expected to have a bidirectional influence on the rest of the system. The components of Boekaert's model are remarkably similar to cognitive-motivational-relational theory, although she makes no mention of that particular theoretical framework. Taken together, research and theory in adolescent research suggests that the cognitive-motivational-relational theory has potential application for 
understanding the coping process for adolescents.

Researchers have only begun to understand the coping process in sport. Most of the current coping instruments used in sport research have been strongly influenced by the transactional model of coping. However, coping measures aimed at understanding the coping process have often been empirically, rather than theoretically, developed. Further, most instruments were developed originally for non-sport populations.

\subsubsection{Messurement of Coping in Sport}

Coping has primarily been measured in sport and physical activity studies with sport modifications of Folkman and Lazarus's (1985) Ways of Coping Checklist (WCC) and Carver, Scheier, and Weintraub's (1989) COPE scale. Various versions of the WCC have been used with distance runners (Madden, Kirkby, \& McDonald, 1989), basketball players (Madden, Summers, \& Brown, 1990), competitive athletes from various sports and levels (Crocker, 1992), and female athletes (Haney \& Long, 1995). Modified versions of the COPE have been used to examine coping strategies used by disabled athletes (Bouffard \& Crocker, 1992), competitive athletes from various sports and levels (Crocker \& Graham, 1995; Eklund, Grove, \& Heard, 1998; Grove, 1995), and youth swimmers (Crocker \& Isaak, 1997).

Sport modifications of the WCC and COPE ask athletes to recall recent, stressful situations and how the situation was managed. Athletes indicate what coping strategies were used, as well as the extent to which they used each strategy. These instruments have a number of items which assess underlying coping dimensions, such as seeking social support for emotional reasons, wishful thinking, increasing effort, active coping, planning, as well as numerous other dimensions. The number of dimensions on the scales generally range from approximately 8 to 13 in number (the exception is Haney and Long's [1995] modification which attempted to assess higher-order coping strategies, and thus, had only two dimensions; engagement and disengagement coping). These various coping 
dimensions were developed to reflect either the intention to change the situation (problem-focused coping) or the regulation of emotional experience (emotion-focused coping), which are the two key dimensions in the transactional model of coping (Lazarus, 1991). The reliability of the various scales has been assessed by the use of internal consistency analysis. Internal consistency values generally have ranged from between .65 and .85 , although numerous scales in various studies had internal consistency values lower than .65 .

The most glaring weakness of the modified WCC and modified COPE instruments is that their validity has not been systematically demonstrated for sporting populations, more specifically for adolescent sporting populations. Validity support for both the modified WCC and COPE has been limited. Madden et al. $(1989,1990)$ found that scales in the modified WCC were related to performance slumps and increased stress. Crocker (1992) provided some content and construct validity evidence by modifying items to increase face validity for sport and then demonstrating that athletes use a wide range of cognitive and behavioural strategies to manage sport-related stress. Haney and Long (1995) showed some evidence that coping strategies were related to performance and control appraisals. The validity of the modified COPE instruments has received even less attention than the modified WCC. Coping strategies on the modified COPE have been related to affect and shown to differ for males and females (Crocker \& Graham, 1995). Also, the modified COPE subscales are similar to categories of coping strategies found by Gould et al. in qualitative research with national champion figure skaters (Gould, Finch, \& Jackson, 1993) and U. S. Olympic wrestlers (Gould, Eklund, \& Jackson, 1993).

Establishing validity for sporting populations for these instruments is important because both original versions of the WCC and COPE were initially designed for non-sport populations. Sport populations likely vary a great deal in the types of demands they face and the coping strategies employed compared to non-sporting populations. For example, sport participants are rarely dealing 
with situations which the involve life and death battles reported in the health literature. However, sport may present additional demands such as the presence of the media, aggressive opponents, and bad officiating that are not common in other areas such as health and academics. The item modification for sport does provide some content validity support, but these instruments may not adequately tap the domain of coping for an athletic population.

Another weakness of these instruments has to do with their factor stability. Factor stability refers to the degree to which observed measures are constant in their representation of constructs (Schutz, 1998). Factor stability is important because if this type of structural stability does not hold, then a researcher cannot be confident that the measured items are measuring the same construct over time. Most studies using the modified WCC or COPE have employed factor analysis, either to develop the scale dimensions or examine the factor structure. Results have generally shown little consistency in factor stability in the WCC across studies, with items tending to change factors. For example. Crocker (1992) found the modified WCC had a different factor structure than the original WCC (Folkman, Lazanus, Dunkel-Schetter, Delongis, \& Gruen, 1986). Also, the factor structure found by Crocker was different than found in other sport studies using the WCC. As an example, the item "I knew what I had to do, so I doubled my efforts to make things work" loaded on a problem-focused coping factor in the Crocker study, but was on an increased effort dimension in Madden's et al.'s (1990) work. This clearly is a problem if the items on the scales are posited to be assessing underlying unidimensional coping dimensions. The factorial validity of the COPE and modified COPE is generally stronger than for the WCC (Crocker et al., 1998). Eklund et al. (1998), using groups of athletes recalling performance slumps, found that four different COPE models ( 13 to 15 factors) and four different modified COPE models (10 to 12 factors) provided an adequate fit to the data using confirmatory factor analysis. Intercorrelations among latent factors were similar to previous research using the COPE and modified COPE. Despite this apparently strong factor structure on the COPE, 
numerous scales on the COPE have been found to have internal consistency values below .70 , and frequently much lower. For example, Crocker and Graham (1995) found the active coping, behavioural disengagement, wishful thinking, and denial scales all to have internal consistency values below .70 , with denial being as low as .42 . Likewise, in a study by Crocker and Isaak (1997) with adolescent sport participants, the denial and behavioural disengagement scales were dropped from the aualysis for having internal consistency values below .50 .

The instability of factor scores and numerous low coefficient alpha values in previous research suggests that either the items are not tapping homogeneous underlying dimensions or that factor analysis and internal consistency by themselves are inadequate standards by which to judge the measures. Stone, Kennedy-Moore, Newman, Greenberg, and Neale (1992) bave questioned the over reliance on factor analysis in coping research. First, the elimination of itenıs which do not load highly on any factor, but rather on multiple factors, is problematic because each item represents a particular coping response, and elimination of these items will likely decrease the scale's content validity. Second, factor scores and coefficient alpha rely on inter-item correlations, but in particular domains the use of one strategy may lessen the utilization of others in that same domain, especially if it is successful. Third, factor-based scores rely on items loading on only one factor, but some strategies may serve a number of purposes. Aldwin (1994) echoed Stone and his colleagues' concern by suggesting that, for the most part, the original factor items have not been theoretically driven.

Despite the criticisms regarding the use of intemal consistency analysis to evaluate reliability of coping instruments (Aldwin, 1994; Stone et al., 1992; Thoits, 1991), these methods are likely appropriate to evaluate reliability on coping measures. Rather than modifying or relaxing traditional statistical techniques in coping scale construction researchers may need to work harder at effectively reaching psychometric standards (Parker \& Endler, 1992). Ghiselli, Campbell, and Zedeck (1981) suggested that a domain sampling model is an appropriate model to follow when measuring most 
psychological variables. The model of domain sampling proposes that a trait is a group of behaviours all of which have some property in common. The reason coping may be difficult to assess is that often there may be a low covariation among components (coping strategies) within a given coping function (the purpose the coping strategy serves), which has led some to suggest intemal consistency analysis and factor analysis techniques may be inappropriate when assessing coping measures. For example, seeking out information and increasing effort may both serve a problem-focused coping function, but the successful use of one may reduce the need to use the other strategy. However, according to domain sampling theory, a domain consists of an infinite number of behaviours or cognitions that make up the domain. A particular instrument will not be able to measure the complete domain, but rather, only measure a sample of that domain (Ghiselli et al., 1981). What coping researchers need to do is to find a collection of items which best represent the proposed dimension.

From a domain sampling perspective, internal consistency analysis is an appropriate method of assessing reliability for even a dynamic trait. Internal consistency analysis reflects the correlation between the existing measure and a hypothetically parallel measure (Ghiselli et al., 1981). Items that are truly measuring the same underlying dimension, and trying to account for an adequate proportion of that domain, should have acceptable item-total correlations indicating the items are measuring the same dimension. If the items are not correlated, then we cannot be confident we are measuring the characteristic intended to be measured. Thus, it is consistent with domain sampling theory that coping dimensions should be composed of items that are related to one another because they are all attempting to represent some underlying dimension. The difficulty is in developing items with adequate psychometric properties and still remain consistent with theory.

Another potential limitation in the way coping is assessed on both the modified WCC and COPE is the meaning of the scale scores. On both scales, individuals are asked to report the extent to which they use particular strategies. Stone, Greenberg, Kennedy-Moore, and Newman (1991) 
criticised this approach because it is unclear whether the extent to which athletes rate the use of coping strategies means that they used the strategies often, for a long period of time, or with a great deal of effort. The assessment of coping potentially could be strengthened by clearly defining what is meant by extent, or by assessing frequency, duration, and intensity of use of particular strategies separately. This would also allow the examination of how different types of coping efforts occur under different conditions.

Coping assessment tools also need to adequately reflect the transactional nature of stress and coping. There are various stages of the stress process, including anticipation of the stressor, confronting the stressor, the possibility of being overwhelmed, and subsequent evaluation of coping responses (Meichenbaum, 1985). When athletes are asked to recall a recently stressful situation, it is unclear as to what stage of the stress process they are referring. Depending on the stage of stress they are reporting, coping strategies will likely be much different. Thus, it is important for coping instruments to try to account for the stage of the stress process that is being referred to when coping strategies are reported (Stone et al., 1991). Emotion and coping are constantly changing (Lazarus, 1991). Folkman and Lazarus (1985) showed that both emotion and coping changed across three stages of a college mid-term exam. Similarly, Scherer, Drumheller, and Owen (1993) showed that appraisal and coping changed over the stages of stress. Thus, when an athlete reports use of two different coping strategies, is that athlete suggesting that the two strategies were used to manage different stressors at different stages of the stress process or both strategies at the same stage? Because of the dynamic nature of coping, and its close relationship with stress and appraisal, if athletes are reporting different strategies for different stages of the stress process, then they are actually reporting on different stressors. If coping efforts are summed over the whole stress experience, it is unclear what the athletes are trying to manage. A solution to the problem of what stage of stress are athletes reporting would be to follow the athlete over time and use multiple measurements in an effort to try 
to capture the unfolding nature of emotion and coping. Another solution may be sinply to ask what coping strategies were used at various stages of the stress process. Breaking down the emotion process into stages may serve as a cue for individuals to help them remember bow they coped at various stages of the process.

\subsubsection{Conceptual Issue of Assessing Coping Functions or Coping Strategies}

A key question to be answered is whether coping strategies should be assessed at more global or more specific levels (Carpenter, 1992). More specific coping strategies, such as those in both the modified WCC and COPE, may be too situation specific. Measuring specific coping strategies may not allow researchers to address more basic coping questions regarding stability of coping goals over time and changes in coping across situations (Aldwin, 1994). As well, specific coping strategies will likely be more sample specific and more likely to vary as a function of a specific stressor (Compas, et al., 1992). On the other hand, global coping dimensions may not be very useful to understand what coping strategies were used in specific situations. The resolution of this seems to be that both types of measures are needed, and the use of one or the other will depend on the research questions that are being asked. Therefore, there is a need for both micro- and macro-level analysis of coping.

The most appropriate method of assessing coping in some situations may be to not only assess specific coping strategies but the function of the coping behaviour as well (Carpenter, 1992). The modified WCC and COPE scales measure specific coping strategies (i.e. "I took it out on other teammates" and "I made a plan of action and followed it"), which are proposed to fall within higherorder coping dimensions (problem- and emotion-focused coping). The use of these scales focus on the subtypes (e.g. social support, problem-solving, religiosity) within the higher-order coping dimensions. Compas et al. (1992) suggested that coping subtypes will vary, to a large extent, on the characteristics of the sample.

The importance of looking at coping functions, as well as specific coping strategies has been 
stressed in the literature (Carpenter, 1992). The main reason for looking at coping function is that most behaviour can serve more than one coping function depending on the specific person-environment relationship (Stone \& Neale, 1984), and often a behaviour can serve multiple functions simuitaneously (Patterson \& McCubbin, 1987). Gould, Eklund, and Jackson (1993) found elite athletes were not limited to particular coping strategies. If multiple strategies can be used, it may be useful to look at the function those strategies serve.

When looking at the relationship between coping and appraisal variables (such as controllability, future expectancies, and goal importance), the assessment of coping function may be a useful level of analysis. For example, one individual may be angry at an opponent during a hockey game and retaliate in an attempt to stop an opposing player from committing unsportsmanlike play. In another situation, an athlete may feel anxious about an upcoming competition, and in an attempt to reduce the uncertainty of the future outcome, spend additional time improving sport-related skills. At first glance, these two situations seems very different and would indeed be very different on measures such as the modified WCC and COPE. On the other hand, if analysis is conducted at a more global level, these situations may be similar in that there is at least some degree of perceived personal control over the situation and the coping strategy is one of trying to change the situation. At a global level, these situations may be very similar in terms of appraisal patterns and coping functions. This relationship would not be observed in a micro-level analysis.

If a scale is to be developed to capture more general coping dimensions, the question is what dimensions should be included on the scale? A cognitive-motivational-relational theory of coping and emotion suggests that coping consists of problem-and emotion-focused coping efforts (Lazarus, 1991). Problem-focused coping efforts are aimed at changing the self or the environment to alter the emotional experience. Examples of strategies typically classified as problem-focused coping include planning, confrontation, skill development, and suppression of competing activities. Emotion-focused coping, 
on the other hand, is not an attempt to change the situation but rather an effort to regulate emotional arousal and distress, and includes such efforts as relaxation, seeking sympathy, and reappraisal of the situation. Lazarus (1993a) recognized that coping strategies may have many functions, only two of which are problem- and emotion-focused coping. Most existing scales, such as the WCC and COPE were developed to fit this two dimensional framework, but these scales are designed to assess coping at the sub-domain level rather than as higher-order coping dimensions. Thus, adequate measurement of even these two (problem- and emotion-focused coping) broad dimensions is needed.

\subsubsection{Coping Dimensions on Existing Higher-order Coping Measures}

Some researchers have attempted to assess more general coping dimensions. The number and types of dimensions on existing coping measures varies. Examples of general dimensions that have been used (each of which will be discussed below) include engagement and disengagment coping (Haney \& Long, 1995), problem solving, seeking social support, and avoidance (Amirkhan, 1990), active coping, internal coping, and withdrawal (Seiffe-Krenke, 1995), task-oriented coping, emotionoriented coping, and avoidance-oriented coping (Endler \& Parker, 1990), and problem-focused coping, appraisal-focused coping, and emotion-focused coping (Patterson \& McCubbin, 1987).

Haney and Long (1995) modified the WCC to assess higher-order coping strategies. The two higher-order coping dimensions were engagement (managing a situation through active coping) and disengagement (distancing or detaching oneself from the task). This modified WCC consisted primarily of items from the original WCC and was developed through factor analysis. Although Haney and Long's modified WCC was an attempt to assess coping at a more global level and was modified specifically for a sporting population, the approach-avoidance coping methodology for assessment may not be adequate. There are different functions of approach and avoidance oriented coping strategies (Roth \& Cohen, 1986). An individual may continue to engage in a task and use more emotion regulation strategies, or engage in a situation with efforts aimed at changing the situation. 
Thus, the engagement-disengagement approach may actually be too general when looking at the relationship between coping strategies and appraisal variables. Also, although the modified WCC was designed for a sporting sample, the items were from the original WCC, which was developed for nonsporting populations and may not adequately reflect the experience of an individual engaged in sport. Also, assessing higher-order dimensions of coping may require items written at a similar global level. Amirkhan (1990) developed a three factor coping measure for a heterogeneous community sample. His Coping Strategy Indicator (CSI) was developed primarily from empirical methods and resulted in problem solving, seeking social support, and avoidance coping dimensions. Although a strength of the CSI is its psychometric properties, some have argued that social support may not be suitable as a coping dimension (Endler \& Parker, 1993). Social support can serve a number of functions, from talking to others to help solve a problem, to having others near for emotional support. Thus, the CSI dimensions seem to contain both coping strategies and coping functions at the same level of analysis, or may instead measure three types of coping strategies. A cognitive-motivationalrelational theory of coping and emotion seems to suggest that social support can be used for both problem- and emotion-focused reasons, but may not be an independent dimension at the functional level. The CSI social support items seem to include strategies with both emotion- and problem-focused function. For example, the social support scale includes "Talked to people about the situation because talking about it helped you feel better" (emotion-focused) and "Went to a friend for advice on how to change the situation" (problem-focused). Thus, it appears that social support is an important aspect of coping but may be best measured at the coping strategy level rather than at a coping function level where there are fewer more broad coping dimensions.

Seiffge-Krenke (1995) also assessed coping using a three dimension scale which included active coping, internal coping, and withdrawal. The scale was developed for adolescents and largely through factor analysis procectures. At first glance, this scale appears to capture the coping process 
and represent the cognitive-motivational-relational theory by including problem-and emotion-focused coping as well as a separate withdrawal dimension. Closer examination of the items within each scale, however, indicates there are problems surrounding the meaning of each. The active coping scale seems to fairly well represent problem-focused coping efforts aimed at changing the situation, with items such as "I try to solve the problem with the help of my friends" and "I look for information in magazines, encyclopaedias, or books". The intemal coping dimension, on the other hand, seems to include both problem- and emotion-focused coping items. Items such as "I tell myself that there will always be problems" seems to have a strong emotion-focused coping function, whereas the item "I compromise" would appear to serve more as an attempt to change the nature of the person-environment transaction. Also, the withdrawal scale has items that clearly indicate efforts to leave the situation, such as "I withdraw because I cannot change anything anyway", and items that seem to serve more emotionfocused coping function but do not necessarily detach the person from the situation (i.e. "I try to let my aggression out (with loud music, riding my motorbike, wild dancing, sport, etc.l').

The problem-focused, emotion-focused, avoidance/withdrawal dimensions for a coping scale appear to have some theoretical appeal, and again appear in Endler and Parker's (1990, 1993, 1994) Coping Inventory for Stressful Situations (CISS). The scale was developed from theoretical considerations and emphasized problem- and emotion-focused coping items. Factor analysis techniques found that three factors emerged, including task-oriented coping, emotion-oriented coping, and avoidance-oriented coping. The CISS demonstrated adequate reliability and validity for undergraduate students, but there are some limitations in the CISS that warrant development of an additional coping measure. First, the CISS was designed to assess coping styles as opposed to actual coping behaviours in response to a specific person-environment transaction. In fact, Endler and Parker, stressed the need for supplementary situational measures of coping. In studies designed to look at the relationship between specific appraisals and coping behaviour, there is a need for a more 
situation specific measure because actual coping likely depends a great deal on the appraisals relevant to a specific emotional experience. Also, coping may be very different at various stages of the coping process, and assessment of coping styles aggregates coping over the entire process. Second, similar to other measures, the CISS relied heavily on factor analysis in its development, and items that may be theoretically important may have been discarded because they did not fit any of the factor structures. Third, a problem common with most measures of coping, is that the CISS was not developed for a sporting population. Although numerous items are likely relevant to sport (i.e. "Adjust my priorities" and "Take time off and get away from the situation"), there may be other coping strategies that are unique to sport which would add to scale validity when used with a sporting population. For example, strategies used by athletes such as visualization and keeping in shape on own identified by Gould, Finch, and Jackson (1993) may be difficult to report within the framework of the CISS. Fourth, items in the emotion-oriented coping dimension seem to reflect largely emotional reaction (i.e. "Become very upset"; "Feel anxious about not being able to cope") and self-blame (i.e. "Blame myself for having gotten into this situation"; "Blame myself for not knowing what to do"), as opposed to reflecting efforts to try to control emotions. A subsequent shorter version (CISS-SSC) has been developed to assess coping in specific situations (Endler, Kantor, \& Parker, 1994); however, many of the limitations in the CISS are common to the CISS-SSC.

One measure that has been developed with high school students is the Adolescent Coping Orientation for Problem Experiences (A-COPE; Patterson \& McCubbin, 1987). The A-COPE was designed to assess three functions of coping; problem-focused coping, appraisal-focused coping, and emotion-focused coping. The A-COPE asks students to record how often they used specific behaviours when they faced difficulties or felt tense, and thus appears to measure coping styles. Twelve coping factors on the A-COPE include ventilating feelings, seeking diversions, developing selfreliance, developing social support, solving family problems, avoiding problems, seeking spiritual 
support, investing in close friends, seeking professional support, engaging in demanding activity, being humorous, and relaxing. Intemal consistency values found by Patterson and $\mathrm{McCubbin}$ were generally above .70 for the scales (notable exceptions were developing self-reliance, .69 ; seeking professional support, .50 ; engaging in demanding activity, .67; relaxing, .60$)$. They also found that some coping strategies (e.g. solving family problems, seeking spiritual support, and engaging in a demanding activity) mitigated against substance use while others (e.g. investing in close friends, ventilating feelings, and developing social support) facilitated substance use. The authors concluded that most of the coping patterns addressed more than one coping function, and thus, the A-COPE appears to assess coping strategies (similar to WCC and COPE) as opposed to coping function.

\subsubsection{Functional Themes for Coping}

A model of coping functions based on sport and non-sport coping research and a cognitivemotivational-relational theory of emotion and coping can serve as a basis for developing a measurement instrument for sport. The present study proposed that there are three functional themes for coping in sport. First, there is an effort to actively change (through either directly acting upon the environment or changing our part in that relationship) and remain in the situation that was causing the stress. Second, there can be efforts aimed at controlling thoughts or emotions while remaining in the situation that was causing the stress, without actually changing that relationship itself. These first two functional themes for coping come directly from a cognitive-motivational-relational theory of coping and emotion and are what Lazarus refers to as problem- and emotion-focused coping.

Problem-and emotion-focused coping are included as an important distinction on most coping scales. Problem-focused efforts generally include things such as confrontive coping, active coping, and planful problem-solving. Emotion-focused coping includes things like distancing, self-control, accepting responsibility, and positive reappraisal. Other forms of coping such as seeking social support have been proposed to serve both functions. The coping measures reviewed earlier all include 
this distinction between problem- and emotion-focused efforts. Research in sport has shown that individuals use both problem- and emotion-focused coping strategies to deal with stressful situations (e.g. Crocker \& Graham, 1995; Crocker \& Isaak; Goyen \& Anshel, 1998).

A third functional theme for coping in sport that has been proposed is an effort to remove oneself either permanently or temporarily from the situation that was causing the stress. This effort to avoid the stressful situation has been proposed to be important in coping research, and has been included on existing higher-order measures either as withdrawal (Seiffge-Krenke, 1995) or avoidance (Amirkhan, 1990; Endler \& Parker, 1990, 1993, 1994). Although current research perspectives on withdrawal and avoidance differ conceptually both from a theoretical and measurement perspective, they all seem to reflect some effort to avoid or remove oneself from a stressful situation.

Avoidance may be a very relevant dimension for sporting researchers because many times there is at least the possibility of avoiding a particular sporting environment when faced with stress. For example, an athlete may be in conflict with a coach and quit the team or miss practice to avoid dealing with the situation. Another example is someone dealing with the time management stress caused by both high academic and sport demands who withdraws from the sport to reduce the time management stress. The option to avoid the situation may make sport distinct from other areas of coping research where the option to avoid the stressful situation simply is not presunt or very difficult. It is much more plausible to expect the coping option of avoidance, at least in terms of removal from the stressful situation, to be more salient for youth in basketball than youth experiencing puberty or terminal illness. The high incidence of drop-out from organised sport among children and adolescents points to the very real choice to withdraw (Petlichkoff, 1996).

Avoidance differs from problem- and emotion-focused coping in that an individual avoiding a situation has actually removed him or herself from the stressful situation, whereas problem- and emotion-focused coping efforts help the athlete manage the stressful situation, but the individual 
remains in the situation. For example, when engaged in an emotion generating athlete-coach conflict one athlete may quit the team, whereas another athlete may use cognitive strategies such as self-talk to help manage the emotional experience. In the first case, the troubled athlete-coach relationship has been removed, but for the second athlete the situation remains, and either the athlete has effectively managed emotion or must engage in other strategies in a further attempt to do so.

\subsubsection{Rationale for the Avoidance Coping Function}

Avoidance is expected to be an important aspect of coping with stressful situations in sport. A number of children and adolescents withdraw from organized sport each year, and reasons for withdraw are numerous, including such factors as too much time required, overemphasis on winning, fear of failure, too much pressure, and dislike for the coach (Petlichkoff, 1996). Not all individuals who withdraw drop-out for similar reasons. Generally, there are three distinct types of drop-outs that have been identified; (a) volunteer drop-outs (not unhappy in present situation but wanted to try other activities), (b) resistant drop-outs (values sport participation but was unhappy in the present situation), and (c) reluctant drop-out (forced out of sport participation due to factors such as structure of sport, prohibitive cost, and injury) (Petlichkoff, 1996). Therefore, withdrawal needs to be considered on a continuum and can take various forms. Some forms of withdrawal simply reflect a child or adolescent's interest in other sport and non-sport activities and may not be stress related, as with the volunteer dropout.

Weiss and Petlichkoff (1989) have suggested that it is the resistant drop-outs who should be of concern because they are dropping out for stress/emotion related reasons but still value sport involvement. A child weighs the costs and benefits of participation, and when the costs become too high relative to the benefits of participation there is a greater chance of withdrawal, even if the situation is relevant to important goals.

Most children are not discontinuing sport involvement due to excessive competitive stress 
(Gould, 1993), however, a significant number of athletes in sport do experience a great deal of sport related stress. The long-term consequences of stress in sport are not known but there can be negative physical and behavioural results (Gould \& Eklund, 1996). One form of withdrawal that has been associated with prolonged stress is bumout (Gould, 1993; Gould, Tuffey, Udry, \& Loehr, 1996; Smith, 1986). Bumout is defined as psychological, emotional, and physical withdrawal from a formerly pursued and enjoyable activity that results as a reaction to chronic stress (Smith, 1986). An imbalance between perceived demands and resources over a long period of time can lead to cognitions associated with burnout (Smith, 1986). Thus, it appears that burnout is a special case of withdrawal (Gould, 1993).

Burnout is clearly stress related, but it seems likely that withdrawal often occurs for stress related reasons before the point of bumout occurs, such as when the stress cognitions result in interests in other activities (Gould, Udry, et al., 1996). Schmidt and Stein (1991) have suggested that dropout from sport occurs when the level of stress pushes the value of the outcome of being involved in the particular sporting situation below the value of being involved in other activities. Often, the athlete will drop out before the stress reaches the chronic stage. Therefore, withdrawal can be used as coping strategy to manage sport related stress both in reaction to stress over time and/or as a reaction to more discrete stressful events.

Withdrawal due to stress seems often to be the last coping option, many times occurring only after a long process of decision making (Weiss \& Petlichkoff, 1989). In Gould, Tuffey, et al.'s (1996) qualitative study of competitive tennis players, withdrawal due to bumout occurred only after a long period of trying to manage competitive stress. Often the value of remaining in an activity is greater than alternative activities despite increasing costs of participation (Smith, 1986). The use of other coping strategies often delays the process of withdrawal due to burnout (Coakley, 1992). And as mentioned, sometimes withdrawal occurs as an effort to prevent the stressful experience from reaching 
a stage of burnout, or a point where the stress becomes crippling (Roth \& Cohen, 1986). Scheier, Weintraub, and Carver (1986) suggested that implicit in the meaning of problem-and emotion-focused coping efforts is that they will eventually result in reduction of stress. Often though, people may find they are unable to reduce the demand versus resources discrepancy in a stressful transaction and may give up their efforts to attain even their important goals.

One reason why withdrawal may not be used early in a stressful transaction is that coping efforts can sometimes create stress in other areas (Folkman, 1984; Patterson \& McCubbin, 1987). Withdrawal may not be an attractive option because it may actually create more distress in other areas than is present in the current situation. For young athletes whose ego-identity is tied to sport involvement, disengagement may create greater distress. The loss of their 'athlete-identity' is more threatening compared to threats to their sport related goals. The choice to withdraw needs to be considered in the larger context of the athlete's life, and often withdrawal may be more stress inducing than stress relieving, at least until a point where the costs become too great.

Often withdrawal is not permanent (Petlichkoff, 1996), and may take a psychological form. such as reducing effort or making excuses not to practice (Gould, Udry, et al., 1996). Thus, withdrawal may not necessarily mean dropout from sport altogether, but rather, withdrawal may include switching sporting activities or temporary withdrawal that allows the athlete to get away from the stressful transaction. Because withdrawal is not always permanent, the term avoidance may be more appropriate. Avoidance needs to be considered as an effort to remove oneself from the stressful situation, regardless of the time frame.

\subsubsection{Assessment of Avoidance in the Coping Literature}

It was discussed earlier that many coping scales assess a variety of coping behaviours and functions in the literature. Many of these scales include a component such as withdrawal (SieffgeKrenke, 1995), avoidance (Feifel \& Strack, 1989; Patterson \& McCubbin, 1987), or disengagement 
(Haney \& Long, 1995). Existing measures have limitations as measures of avoidance consistent with the distinction between problem-focused, emotion-focused, and avoidance in the present study.

Patterson and McCubbin (1987) concluded that the A-COPE contains four coping patterns that are generally directed at avoidance: ventilating feelings, seeking diversions, avoiding problems, and relaxing. These coping factors do not attempt to address the underlying dimension of avoidance and appear to primarily reflect emotion-focused coping strategies. For example, relaxing seems to serve a function to control emotions, as does ventilating feelings. The seeking diversions and avoiding problems factors may contain items that serve to help the individual remove him or herself from the stressful transaction, but the underling coping functions were not assessed. It is quite possible that an item like "Read" which was on the seeking diversions factor could serve a number of underlying functions, only one of which being avoidance. The A-COPE also appears to assess coping style (youths are asked to rate how often they engaged in each coping behaviour when faced with difficulties or when feeling tense).

Haney and Long (1995) attempted to assess engagement and disengagement coping by using sport modifications of the original Ways of Coping Checklist (Folkman \& Lazarus, 1985). They suggested that these two higher-order coping themes reflected the two functional dimensions of coping problem- and emotion-focused coping. Disengagement is proposed to reflect an attempt to disengage from the task. Closer examination of the items on the disengagement scale seem to suggest that it assesses more emotion-focused coping attempts. Also, the items may not be general enough to accurately assess such a broad dimension.

A similar problem can be seen in Seiffge-Krenke's (1995) measure that assessed coping using a three dimension scale. The scale included active coping, internal coping, and withdrawal. The withdrawal scale has items that clearly indicate efforts to leave the situation, such as "I withdraw because I cannot change anything anyway", but also include items that seem to serve more emotion- 
focused coping function but do not detach the person from the situation (e.g. "I try to let my aggression out [with loud music, riding my motorbike, wild dancing, sport, etc.]').

Other scales such as the modified COPE (Crocker \& Graham, 1995) and the modified WCC (Crocker, 1992) attempt to assess multiple coping behaviours that include some component of disengagement or detachment. Although these scales may provide some use in the assessment of an avoidance coping function, the instruments were not designed to assess underlying coping function specifically. Also, the psychometric properties of these disengagement subscales are not strong.

Endler and Farker's (1990, 1993, 1994) Coping Inventory for Stressful Situations (CISS) included the assessment of avoidance-oriented coping. However, the avoidance items do not seem to reflect an attempt to remove oneself from the stressful situation. For example, the avoidance-oriented scale contains items such as "Buy myself something" and "Visit a friend" which may serve functions other than avoidance. As the authors intended, the strategies on their scale more accurately reflect distraction and social diversion, as opposed to disengagement from the stressful situation.

One measure that seems to have a promising dimension of avoidance is Feifel and Strack's (1989) Life Situations Inventory (LSI). The LSI assesses three coping dimensions including problemsolving, avoidance, and resignation. The avoidance items (e.g. "How much did you try to get away from the situation for a while by doing something else"; "How much did you want to just forget about the whole thing") seem to be written at a general enough level to accurately represent avoidance as a coping function. Unfortunately, two of the items seem to represent more emotion-focused coping efforts (e.g. "How much did you refuse to take the situation too seriously" and "How much did you try to make yourself feel better about the situation by eating, drinking, smoking, or taking medication"). The LSI also has a resignation coping scale which has been shown to be moderately related to avoidance (Feifel \& Strack, 1989).

\subsubsection{Relationships Among Coping Functions}


Research and theory describing the relationships among the various coping functions is inconclusive. Folkman (1984) suggested that theoretically the effectiveness of problem-focused coping depends on emotion-focused efforts. Emotion-focused coping may serve to facilitate problem-focused efforts (Aldwin, 1994), possibly by helping the individual control emotions to a point where problemfocused efforts can then become effective. Indeed, research indicates that people often use a combination of problem- and emotion-focused efforts in non-sport (e.g. Folkman \& Lazarus, 1985) and sport (e.g. Crocker Graham, 1995; Gould, Finch, \& Jackson, 1993) studies. Despite the facilitation of problem-focused coping with emotion-focused coping strategies, there may still be a negative relationship between problem-and emotion-focused coping because when direct action is used, emotion-focused coping strategies may be used less often (Stone \& Neale, 1984).

The relationship between avoidance and both problem-and emotion-focused coping is unclear. Gould, Udry, et al. (1996) found dropouts used less planning (problem-focused) and less positive reinterpretation (emotion-focused). Scheier et al. (1986) stated that problem-focused coping and disengagement should be inversely related to each other. An action such as disengagement is an attempt to remove a person from continued problem-focused efforts. Alternatively, it may be that there is no relationship between problem-focused coping and avoidance strategies, as was found by Feifel and Strack (1989). These latter results may have resulted because their problem-focused dimension appeared to contain both problem-focused (e.g. "How much did you try to make some plans in order to resolve the situation") and emotion-focused (e.g. "How much did you try to see something positive in this otherwise difficult situation") strategies. Problem-focused coping (attempt to change the situations) seems theoretically incompatible with avoidance/withdrawal/disengagement from the situation (Scheier et al., 1986) . Exceptions would be if avoidance strategies are used as a problemfocused efforts or if multiple functions can be served even within a specific stage of the stress process. For example, an athlete may disengage from a situation, not to make the situation no longer important, 
but rather in an attempt to actually change it. Alternatively, athletes may attempt to achieve multiple goals when they use coping strategies. Avoidance may serve as a function in itself in that it removes the individual from the situation (at least temporarily), but also as an attempt to achieve problemfocused coping goals. The role of avoidance in coping has yet to be established; however, disengagement strategies may be more important in the coping process than were once believed (Scheier et al., 1986). Given the above debate, problem-focused, emotion-focused, and avoidance coping are likely relatively independent, especially at a functional level. A moderate to high correlation between avoidance coping and either problem-or emotion-focused coping would seem to suggest that the inclusion of avoidance coping at the functional level may not be warranted or at the very least needs to be reconsidered.

\subsubsection{Gender Difierences in Coping}

Adolescence may be a key period in which gender differences emerge in the experience of stress (Groer et al., 1992). There is a generally a consistent pattem in the coping literature that females use more emotion-focused coping, particularily social support, strategies than males (Boekaerts, 1996; Ptacek, Smith, \& Dodge, 1994). However, no consistent pattern has emerged regarding problem-focused coping. The question of how gender influences adolescent coping remains (Hauser \& Bowlds, 1990).

A number of explanations for the gender differences in coping have been proposed. A number of researchers have supported the view that males and females may be socialized to cope differently with stressful experiences (e.g. Compas, Orosan, \& Grant, 1993; Crocker \& Graham, 1995; Patterson \& McCubbin, 1987). Ptacek, Smith, and Dodge (1994) suggested that the common sex role stereotype is that men are expected to be independent, instrumental, and rational, predisposing them to use problem-focused coping strategies. Alternatively, women are expected to be emotional, supportive, and dependent, making it more likely they will use more emotion-focused coping and social support 
than men. Their results demonstrated that even when men and women had similar appraisals in a situation, they still tended to cope differently. Another possible reason for gender differences in coping is that males and females experience different situations, and as a result report differences in coping. Researchers such as Ptacek et al. and Crocker and Graham (1995) who have suggested socialization may be a reason for gender differences in coping, have also stated that the situational explanation cannot be ruled out. Gender differences in coping may emerge because of females increased expressiveness in reporting coping (Thoits, 1991). Females may be more likely to report in greater detail the strategies they used compared with males, resulting in differences in self-reports of coping. Also, it may be that females experience greater levels of stress than males. Female adolescents often report greater stress in areas such as peer acceptance, relationships with the opposite sex, feelings of isolation, and disagreement with parents (Hendren, 1990). Therefore, if females are experiencing more stress, they likely require greater coping efforts to deal with the greater perceived demands on their resources.

An interactive social-psychological model to explain gender-related behaviour has been presented by Deaux and Major (1987). Their model suggests that if there are gender differences in the expectations of others related to gender, gender-related self-schema, and/or the context of the situation, then gender differences in behaviour are more likely to emerge. According to their model, people will assume different identities in different situations but will also make efforts to demonstrate a degree of stability in their behaviour so that interactions with others will be maintained. Expectations by others based on gender beliefs, a desire to maintain a self-concept that is consistent with an individual's gender-related self-schema, as well as characteristics of a particular situation, are critical variables in determining gender related behaviour. For example, if a coach has the belief that females have a greater need for social comfort in stressful situations whereas males are expected to be tough and autonomous, males and females will have different expectations of them and different 
coping options available. Gender differences are even more likely to occur if the athlete has a gender belief system consistent with coach and if the situation is one in which the athlete has various coping options available. Regardless of the reasons for gender differences in coping, differences in coping do emerge. It is important to provide support that an instrument is appropriate for both males and females.

\subsubsection{An Additional Measurement Issue: Time Frame for the Coping Recall Period}

One of the most difficult decisions that one is faced with when trying to assess coping by selfreport is whether to ask the athletes to recall very recent stress experiences (e.g. within the past month or week) or to allow the retrospective recall to extend further into the past (e.g. events that happened more than one month ago). Current coping assessment techniques ask participants to recall coping strategies from a variety of time periods in the past. For example, various versions of the Ways of Coping Checklist have asked subjects to recall stressful experiences that occurred in the past month (Folkman \& Lazanus, 1980), in the past three weeks (Crocker, 1992), in the past week (Folkman \& Lazarus, 1986), or immediately following an event (Haney \& Long, 1995). Other examples include the modified COPE (Crocker \& Graham, 1995) which asks athletes to recall coping strategies used in a recent stressful performance situation, and the Coping Strategy Indicator (Amirkhan, 1990) which asks participants to recall a recent event that happened within the past 6 months. For adolescents, Compas, Malcarne, and Fondacaro (1988) asked older children and adolescents between 10 and 14 years of age to recall coping strategies used for self-identified events in an interpersonal and an academic domain that occurred within the past 3 months. Ebata and Moos (1991) have asked how adolescents managed the most important problem they faced in the previous year.

It is clear that there is no consensus in the stress and coping literature as to the appropriate time frame from which to ask individuals to recall. Due to memory limitations in the ability to recall past events, and due to reconstruction of events over time (Thompson, Skowronski, Larsen, \& Betz, 
1996), it is not surprising that Cohen (1995) has suggested that the shorter the time interval between the event and the recall, the better. The preference for recalls of recent events is presumably based on the assumption that when an event is more recent, the recall of that event will be more accurate. Recently, Ptacek, Smith, Espe, and Raffety (1994) showed that there was a limited correspondence between daily coping reports and a retrospective coping recall. Looking at only a five day period, aggregated daily coping reports shared a limited amount of common variance with retrospective recall for three coping dimensions (problem-solving, 34\%; seeking social support, 24\%; avoidance, $22 \%$ ). These results suggest a problem when attempting to assess retrospective recall of coping. Ptacek et al. suggested that episodic memory decay was the most plausible explanation for the lack of correspondence between daily reports and retrospective recalls of coping. Thus, one cannot assume that just because the recall period is very recent (e.g. even within the past week) that the retrospective recall will necessarily be accurate. There may be other factors which may be just as or even more important in enabling individuals to recall events other than solely how recent it occurred.

As mentioned, one of the primary justifications for using recent rather than more distal events as the basis for recall is the possibility of reconstruction of the event over time. One possibility is that over time specific events begin to lose their distinctiveness, with numerous memories blending with similar memories and increasing the probability that what is being remembered as being less accurate (Durante \& Ainsworth, 1996). Although this would seem to suggest that a very short period of recall for coping strategies is preferable, this may not necessarily be the case because such blending of memories is more likely for frequently repeated or highly routinized activities. Distortions to memory are more likely for familiar events (Brewer, 1996), and thus, when looking at a class of repeated events, the recall of these types of events have to be more recent period than for more infrequent events which can be recalled from a more distal time in the past (Brewer, 1994). Therefore, for a behaviour such as physical activity a shorter recall period is probably more important because physical activities 
are more routinized than a more unique event such as having to cope with a stressful situation.

When constructing a recall questionnaire to assess coping, a longer time period of recall may be necessary to capture an unique event. If the recall period is very short, unless an experimental manipulation has occurred or the group is known to have experienced a common stressful situation recently, then only frequently occurring events may have occurred. Frequently occurring or highly routinized events may have been all that occurred in the past week for many individuals. The recall of the events may be less accurate with a short time frame because of the difficulty in trying to recall specifics about frequently occurring events.

Two factors that may be critical for recall of past events, especially for more distal events, mry be the salience or importance of the event and the emotion associated with the event to the individual (Wagenaar, 1986). Individuals are more likely to remember real-life events that are emotion arousing, than neutral every-day events (Christianson \& Safer, 1996). Not only are events remembered better if they involve emotions, but memorable events are also based on the rareness or uniqueness of actions associated with a person's past (Brewer, 1996). Brewer's (1996) review of recollective memory (when an individual recalls a specific episode from his/her past experience) revealed that better memory was associated with low frequency events, that overall level of emotion (both pleasant and unpleasant) is associated with better memory performance, and also that highly emotional events tend to be infrequent events.

Importance and emotion are two key features in the coping process according to a cognitivemotivational-relational theory (Lazanus, 1991, 1993a, 1993b). Since personal importance of an event is an important determinant of emotion, and stress is considered to be a subset of emotion (Lazarus, 1993a), it seems that recall of stress and coping periods that extend further into the past would be appropriate. The longer period of recall would also allow the individuals to have experienced an important, emotionally involved event within the time limits asked on a questionnaire. 
Other factors that suggest a longer period of recall may be appropriate when assessing coping include the generality of coping assessment and defining coping as involving conscious effort. First, coping functions, as opposed to specific coping strategies, provide the basis for measurement in the present study. Problems due to reconstruction of events over time are more likely for peripheral as opposed to central details of an event (Thompson et al., 1996). Although recall of specific details of an event may be open to large memory errors due to distortion, it seems likely that very central details such as whether there were attempts to change the situation, control emotion, or avoid the situation would be quite resilient to memory decay when recalling stressful events given the importance coping plays in the stress process. Recollective recall has a relatively low rate of forgetting over long time intervals, and there is little data to support the incidence of schema-based distortions in recollective memory (Brewer, 1996). Also, as mentioned previously, when distortions or reconstructions of past events occur they are more likely for peripheral details of the event and for frequently occurring events (Christianson \& Safer, 1996). The questionnaire being constructed in the present study was developed on the assumption that coping is a central aspect of the stress process and that the stressful situation being recalled is more of a unique event than frequently occurring event, both of which would suggest assessment of coping may be possible for events that have occurred further in the past than the previous week or even month.

Second, coping is proposed to include only conscious, effortful attempts to manage a stressful situation, which distinguishes coping from more automatic processes, which have been termed management skills by Aldwin (1994). She suggested that management skills may develop from having to cope with situations, but once they become routinized skills used to prevent stress, they are no longer considered coping strategies. This cognitive involvement necessary to evaluate and select coping strategies at the time of the event should make such strategies easier to recall over time. Automatic processes are not considered to be true coping attempts within the present framework, and 
therefore, at some point the individual needs to have been consciously aware of an attempt to change the situation, control emotion, or avoid the situation. The individuals are not asked to report on processes that occurred at the unconscious or subconscious level.

Based on the above review, a recall period of a stressful situation that occurred in the past 12 months was selected for this dissertation research. Reasons for the choice of a 12 month recall period are highlighted below:

(a) A 12 month period is much more likely to include a unique, less frequently occurring, salient, emotional event than a period which includes only the previous week or month.

(b) The longer time period was deemed appropriate because of the definition of coping as requiring effort, implying that cognitive involvement was necessary at the time of coping strategy selection. Therefore, the coping strategies would be much more likely recalled over a longer period of time because of this initial cognitive involvement.

(c) The assessment of a short recall period would make the coping questionnaire much more subject to seasonal variation and restrict the sample size as well. If assessments were conducted during the summer and the sport participant was involved solely in a winter sport (e.g. ice hockey), then it is possible that this individual may have had no stressful sport experiences during the past week or month because the assessment period did not fall within the competitive season.

(d) The coping scale proposed to measure three functions of coping (problem-focused, emotion-focused, avoidance) and it is important that each of these coping functions has a chance to emerge in a scale. For a short recall period, it is likely that problem- and emotion-focused coping strategies would be used, but the short recall period may severely restrict the variance on the avoidance scale. Often, avoidance may be the last option, and if stress is recalled from only the previous week, avoidance strategies may not have been used or used very little. Also, the concept of avoidance includes, but is not restricted to, sport withdrawal. Those who dropped out of sport would be missed 
if a sport participant is defined as an individual currently competing in sport.

(e) Because the assessment of coping focuses on coping function as opposed to specific coping strategies, the function of coping strategies would seem to be a very central detail of the stress experience. Since central details are not as likely to be cognitively distorted or reconstructed as more peripheral details of an event, and also are quite resilient in terms of memory over time, it seems likely that assessment over a longer period of time may be quite accurate.

\subsubsection{Steps in Developing a Coping Instrument}

Clearly, the measurement of coping in sport needs to be improved, especially for adolescents. Boekaerts (1996) suggested that researchers need to construct instruments that differ from past research on coping with stress in childhood and adolescence. She suggested that coping needs to be measured at different levels in addition to specific strategies. Measures of coping goals, preferences for coping strategies, and timing of coping responses may further our understanding of how adolescents manage stress. A scale to measure coping in an adolescent sporting population needs to be developed from a strong theoretical base. The cognitive-motivational-relational theory presented earlier provides a framework for coping instrument development.

There are generally three steps common to any measurement process (Thorndike, Cunningham, Thomdike, \& Hagen, 1991). First, the attribute or quality that is to be measured needs to be identified and defined. Second, the set of operations by which to measure the attribute must be defined. Third, the measurement of the attribute must somehow be put in quantitative terms to allow the researcher to determine how much of the attribute is present in the individual. Measurement then, has the primary goal of providing a quantitative description of the extent to which individuals manifest specified characteristics (Ghiselli et al., 1981).

The first necessary step in developing an instrument is to clearly define the construct of coping. The more precise the definition, the more useful it will be, because it will describe the nature 
of coping, how coping is different from other variables, and will suggest operations by which to measure coping (Ghiselli et al., 1981). The cognitive-motivation-relational theory provides a useful framework from which to define coping as a construct. Within this theoretical framework, three functions of coping were defined. Problem-focused coping was defined as an effort to actively change and remain in the situation that was causing the stress. Emotion-focused coping was defined as an effort to control thoughts or emotions while remaining in the situation that was causing the stress. Avoidance coping was defined as an effort to remove oneself either permanently or temporarily from the situation that was causing the stress. The content of these coping constructs helps specify what should be considered part of coping, as opposed to aspects of other constructs.

The instrument must try to account for the dynamic nature of the stress and coping process, as opposed to assuming that coping is static in nature. Obviously, this makes the measurement of coping difficult, because the researcher has to try to account for adolescents trying to use different coping strategies at different times in response to different stressors. The coping instrument must somehow try to account for this dynamic aspect of coping. The instrument must clearly identify what behaviours and behavioural intentions should be considered coping. The transactional model presents a framework for what should be considered coping, and what is not. For example, coping is considered to require effort, and is considered part of a process, which is quite different from behaviour outcomes. Also, the transactional model specifies various intentions of coping efforts (e.g. problem-focused versus emotion focused) which must be accounted for in the coping instnument. The coping instrument may also need to take into account various levels of coping, including coping goals, preferences for specific strategies, as well as coping intentions and timing of coping responses (Boekaerts, 1996). It is clear that following a specific theory of coping will provide a framework for the questions that will be asked on the instrument.

The operations for measuring coping will be determined by the questions the researcher asks, 
as well as practical considerations (Ghiselli et al., 1981). When questions reflect degree, frequency, or kinds of coping, then the variation among individuals can be considered a quantitative question (Ghiselli et al., 1981). Questions such as, under what conditions do adolescents choose particular strategies, what strategies do they use consistently, what functions do strategies serve, and what gender differences exist in coping will determine choice of a measurement instrument. For example, if a researcher is interested in understanding what specific types of coping strategies were used by an individual, the choice of instrument will differ than for questions related to how appraisal is related to coping goals. As was discussed previously, this dissertation focuses on the development of an instrument to assess coping function.

To answer questions related to coping function, a reliable and valid instrument would be of much use, because assessment in larger populations is needed. Also, the measurement must take into account factors such as test length, size of samples that will be assessed, and the practicality of being able to tap the entire domain of interest. Self-report methods are not only practical for larger populations, but self-report is often used because only the individual has direct access to internal processes (Ptacek, Smith, Espe, \& Raffety, 1994).

Once the coping theory has provided a framework for instrument development, the next step is to develop instrument items and provide validity and reliability evidence for the instrument. The quantification of individual scores allows the researcher to make comparisons among individuals and have numbers which represent how much of an attribute is present in the individual (Thorndike et al., 1991). This quantification makes communication of scores on the construct more efficient and precise, and also allows the researcher to use statistical methods for the data to make the observations more meaningful. Thus, questions of reliability and validity of test scores become fundamental questions in measurement (Ghiselli et al., 1981).

The development of a coping instrument will go hand in hand with issues of reliability and 
validity. Reliability is the degree of consistency of scores earned by an individual (Ghiselli et al., 1981). Reliability is important because psychological characteristic such as coping can never be measured perfectly. Validity is concerned with the usefulness or appropriateness of test scores (Ghiselli et al., 1981).

There are different types of reliability questions. A researcher can look at the internal consistency of a measure, which is defined as the homogeneity of items that comprise a scale (DeVellis, 1991). Altematively, the researcher can look at the reliability of scores on two separate versions of a scale or on the same scale on repeated occasions (DeVellis, 1991). The use of a reliability method will depend on a number of factors (Ghiselli et al., 1981). For example, it would be inappropriate to determine reliability for a dynamic construct from repeated assessments over time. Also, it would be inappropriate to use internal consistency as a method of determining reliability for a scale that had items which were tapping multiple factors. Thus, the choice of method for determining reliability will depend on theory and purpose for which the test scores will be used. Coping with specific sport situations in the present dissertation was expected to be dynamic; and therefore, repeated assessment over time as a measure of reliability was deemed inappropriate. However, it was expected that items could be developed that would form homogenous coping function scales; and thus, internal consistency analysis was deemed an appropriate measure of reliability.

There are different types of validity that can be evaluated (DeVellis, 1991). First, a general type of validity evidence is content validity. Content validity refers to the degree to which a specific set of items reflects the content domain. Content validity is concemed both with the extent to which each item pertains to the construct of interest, and whether the items reflect all aspects of the domain of interest. Second, criterion validity is concerned with how well the scores on the test correspond to, are related to, or predict scores on a criterion variable. There are two types of criterion related validity, predictive validity and concurrent validity. Predictive validity describes the extent to which 
current test scores can estimate the extent to which a characteristic will be manifested in the future. Concurrent validity is concerned with how well test scores estimate other present properties of the individual, where the predictor and criterion are measured at about the same time. A third general type of validity is construct validity, which refers to the extent to which a test score adequately reflects an individual's standing on the construct. The theoretical model will specify the meaning of the construct. how it is related to other constructs, and how it is related to specific observable behaviour.

Rather than seeing types of validity as being altemative ways of providing validity evidence for test scores, it may be more appropriate to see validity as a unitary construct whereby each type acts as a supplement to another (Messick, 1989). According to Messick, convergent and divergent validity evidence is required to protect against construct underrepresentation and construct-irrelevant variance in a test. Convergent validity provides evidence that the measure is related to other measures it should be related to on theoretical grounds. Divergent evidence demonstrates that the measure does not have unexpectedly strong relationships with other construct scores. Messick suggested that all types of validity contribute to the more unitary form of construct validity because all validity types contribute to score meaning.

DeVellis (1991) provided a framework for test construction that is most useful for the development of a coping instrument for adolescent athletes. The researcher must develop an item pool that reflects the coping construct and the purpose of the scale. These items may be a combination of items from existing measures and new items, but should clearly reflect the entire range of the construct boundary. These items need to reflect not only an adolescent's unique experiences, but also be relevant to the sporting domain. Also, the items should reflect the level of intended analysis. If more global dimensions of coping are of interest, then the use of very specific items may not be warranted. Initial item development should not be concerned with redundant items because it is better to be all inclusive than not have items which adequately represent the coping domain. At this stage, it is also better to 
have a large number of items, but items which are not too lengthy. Of key concem in assessing coping for adolescents is that the items be developmentally appropriate. The use of shorter words and sentences may be more appropriate for the assessment with this population. In the present dissertation the population of interest was adolescents between the ages of 13 to 19 (the majority of which would be classified as in middle to late adolescence according to Hendren [1990]). Other suggestions for appropriate item writing should also make the items more appropriate such as having the items deal with a central thought, precise language, and avoiding awkward word arrangements (Ghiselli et al., 1981). Moreover, the content of the scale should assess relevant and salient concerns for the age group of interest (Brustad, 1998).

The development of an appropriate format for the scale items should occur simultaneously with the item generation. Likert scales are generally used in sport coping research (e.g. Crocker, 1992: Crocker \& Graham, 1995), primarily because the question of extent to which particular types of strategies are used is asked. The measurement format should best reflect the nature of coping and the questions of interest.

Content validity is supported when the items adequately tap the construct of interest. This can be developed by having experts judge the extent to which the items do reflect the defined universe. These experts can provide information regarding relevancy of the items, the clarity of the items, and can provide suggestions as to additional items which may add content validity to the instrument. Validity items may also be added to the scale which would help to detect flaws and problems with the scale, detect social desirability, and detect possible response bias. Assessment of content-related evidence is a necessary, but not sufficient step, in test score validation.

Once the item content has been decided on, the scale should be administered to a large, representative sample, which would allow an evaluation of the adequacy of the items. Item analysis can take many forms including examination of item means and variances, item distributions, and 
intercorrelations among items (Ghiselli et al., 1981). From this, new items may be added, dropped, or changed to become more appropriate.

It is then important to evaluate the validity and reliability of the scale, as well as other test characteristics, with a sample from the population of interest. Factors such as item distributions, item means, item variances, and inter-item correlations should all be examined. This information will be important in assessing the adequacy of the scale for the measurement of coping. For example, items with small variances may provide little information because they are unable to discriminate among individuals.

Reliability of a scale is important because if it is not reliable it cannot be valid (Thomas \& Neison, 1990). It may be difficult to assess the reliability of coping scales. Coping by definition is a dynamic process. Therefore, assessing the reliability of coping strategies over time may not provide useful information regarding measurement reliability. If reliability over time is demonstrated to be low, it may be because the measure is not reliable or that the use of coping strategies change over time. On the other hand, domain sampling measurement theory suggests that internal consistency is necessary if the items are proposed to represent underlying coping dimensions (Ghiselli et al., 1981).

The evaluation of criterion-related validity may also be very difficult for coping instruments. For concurrent validity, an appropriate criterion needs to be selected against which to judge the validity of the test scores. Because of the difficulties in measuring coping strategies, a sufficient criterion does not exist. Still though, one would expect that the coping measure should be related to existing coping measures to some degree, which would provide some evidence of concurrent validity. Predictive validity may also be difficult to evaluate because the relationships surrounding coping, especially coping for adolescent athletes, are not well known. The selection of an appropriate criterion is difficult.

The future in determining the effectiveness of an instrument to evaluate coping will rely greatly 
on construct validation. Construct validation can be determined a number of ways (DeVellis, 1991; Ghiselli et al., 1981), and encompasses all types of validity (Messick, 1989). Probably the most useful way of examining construct validity is to develop a hypothesized network of interrelationships among coping variables, other constructs, and observable behaviour. The transactional model provides a strong framework for testing these relationships.

\subsubsection{Perceptions of Control and Coping}

A useful way of examining construct validity of an instrument is to look at the relationships among constructs hypothetically related to coping. It has been proposed that perceptions of control while experiencing a stressful situation is important in determining coping efforts (Thoits, 1991). Perceptions of control play an important role in understanding the stress process because it is a critical variable in cognitive appraisal (Folkman, 1984) and uncontrollable stressors are associated with an increased stress (Aldwin, 1994; Carpenter, 1992). Perceived control is an important variable in secondary appraisal, or the "what can I do" component of appraisal. Low perceived control is proposed to result in individuals feeling there are less coping options to meet environmental demands, and therefore stress is greater due to a greater demands versus resources discrepancy. Individuals who feel helpless and feel there is little that can be done to alter their situation are more likely to be depressive or anxious (Lefcourt, 1992), and many intervention techniques focus on fostering selfcontrol strategies (e.g. Meichenbaum, 1985; Smith, 1980).

\subsubsection{Problem-Focused Coping, Emotion-Focused Coping, and Perceived Control}

Perceived control influences both the experience of stress and the coping strategies used to manage the stress. There are a number of studies in the general psychology literature that support the importance of perceived control in the coping process. A number of studies have shown that perceived control is associated with an increased use of problem-focused coping strategies (Carver et al., 1989; Folkman \& Lazarus, 1980; Folkman \& Lazanus, 1985; Folkman et al., 1986). Problem- 
focused coping strategies are generally more effective in controllable situations, whereas emotionfocused strategies are generally more effective in uncontrollable situations (Aldwin, 1994; Folkman, 1984). These findings are consistent with the notion that coping strategies are not inherently adaptive or maladaptive. Rather, coping effectiveness depends on the appropriateness of a particular coping strategy given the demands and constraints of a situation, commonly referred to as the goodness-of-fit model (Folkman, 1992). Folkman and Lazanus (1985) found that perceptions of control were positively related $([=20)$ to problem-focused coping and negatively related to wishful thinking and distancing $(r=-15)$ for three stages of a midterm exam for college students. Distancing was especially prominent during the waiting period between the exam and posting of the grades. The authors speculated these distancing strategies occurred because the students perceived few if any ways they could change the environment during that time. Likewise, Carver et al. (1989) found active coping and planning were positively related to perceived control, whereas denial and behavioural disengagement were negatively related to perceived control for undergraduate students who reported how they respond to stress in their lives.

In another study, 85 married couples were asked about a stressful encounter they experienced during the past seven days and ways they coped with the situation (Folkman et al., 1986). The couples reported using more accepting responsibility, more confrontive coping, planful problem-solving, and positive reappraisal in situations that were appraised as changeable. Alternatively, the couples used more distancing and escape-avoidance strategies in situations appraised as having to be accepted. Folkman and her colleagues concluded these results support the hypothesis that problem-focused coping is associated with changeable situations and emotion-focused coping is associated with situations where people could not change the outcome.

Little is known regarding coping and cognitive appraisal in children and adolescence (Compas et al., 1988), but similar results between perceived control and problem- and emotion-focused coping 
have been hypothesized for adolescents. When youth are convinced they can do something to change a situation they will use predominantly active coping, and often they realize that emotion-focused coping is maladaptive in response to controllable stressors (Boekaerts, 1996). Compas et al. (1988) looked at coping strategies and perceived control in 130 ten to fourteen year olds. They found that the youth reported more control over causes of academic events than social events, and subsequently generated more problem-focused alternatives to manage the academic related stress events. No differences were found for emotion-focused coping.

It is unclear whether problem-focused coping efforts will decrease fairly quickly or slowly as the situation becomes more uncontrollable (Thoits, 1991). The rate at which problem-focused coping decreases along with decreases in perceived control may be moderated by situational and appraisal variables, but a decrease in problem-focused efforts as perceived control decreases is consistent across various theories. It is also unclear what level of emotion-focused coping will be used in response to a controllable stressor. Emotion-focused coping may be used to facilitate problem-focused efforts (e.g. controlling emotion helps one make an effective plan of action), and thus, emotion-focused coping may still be present even when the situation is perceived to be under personal control. However, emotionfocused coping is expected to be high in situations of low perceived control (Lefcourt, 1992). The overall relationship between emotion-focused and perceptions of control coping may be moderate to low if emotion-focused levels are high at moderate to high levels of control. Also, Compas, Banez, Malcame, and Worsham (1991) suggested that although problem-focused coping may be related to perceived control, emotion-focused coping may not. Rather, emotion-focused coping may be related to subjective distress rather than perceived control.

\subsubsection{Avoidance and Perceived Control}

There seems to be evidence that perceived control is also related to the choice of avoidance strategies. Avoidance strategies may be common in situations perceived as uncontrollable or taxes the 
person's resources too heavily (Boekaerts, 1996). Other costs of engagement type coping strategies (such as problem- and emotion-focused coping in which the person remains engaged in the situation) include that such efforts are time consuming and nonproductive if there is no possibility to change the situation or manage the emotion (Roth \& Cohen, 1986). Johnston and McCabe (1993) suggested approach strategies are more appropriate in situations high in perceived control. When there is no perceived control, an avoidance strategy is more appropriate. Often giving-up is an adaptive coping strategy if the stressor is uncontrollable (Boekaerts, 1996).

Stressful situations that cannot be changed strongly affect an individual's well-being (Lefcourt, 1992). When perceived control is low, it is likely that often the stress will continue because the individual feels nothing can be done to change it and will attempt no actions to change it. Eventually, increased demands may become overwhelming and eventually lead to decisions to avoid the situation to prevent the stress from negatively affecting their well being or result in bumout due to chronic stress. Lefcourt (1992) suggested that with perceived control comes an increase in coping flexibility.

Perceived personal control (along with intemal and stable attributions) is one of the key variables in perceived competence, according to competence motivation theory (Weiss, 1993). Children will continue involvement in areas in which they perceive themselves as competent (Weiss \& Petlichkoff, 1989). Often if low accomplishment occurs over an extended period of time, low perceived control can result, and the person may conclude that nothing can be changed (Smith, 1986). Therefore, it appears that perceived control is important in determining whether the individual will remain engaged in a stressful situation and attempt coping efforts to manage that stress, either through problem- or emotion-focused coping, or whether the individual will disengage from the stressful transaction, at least in part due to low perceptions of competence.

Perceived control is also an important aspect of burnout (Coakley, 1992). When an athlete 
burns out, he or she feels that it is not possible to meet the demands of sport (Gould, 1993). Coakley's (1992) model of bumout stresses the role of perceived control. He suggested that the development of an unidimensional self-conceptualization and a lack of control are the causes of stress and bumout. Similarly, Smith's (1986) cognitive-affective stress nodel emphasizes the demand versus resources discrepancy in the experience of stress and coping which results, in part, from perceptions of control. Thus, a common element in both models of burnout is perceptions of control. In their qualitative analysis of competitive junior tennis players, Gould, Tuffey, et al. (1996) concluded that both Smith's and Coakley's models were adequate in explaining burnout in most athletes they interviewed. Gould, Udry, et al. (1996) also showed amotivation (similar to leamed helplessness whereby individuals have low perceptions of control because the outcomes of their actions do not seem to be contingent on their actions) contributed most to a significant overall multivariate effect in differentiating between bumouts and other athletes.

It appears that in situations of low perceived control, an athlete may alleviate stress by withdrawing from the stressful situation because it removes the athlete from the transaction. The demands of the formerly stressful situation are then subsequently reappraised as irrelevant (Johnston \& McCabe, 1993). It is recognized though that perceived control is not the only factor that determines whether an athlete will continue in a sporting environment.

\subsubsection{Conceptualization of Perceived Control}

Recently, due to the lack of consistency in defining perceived control, Skinner $(1995,1996)$ proposed that the construct of perceived control can be conceptualized according to the relations among agents, means, and ends. She defined three sets of beliefs (control, capacity, and strategy beliefs) based on the connection between agents and ends, between means and ends, and between agents and means. Control beliefs refer to the expectancy that the individual feels he or she can produce desired or prevent undesired events. These control beliefs represent agent-ends relations. 
Control beliefs can be distinguished from capacity beliefs which represent agent-means relations and refer to the extent to which an individual can produce an appropriate cause. Capacity beliefs involve evaluations of whether the individual feels he or she can produce certain responses, but these responses do not necessary result in the desired end or outcome. Control beliefs can also be distinguished from strategy beliefs which represent means-ends relations and refer to the expectancies that certain means are sufficient for the production of ends or outcomes. The relations among control, capacity, and strategy beliefs are presented in Figure 1.1.

Control beliefs are proposed by Skinner (1995) to be the primary regulators of action, and therefore, are likely the most important control belief that needs to be considered when examining attempts to cope with or manage stressful situations. In an agent-ends conceptualization of perceived control, a control belief refers to an individual's perception of his or her ability to produce the appropriate means to achieve a desired outcome. According the previous discussion of coping functions, one such outcome may be an attempt to change the stressful situation (problem-focused coping). Alternatively, there may be capacity beliefs which are an individual's expectations that he or she could produce certain means, not all of which would necessarily have the desired outcome. For example, an athlete may feel he or she has the ability to produce a number of responses, such as good planning skills, increasing effort, confronting a coach, or seeking social support, but does not necessarily feel that these means will result in the desired outcome. Thus, an individual may feel he or she can increase effort greatly but have little confidence that it will change the stressful situation. Strategy beliefs, on the other hand, refer to the means needed to produce the outcome, regardless of whether or not the individual has access to these means. For example, an athlete may feel that in order to change a stressful situation the most effective means would be to improve his or her skill level, but may or may not feel that is possible.

The conceptualization of different aspects of perceived control proposed by Skinner (1995, 


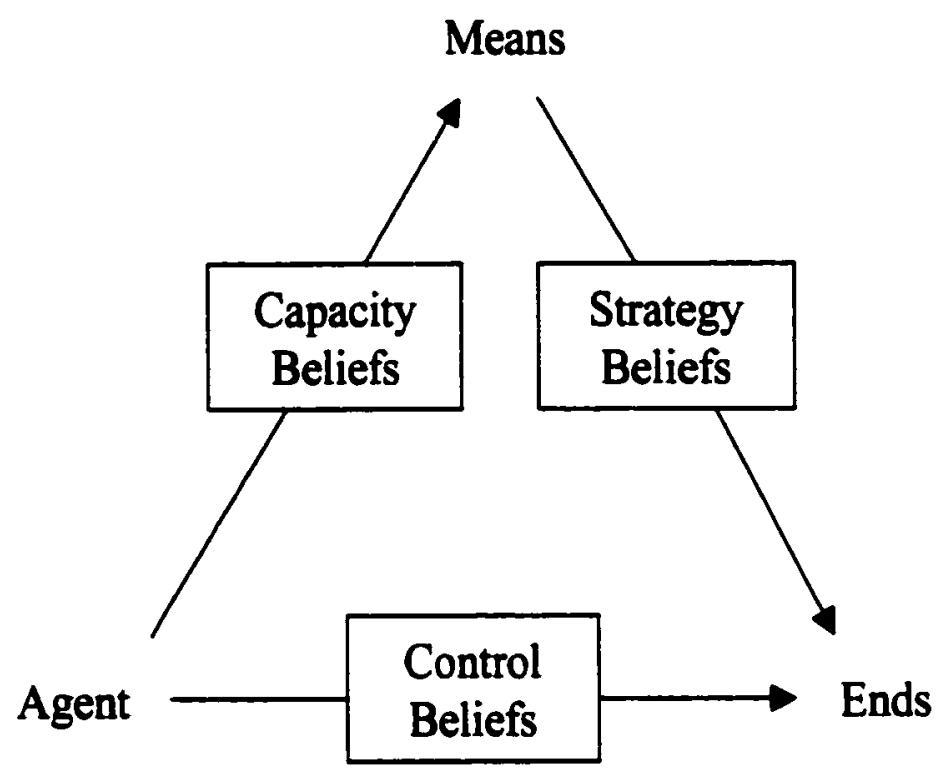

Figure 1.1. Perceived control: Distinction among control, capacity, and control beliefs (Skinner, 1995). 
1996) seems to be of primary theoretical importance to the study of coping. It is likely that coping efforts will be attempted not only when the individual feels he or she is able to produce certain means, but also when those means will result in the production of desired ends or outcomes. Therefore, when examining the functions served by coping attempts, control beliefs should be considered because one is concerned with the individual's perception of his or her ability to achieve certain outcomes, regardless of the means used.

When looking at perceptions of control it may also be important to improve on ways perceived control is measured when looking at relationships with coping. Perceived control has typically been assessed with one-item questions either to categorize situations as low/high control (e.g. Folkman \& Lazanus, 1980; Forsythe \& Compas, 1987) or as a scaled variable (e.g. Carver et al., 1989; Compas et al., 1988; Folkman \& Lazarus, 1985). A multiple item questionnaire would allow researchers to examine the adequacy of a perceived control measurement model.

It may also be important to consider the various ends or outcomes that are being evaluated. Similar to coping, perceived control may be a multidimensional construct. There is potential value in developing measures of control specific to the domain one is trying to assess. Such measurement dimensions may include a distinction between perceived control over changing the situation/external events and perceived control over emotions, as has been attempted in previous research (Haney \& Long, 1995; Rapee, Craske, Brown, \& Barlow, 1996).

The type of outcome being evaluated when determining control beliefs may have implications for coping. It may be that problem-focused, emotion-focused, and avoidance coping strategies may be related differently to control depending on what aspect of perceived control is being assessed. For example, it may be that increased problem-focused coping is associated with increased perceived control over changing the situation (Thoits, 1991), whereas emotion-focused coping may be associated with control over emotions. It may be that avoidance only occurs when there is low perceived control 
over both the situation and emotions, ultimately at a point when the individual feels overwhelmed by a perceived inability to control both the situation and emotions and feels the situation can be avoided.

\subsubsection{Conclusion, Issues, and Hypotheses for Perceived Control and Coping}

Perceived control has been discussed as important in the determination of coping function for three reasons. First, perceived control is important in the experience of stress. With increased stress, the possibility of avoidance may be more likely. Second, perceived control is an important component of perceived competence. Individuals high in perceived competence are more likely to continue engagement in an activity. Third, there is evidence in the literature demonstrating the relationship between perceived control and the types of coping strategies that are selected. It is important to note, however, that perceived control is specific to a situation and changes over time (Folkman, 1984). This has implications for assessing the relationship between perceptions of control and coping. Perceptions of control should be assessed for the time period over which coping strategies are being recalled, or the relationship between them will likely be difficult to establish.

Given the proposed importance of perceived control in the coping process, the following issues related to perceptions of control were addressed:

(a) A perceived control measure based on Skinner's (1995) control beliefs was developed. The multidimensional nature of perceived control was considered, as multiple item control beliefs scales related to changing the situation, control emotion, and avoidance were developed. The multidimensional, multiple item perceived control measure allowed more adequate evaluation of the instrument's measurement properties compared with unidimensional, single item measures that have often been used in previous research.

(b) Different dimensions of perceived control were expected to havedifferent relationships with different functions of coping. Problem-focused coping function should be related to perceptions of control over changing the situation. Emotion-focused coping function should be positively related 
to perceived control over emotions. Avoidance coping function should be positively related to perceived control over avoidance. However, avoidance coping function may also be negatively related to perceptions of control over changing the situation and emotions because avoidance may be more likely when the individual feels there are few other coping options.

\subsubsection{Conclusion}

The development and validation of a coping instrument for adolescents is clearly a difficult task. The complexity and dynamic nature of the coping construct makes item development challenging, and evaluations of reliability and validity problematic. A strong theoretical model, welldefined research questions, and systematic scale evaluation provide the best opportunity for researchers to examine coping strategies for adolescent athletes. It is possible that coping may never be adequately measured by questionnaire, and other research methodologies may necessarily need to be employed. Multiple methods to examine coping will always be useful to answer different questions. The potential benefits of an adequate coping instrument that is able to assess the relationship between coping and other variables warrants the effort by researchers to develop a reliable and valid measure.

\subsection{Statement of Purpose}

The purpose of this project was to develop and provide preliminary validation evidence for a measure designed to assess coping function for adolescents sport participants. The adolescent population of interest in the present studies was sport participants between 13 and 19 years of age. Sport participation was defined as participation in organized sports (teams or clubs with organized leagues or competitions) in the past 12 months. The theory-based instrument assessed three functional themes for coping; problem-focused coping, emotion-focused coping, and avoidance. Two studies were conducted which addressed item development and scale reliability and validity.

An important question in the present research was whether the coping function questionnaire developed is appropriate for an adolescent sport participant population. Brustad (1998) suggested a 
multiple step approach to determine the developmental appropriateness of a measure. Since developmentally appropriate measures need to be understandable to the participants, interview procedures and pilot testing can be used to determine whether the measure is comprehensible. Social desirability can also be administered to determine if a response bias is present. Examining the internal consistency is also important because it can indicate problems with comprehension and interpretation of items and concepts on the measure. Convergent validity with similar constructs can provide evidence that the measure is appropriate for the population of interest. He also suggested that confirmatory factor analysis procedures be used to examine the factor structure of the measure and whether it is stable across groups. These suggestions were incorporated into the two studies to provide evidence that the coping measure is appropriate for adolescent sport participants. 


\section{CHAPTER 2}

\subsection{STUDY 1}

The purpose of the first study was to develop an appropriate coping scale for adolescents in a sporting setting with adequate content validity. The framework provided by DeVilles (1991), as described in section 1.2.11, was used in the development of a coping instrument for adolescents.

\subsubsection{Part A}

2.1.1.1 Step 1. Thirty items for three coping function scales were written based on the sport and non-sport coping research and a cognitive-motivational-relational theory of emotion and coping (Lazarus, 1991, 1993a, 1993b). Coping strategies were written for the three coping functions of problem-focused, emotion-focused, and avoidance. The new scale was named the Coping Function Questionnaire (CFQ). Throughout the instrument development process the CFQ was preceded by two stress appraisal items (asking for a description of the situation and why it was important) which served as a reference frame for the CFQ. Two graduate students in the area of emotion and coping provided feedback on the content and format of the original items and scale. General written comments were made regarding clarity of the items, preferences for similarly worded items to rectuce the length of the questionnaire, and whether items were appropriate for the intended coping function.

2.1.1.2 Step 2. Following initial feedback, a 22 item CFQ was administered to 8 athletes (one male and one female athlete in each grade from 9 through 12). The CFQ, along with a demographics questionnaire asking about sport participation in the previous 12 months, was given to the athletes in 
small groups of 1 to 3. A researcher was present to answer questions. Once each athlete completed the questionnaires, a brief interview followed to obtain feedback on the content and format of the items and scale.

2.1.1.3 Step 3. Following scale modifications based on the athletes' responses and interviews, the CFQ was mailed to five content specialists in the area of emotion and coping. These experts were asked to judge (a) the coping function each item was assessing and (b) the extent to which each item reflected the proposed function. Two procedures outlined by Hambleton (1984) were combined to address the item-function congruence. The content specialists were presented the conceprual definitions of the three coping functions and were asked to indicate which coping function was being assessed by each item. A summary of the content specialists' ratings for each of the 22 items is presented in Table 2.1. One judge failed to respond to the item-function matching task. Overall, the results suggested a very high agreement between intended coping function and content specialist ratings, with lack of agreement occurring for two items (items 11 and 14).

The content specialists were then provided with the corresponding coping function for each item and were asked to rate the item-function match on a 5-point scale ranging from poor match (1) to excellent match (5). A summary of the content specialists' ratings of the 22 coping items are presented in Table 2.2. The content specialists also provided information regarding relevancy of the items and the clarity of the items. They also had the opportunity to provide suggestions as to additional items that could add content validity to the instrument. Based on the feedback from the content specialists, 3 items were discarded (items 3, 12, 14), 13 items were reworded, and 6 items were retained in their original form. Twelve items with content specialist rating means of four or greater and a range of three or less (see Table 2.2) were considered strong items (four items on each of the three coping function scales).

2.1.1.4 Step 4. Following content specialists' feedback, the 19 item CFQ was administered 
Table 2.1

Summary of Content Specialists' Item-Coping Function Matching Task

\begin{tabular}{|c|c|c|c|c|c|c|}
\hline \multirow[b]{2}{*}{ Function } & \multirow[b]{2}{*}{ Item $^{b}$} & \multirow[b]{2}{*}{1} & \multicolumn{3}{|c|}{ Content Specialist } & \multirow{2}{*}{$\begin{array}{c}\text { Percentage of } \\
\text { Matches For Each Test Item }\end{array}$} \\
\hline & & & 2 & 3 & 4 & \\
\hline \multirow[t]{7}{*}{1} & 1 & $l^{c}$ & 1 & 1 & 1 & 100 \\
\hline & 4 & 1 & 1 & 1 & 1 & 100 \\
\hline & 7 & 1 & 1 & 1 & 1 & 100 \\
\hline & 10 & 1 & 1 & 1 & l & 100 \\
\hline & 13 & 1 & 1 & 1 & 1 & 100 \\
\hline & 16 & 1 & 1 & 1 & 1 & 100 \\
\hline & 18 & 1 & 1 & 1 & 1 & 100 \\
\hline \multirow[t]{9}{*}{2} & 2 & 1 & 1 & 1 & 1 & 100 \\
\hline & 5 & 1 & 1 & 1 & 1 & 100 \\
\hline & 8 & 1 & 1 & 1 & 1 & 100 \\
\hline & 11 & 1 & 1 & 0 & 1 & 75 \\
\hline & 14 & 0 & 1 & 0 & 1 & 50 \\
\hline & 17 & 1 & 1 & 1 & 1 & 100 \\
\hline & 19 & 1 & I & 1 & 1 & 100 \\
\hline & 21 & 1 & 1 & 1 & 1 & 100 \\
\hline & 22 & 1 & 1 & 1 & 1 & 100 \\
\hline \multirow[t]{6}{*}{3} & 3 & 1 & 1 & 1 & 1 & 100 \\
\hline & 6 & 1 & 1 & 1 & 1 & 100 \\
\hline & 9 & 1 & 1 & 1 & 1 & 100 \\
\hline & 12 & 1 & 1 & 1 & 1 & 100 \\
\hline & 15 & 1 & 1 & 1 & 1 & 100 \\
\hline & 20 & 1 & I & 1 & 1 & 100 \\
\hline \multicolumn{2}{|c|}{$\begin{array}{l}\text { Percentage of matches for } \\
\text { each content specialist }\end{array}$} & 95.5 & 100 & 90.9 & 100 & \\
\hline
\end{tabular}


Table 2.1 (continued)

"One content specialist did not complete the item-coping function matching task.

The item numbers are for the original version of the CFQ sent to content specialists.

"A score of "0" means that the content specialist did not match the test item to the coping function it was developed to measure. A score of " $\mathrm{l}$ " means that the content specialist did make the expected match. 
Table 2.2

\section{Summary of Content Specialists' Ratings of 22 Coping Items}

\begin{tabular}{|c|c|c|c|c|c|c|c|c|c|}
\hline \multirow[b]{2}{*}{ Function } & \multirow[b]{2}{*}{ Item $^{2}$} & \multicolumn{5}{|c|}{ Content Specialists' Ratings } & \multicolumn{3}{|c|}{ Summary Statistics } \\
\hline & & 1 & 2 & 3 & 4 & 5 & Mean & Median & Range \\
\hline \multirow[t]{7}{*}{1} & 1 & 2 & 4 & 5 & 4 & 4 & 3.8 & 4 & 4 \\
\hline & 4 & 3 & 4 & 5 & 4 & 4 & 4 & 4 & 3 \\
\hline & 7 & 3 & 5 & 5 & 4 & 3 & 4 & 4 & 3 \\
\hline & 10 & 2 & 4 & 5 & 4 & 4 & 3.8 & 4 & 4 \\
\hline & 13 & 3 & 5 & 5 & 4 & 4 & 4.2 & 4 & 3 \\
\hline & 16 & 2 & 5 & 3 & 4 & 3 & 3.4 & 3 & 4 \\
\hline & 18 & 5 & 4 & 5 & 3 & 4 & 4.2 & 4 & 3 \\
\hline \multirow[t]{9}{*}{2} & 2 & 5 & 5 & 5 & 4 & 4 & 4.6 & 5 & 2 \\
\hline & 5 & 4 & 4 & 5 & 4 & 3 & 4 & 4 & 3 \\
\hline & 8 & 4 & 3 & 4 & 4 & 3 & 3.6 & 4 & 2 \\
\hline & 11 & 4 & 3 & 2 & 4 & 3 & 3.2 & 3 & 3 \\
\hline & 14 & 1 & 2 & 1 & 3 & 2 & 1.8 & 2 & 3 \\
\hline & 17 & 3 & 2 & 4 & 4 & 3 & 3.2 & 3 & 3 \\
\hline & 19 & 3 & 5 & 4 & 4 & 2 & 3.6 & 4 & 4 \\
\hline & 21 & 5 & 5 & 5 & 4 & 4 & 4.6 & 5 & 2 \\
\hline & 22 & 4 & 5 & 5 & 3 & 3 & 4 & 4 & 3 \\
\hline \multirow[t]{6}{*}{3} & 3 & 2 & - & 5 & 4 & 2 & 3.25 & 3 & 4 \\
\hline & 6 & 4 & 5 & 5 & 4 & 4 & 4.4 & 4 & 2 \\
\hline & 9 & 3 & 5 & 5 & 3 & 4 & 4 & 4 & 3 \\
\hline & 12 & 3 & 4 & 5 & 3 & 3 & 3.6 & 3 & 3 \\
\hline & 15 & 4 & 5 & 5 & 4 & 4 & 4.4 & 4 & 2 \\
\hline & 20 & 4 & 4 & 5 & 4 & 4 & 4.2 & 4 & 2 \\
\hline
\end{tabular}


Table 2.2 (continued)

Content specialists' absolute discrepancy from median

\begin{tabular}{llllll} 
Function 1 & 9 & 4 & 6 & 2 & 1 \\
Function 2 & 3 & 4 & 5 & 6 & 7 \\
Function 3 & 2 & 4 & 8 & 2 & 1 \\
& & & & & \\
Total & 14 & 12 & 19 & 10 & 9 \\
\hline
\end{tabular}

The item numbers are for the original version of the CFQ sent to content specialists. 
in a pilot study to a group of 15 female fastball players (ages 14 to 16 ) to detect potential problems with the scale. The primary purpose of the pilot study was to evaluate the clarity of the questionnaires in a field setting. The athletes were given the CFQ, a demographics questionnaire which assessed sport participation in the previous 12 months, and a perceived control measure between two sessions of a weekend identification camp. Athletes were asked to provide written and/or verbal feedback on the scales' items and format.

The perceived control measure was developed based on Skinner's (1995, 1996) conceptualization of control beliefs. Athletes were asked to respond whether they disagree or agree with control belief statements regarding the stressful situation described on the CFQ. Responses were scored on a 5-point scale ranging from 1 (strongly disagree) to 5 (strongly agree). The perceived control measure consisted of 12 items and assessed control beliefs related to two dimensions: perceptions of control over changing the situation and perceptions of control over emotions. Six items for each domain were developed based on Skinner's (1995) framework that she originally presented to assess students' perceptions of control in an academic domain. Three of six items for each domain were negatively worded. For both domains, the result was a three item scale for positive events (positively worded items) and a three item scale for negative events (negatively worded items).

No concerns regarding the format of the CFQ or perceived control emerged from the fastball players. Mean and standard deviations for the three coping function scales on the CFQ were as follows: problem-focused coping, $\underline{M}=2.59, \underline{S D}=1.20$; emotion-focused coping, $\underline{M}=3.25, \underline{S D}=.88$; and avoidance coping, $\underline{M}=1.69, \underline{S D}=1.05$. Although the sample size was small, the mean and standard deviation values for the three scales were deemed adequate to continue on to Part B of Study 1.

The perceived control scale was modified prior to Part B of Study 1 following feedback on the scale provided by an expert in the area of perceived control. More specifically, the expert was 
familiar with Skinner's (1995, 1996) conceptualization of control beliefs. Based on this feedback, the scale items were slightly reordered, some items were eliminated, and an additional perceptions of control over the ability to avoid the situation was included. In order to limit the length of the perceived control measure it was decided that 4 items (2 positively, 2 negatively worded) would form a composite for each of the three dimensions of perceived control.

\subsubsection{Part B}

The purpose of Part B of Study 1 was to provide preliminary evaluation of the items and response format on the CFQ, stress appraisal, perceived control, and demographics and sports participation questionnaires developed previously. CFQ scales were expected to have acceptable means and variances, acceptable distributions, and acceptable reliability. Items within each scale were expected to be more highly related to each other compared to correlations with items on other scales. Another purpose of Part B was to evaluate the response format on the CFQ that asked for the break down of coping strategies use into frequency, duration, and effort.

\subsubsection{Participants}

Participants were 132 high school students (grades 9 through 12) in the Saskatoon Public School system. Data from five students were removed because of incomplete data sets, and one student's data was removed for reporting a situation that occurred beyond the required previous 12 months. Thus, the final sample consisted of 126 high school students.

\subsubsection{Measures}

2.1.2.2.1 Demographics and Sport Participation Questionnaire (DSPQ). The DSPQ was designed to provide basic information regarding participant age, grade, gender, and sport participation (see Appendix A). The sport participation portion of the DSPQ asked students "Have you participated in any organized sports (teams or clubs with organized leagues or competitions) in the past 12 months?". If the student responded "yes" to the sports participation item, the sport(s), 
team/club name, and level of sport were listed.

2.1.2.2.2 Stress appraisal. Students provided information regarding characteristics and stress appraisal of a situation. There were five items. The first item asked students to describe in writing the most stressful situation in sport faced in the last 12 months. The second item asked students "How long did the stressful situation last?" and had four response categories $(1=$ less than 1 week, $2=1$ week to 1 month, $3=1$ to 3 months, $4=$ more than 3 months). The third item asked students "When did the stressful situation occur?" and also had four response categories ( $1=$ in the past week, 2 =more than 1 week ago, but less than 1 month ago, 3 = more than 1 month ago, but less than 3 months ago, 4 = more than 3 months ago, but less than 12 months ago). The fourth item, a stress thermometer (Francis \& Stanley, 1989), was adapted similar to Stanton (1991) to assess perceived stressfulness of the self-indicated situation. Students were asked to "Please indicate the amount of stress that you experienced in the situation by marking an ' $\mathrm{X}$ ' on the scale within the thermometer". Responses on the stress thermometer range from 0 (no stress at all) to 100 (intolerable stress). The fifth item asked students to describe in writing why the self-indicated situation was stressful.

The stress thermometer is an analogue scale originally developed to assess subjective stress in a dental situation. It was important to have a measure of stressfulness as a check that self-indicated situations were stressful at least to some degree. Two-month test-retest reliability of the stress thermometer for a group of 37 undergraduate students was .78, and three-month test-retest reliability for a group of 33 students in bachelor's courses was .82 (Francis \& Stanley, 1989). There is also convergent and construct validity evidence for the stress thermometer. As a measure of dental fear, Francis and Stanley (1989) found that the stress thermometer was correlated $\underline{r}=.61$ with dental anxiety for a group of 152 subjects, and that therapy produced a significant reduction in dental fear anxiety scores for a group of 33 volunteers following a treatment program for dental fears. They also 
found the stress thermometer was moderately related to estimates of dental fear made by dentists. Stanton (1991) used the stress thermometer to assess work stress with a group of 30 female secretaries. He found that an experimental group receiving an ego-enhancement intervention program had significantly lower stress thermometer scores immediately following and two months following treatment than a control group. A similar visual analogue scale for anxiety was used by Hornblow and Kidson (1976) who found the visual analogue anxiety scale to be significantly related to state anxiety for a group of 130 students prior to an exam $(r=.84)$ and 75 psychiatric patients at ward meetings or other group activities $(r=.66)$.

\subsection{Coping Function Questionnaire (CFQ). The CFQ assessed coping} function regarding the self-indicated stressful situation described in the stress appraisal section. The CFQ contained 19 items assessing three coping functions; (a) an effort to actively change and remain in the situation that was causing the stress (problem-focused coping; 7 items), (b) an effort to control thoughts or emotions while remaining in the situation that was causing the stress (emotion-focused coping; 8 items), and (c) an effort to remove oneself either permanently or temporarily from the situation that is causing the stress (avoidance coping; 4 items). Items for the CFQ are presented in Table 2.3 (the combined stress appraisal and CFQ questionnaire is presented in Appendix B). First, students indicated if they used each strategy to handle the stressful situation. Second, coping was rated on three dimensions (frequency, duration, and effort) if they responded 'yes' to that particular coping item. Responses for each coping dimension were scored on a 4-point scale ranging from "seldom/little" to "very often/very much". Item scores were determined by taking the mean of the responses to the three coping dimensions ("no" responses were scored 0), ranging from 0 to 4 with higher scores reflecting greater coping. Coping function scale scores were determined by taking the mean of all items comprising each scale. Separate scale scores for each coping dimension were also determined by including only that dimension in the scale score. All scale scores ranged from 0 to 4 . 
Table 2.3

Items on the CFO Used in Study 1.

\begin{tabular}{|c|c|c|}
\hline \multicolumn{2}{|c|}{ Item } & \multirow{2}{*}{$\frac{\text { Coping Function }}{\text { Problem-focused }}$} \\
\hline 1. & I tried to find a way to change the situation. & \\
\hline 2. & $\begin{array}{l}\text { I stayed in the situation and tried to control my emotions } \\
\text { to better deal with the situation. }\end{array}$ & Emotion-focused \\
\hline 3. & I worked harder to try to change the situation. & Problem-focused \\
\hline 4. & $\begin{array}{l}\text { I tried to change how I thought about the situation so it } \\
\text { didn't seem so stressful. }\end{array}$ & Emotion-focused \\
\hline 5. & I got out of the situation as soon as I could. & Avoidance \\
\hline 6. & $\begin{array}{l}\text { I tried to use problem-solving strategies to make things } \\
\text { better. }\end{array}$ & Problem-focused \\
\hline 7. & $\begin{array}{l}\text { I tried to view the situation in a way that made it seem } \\
\text { less stressful. }\end{array}$ & Emotion-focused \\
\hline 8. & $\begin{array}{l}\text { I left or avoided the situation temporarily to get away } \\
\text { from the problem. }\end{array}$ & Avoidance \\
\hline 9. & I did my best to change the situation. & Problem-focused \\
\hline 10. & I talked to someone who could help me feel better. & Emotion-focused \\
\hline 11. & $\begin{array}{l}\text { I looked for ways to solve the problem or change the } \\
\text { situation. }\end{array}$ & Problem-focused \\
\hline 12. & $\begin{array}{l}\text { I got out of the situation for a little while to get away } \\
\text { from the stress. }\end{array}$ & Avoidance \\
\hline 13. & $\begin{array}{l}\text { I talked to someone who could help me solve the } \\
\text { problem. }\end{array}$ & Problem-focused \\
\hline 14. & I accepted the situation. & Emotion-focused \\
\hline 15. & I stayed in the situation and tried to change it. & Problem-focused \\
\hline 16. & I worked through my emotions in order to feel better. & Emotion-focused \\
\hline 17. & I tried to get away from the situation. & Avoidance \\
\hline 18. & I tried to find ways to control my emotions. & Emotion-focused \\
\hline 19. & $\begin{array}{l}\text { I tried to relax so that I could keep my emotions under } \\
\text { control. }\end{array}$ & Emotion-focused \\
\hline
\end{tabular}


2.1.2.2.4 Perceived Control. The perceived control measure was developed based on Skinner's (1995, 1996) conceptualization of control beliefs, and assessed perceptions of control in three domains; (a) perceived control over changing the situation, (b) perceived control over controlling emotions, and (c) perceived control over avoiding the situation (see Appendix C). Students indicated the degree to which they disagreed or agreed with the control belief statements regarding the stressful situation described on the CFQ. Responses were scored on a 5-point scale ranging from I (strongly disagree) to 5 (strongly agree). The perceived control measure consisted of 12 items, four items for each domain. Two of four items for each domain were negatively worded. For all domains, the result was a four item scale reflecting control beliefs in that particular domain.

\subsubsection{Procedure}

A researcher visited a variety of classrooms in the high school and introduced the study to the students. Consent forms (see Appendix D) were given to the students and returned by students to their teachers. Students were allowed to participate only if they returned a signed consent form. Determining the exact percentage of students who returned consent forms could not have been determined without placing an additional burden on the classroom teachers. Attempts were made by both teachers and researchers to encourage the return of consent forms. Approximately one week later the questionnaire package was administered during class time either in class or in an empty classroom in the school.

The students were instructed to complete the questionnaires in three parts. First, students completed the demographics and sport participation questionnaire. Second, students began completing the stress appraisal by being asked to recall a stressful situation they had experienced in sport. Verbal instructions to the students were as follows:

Describe the most stressful situation you have experienced in the last 12 months. Just describe one (the most stressful) situation. This situation can be anything related to sport. It could be during competition, or it can be any issue surrounding your sport. If you have not 
participated in sport in the past 12 months, then you should describe a stressful situation you experienced in a physical activity setting, fitness/dance setting, physical education, or other type of game.

Students then completed the items regarding how long the stressful situation lasted, when the stressful situation occurred, the stress thermometer, and why the situation was important. Third, the instructions for filling out the CFQ were read aloud, and the response format and examples were described. Students then completed the rest of the questionnaire package, including the perceived control scale. Following completion, the students were asked to check over their questionnaires for possible missing items. A research assistant was available to answer any questions. Research assistants were required to sign a researcher confidentiality form prior to the study (see Appendix E).

When possible, the format of the scale was evaluated through brief discussions with one student from each class following administration of the questionnaires. Discussions were possible for four of 10 classes (grade 11 female, grade 10 female, grade 10 male, grade 9 male). Students provided feedback regarding the scale format.

\subsubsection{Data analysis}

Item distributions, item means, and item variances were examined for sport and non-sport participants separately. Inter-item, item-scale, inter-scale correlations were examined through Pearson product-moment correlations. Scale reliabilities for the CFQ and perceived control were examined through Cronbach's alpha.

\subsubsection{Results and Discussion}

2.1.2.5.1 Descriptive Statistics. Students who reported participation in at least one organized sport in the previous 12 months were classified as "sport participants". Students not reporting participation in organized sport in the previous 12 months were classified as "non-sport participants". From the sample of 126 students, 98 were classified as a sport participant and 28 were classified as a non-sport participant. Data for non-sport participants for Study 1 is not presented given 
the small sample size. Frequency statistics for age, grade, how long the stressful situation lasted, and when the stressful situation occurred are provided in Table 2.4. Mean age of the sport participants was $15.39(\underline{S D}=1.12)$.

Descriptive statistics for the items on the CFQ and perceived control scales are presented in Tables 2.5 and 2.6. The means on the avoidance items were relatively low, but the variances on the variables were similar to other items. Two problem-focused items were problematic. Item 6 (I tried to use problem-solving strategies to make things better) had a relatively low mean, indicating that improvements to the item needed to be made. This item might present a strategy that is too specific or may represent an unclear item (students may have been unsure what is meant by a problem-solving strategy, a notion supported by numerous questions regarding the item from the students). Item 13 (I talked to someone who could help me solve the problem) may also be too specific a strategy, and as a result needed to be reworded to capture a greater range of coping strategies to achieve the problemfocussed function. Overall, the item variances appeared to be adequate, as did most means which fell slightly below the midpoint of the scale.

Descriptive statistics for the summary variables are presented in Table 2.7. All variables were approximately normally distributed, except the avoidance coping scale was positively skewed. Results showed a low mean score on avoidance coping, indicating that a large number of sport participants may not be using avoidance strategies to deal with stressful situations in sport. The low mean score on the avoidance coping scale is not a desirable measurement property because of the potential for truncated variance and skewed distribution.

2.1.2.5.2 Relationships among items and scale reliability. Pearson correlations among the items within the CFQ and perceived control scales are presented in Tables 2.8 and 2.9 . Consistent with expectations, items within each CFQ scale were generally more highly related to each other compared to correlations with items on other scales. A notable exception was item 13, a 
Table 2.4

Frequency Statistics for Age, Grade. How Long the Stressful Situation Lasted, and When the Stressful Situation Occurred.

\begin{tabular}{|c|c|c|}
\hline \multicolumn{2}{|c|}{ Variable } & Frequency of Participants \\
\hline \multicolumn{3}{|l|}{ Age } \\
\hline & 13 & 1 \\
\hline & 14 & 23 \\
\hline & 15 & 32 \\
\hline & 16 & 23 \\
\hline & 17 & 17 \\
\hline & 18 & 2 \\
\hline \multicolumn{3}{|l|}{ Grade } \\
\hline & 9 & 20 \\
\hline & 10 & 29 \\
\hline & 11 & 30 \\
\hline & 12 & 19 \\
\hline \multicolumn{3}{|c|}{ Length of time the stressful situation lasted } \\
\hline & less than I week & 48 \\
\hline & I week to I month & 27 \\
\hline & 1 month to 3 months & 12 \\
\hline & more than 3 months & 10 \\
\hline \multicolumn{3}{|c|}{ When the stressful situation took place } \\
\hline & less than 1 week ago & 6 \\
\hline & 1 week to 1 month ago & 14 \\
\hline & 1 month to 3 months ago & 20 \\
\hline & 3 months to 12 months ago & 58 \\
\hline
\end{tabular}


Table 2.5

Descriptive Statistics for Items on the CFO for Study 1.

\begin{tabular}{|c|c|c|c|}
\hline Item & $\underline{\mathbf{n}}$ & $\underline{\mathbf{M}}$ & $\underline{\text { SD }}$ \\
\hline 1 (Problem-focused) & 97 & 1.56 & 1.33 \\
\hline 2 (Emotion-focused) & 97 & 2.29 & .99 \\
\hline 3 (Problem-focused) & 97 & 1.78 & 1.57 \\
\hline 4 (Emotion-focused) & 97 & 1.74 & 1.48 \\
\hline 5 (Avoidance) & 97 & .87 & 1.31 \\
\hline 6 (Problem-focused) & 97 & .71 & 1.14 \\
\hline 7 (Emotion-focused) & 97 & 1.82 & 1.25 \\
\hline 8 (Avoidance) & 94 & .65 & 1.08 \\
\hline 9 (Problem-focused) & 97 & 1.44 & 1.49 \\
\hline 10 (Emotion-focused) & 97 & 1.43 & 1.36 \\
\hline 11 (Problem-focused) & 97 & 1.66 & 1.45 \\
\hline 12 (Avoidance) & 97 & .57 & .94 \\
\hline 13 (Problem-focused) & 97 & 1.35 & 1.36 \\
\hline 14 (Emotion-focused) & 96 & 1.96 & 1.27 \\
\hline 15 (Problem-focused) & 97 & 1.43 & 1.51 \\
\hline 16 (Emotion-focused) & 97 & 1.36 & 1.39 \\
\hline 17 (Avoidance) & 97 & .63 & 1.11 \\
\hline 18 (Emotion-focused) & 97 & 1.61 & 1.39 \\
\hline 19 (Emotion-focused) & 97 & 2.08 & 1.38 \\
\hline
\end{tabular}

Note. Items on the CFQ ranged from 0 (not used) to 4 (used very much). 
Table 2.6

Descriptive Statistics for Items on the Perceived Control Measure for Study 1.

\begin{tabular}{llll}
\hline Item & $\mathrm{n}$ & $\underline{\mathrm{M}}$ & $\underline{\mathrm{SD}}$ \\
\hline 1 (Change situation) & 98 & 2.62 & 1.26 \\
2 (Control emotion) & 97 & 3.90 & .85 \\
3 (Change situation) & 98 & 2.91 & 1.40 \\
4 (Control emotion) & 98 & 3.93 & .96 \\
5 (Avoid situation) & 97 & 2.53 & 1.28 \\
6 (Avoid situation) & 98 & 2.97 & 1.30 \\
7 (Control emotion) & 98 & 3.76 & .76 \\
8 (Avoid situation) & 98 & 3.02 & 1.28 \\
9 (Control emotion) & 98 & 3.68 & 1.03 \\
10 (Change situation) & 98 & 2.83 & 1.23 \\
11 (Change situation) & 98 & 2.95 & 1.33 \\
12 (Avoid situation) & 98 & 2.80 & 1.23 \\
& & & \\
\hline
\end{tabular}


Table 2.7

Summary Variable Descrintive Statistics for Study 1.

\begin{tabular}{llll}
\hline Variable & $\underline{\text { n }}$ & $\underline{\text { M }}$ & $\underline{\text { SD }}$ \\
\hline CFQ & & & \\
Problem-focused coping & 97 & 1.42 & .93 \\
Emotion-focused coping & 96 & 1.78 & .85 \\
Avoidance coping & 94 & .66 & .75 \\
Problem-focused coping frequency & 97 & 1.41 & .96 \\
Problem-focused coping duration & 97 & 1.36 & .92 \\
Problem-focused coping effort & 97 & 1.45 & .96 \\
Emotion-focused coping frequency & 97 & 1.91 & .86 \\
Emotion-focused coping duration & 97 & 1.68 & .83 \\
Emotion-focused coping effort & 97 & 1.77 & .93 \\
Avoidance coping frequency & 97 & .71 & .78 \\
Avoidance coping duration & 97 & .69 & .79 \\
Avoidance coping effort & 97 & .66 & .78 \\
Perceived Control & 97 & 115.26 & 2.89 \\
Control over changing situation & & & \\
Control over emotions & 97.32 & 3.79 \\
\hline Control over avoiding situation & & & \\
\hline
\end{tabular}


Table 2.8

Zero-order Correlations Among Items on the CFQ for Study 1.

\begin{tabular}{|c|c|c|c|c|c|c|c|c|c|c|}
\hline Item & 1. & 3. & 6. & 9. & 11. & 13. & 15. & 2. & 4. & 7. \\
\hline 1. (PF) & - & $.55^{*}$ & $.34^{*}$ & $.62^{*}$ & $.46^{*}$ & $.21^{*}$ & $.42^{\star}$ & .13 & .04 & .00 \\
\hline 3. (PF) & $.55^{*}$ & - & $.22^{*}$ & $.54^{*}$ & $.45^{*}$ & .14 & $.51^{*}$ & $.23^{*}$ & .01 & .07 \\
\hline 6. (PF) & $.34^{*}$ & $.22 *$ & - & $.26^{*}$ & $.33^{*}$ & .07 & .19 & .07 & .02 & -.01 \\
\hline 9. (PF) & $.62^{*}$ & $.54^{*}$ & $.26^{*}$ & - & $.48^{*}$ & .00 & $.43^{*}$ & .07 & -.05 & .04 \\
\hline 11. (PF) & $.46^{*}$ & $.45^{*}$ & $.33^{*}$ & $.48^{*}$ & - & $.20^{*}$ & $.43^{*}$ & .15 & .19 & $.24^{*}$ \\
\hline 13. (PF) & $.21^{*}$ & .14 & .07 & .00 & $.20^{*}$ & - & .03 & $.21^{*}$ & .09 & .14 \\
\hline 15. (PF) & $.42^{*}$ & $.51^{*}$ & .19 & $.43^{*}$ & $.43^{*}$ & .03 & - & $.30^{*}$ & .16 & .05 \\
\hline 2. (EF) & .13 & $.23^{*}$ & .08 & .07 & .15 & $.21^{*}$ & $.30^{*}$ & - & $.33^{*}$ & $.36^{*}$ \\
\hline 4. (EF) & .04 & .01 & .02 & -.05 & .19 & .09 & .16 & $.33^{*}$ & - & $.59^{*}$ \\
\hline 7. (EF) & .00 & .07 & -.01 & .04 & $.24^{*}$ & .14 & .05 & $.36^{*}$ & $.59 *$ & - \\
\hline 10. (EF) & .10 & .06 & .01 & -.02 & .09 & $.69 *$ & -.01 & .17 & $.30^{*}$ & $.25^{*}$ \\
\hline 14. (EF) & -.14 & -.05 & .04 & -.09 & -.03 & .05 & -.12 & $.24^{*}$ & $.29 *$ & $.41^{*}$ \\
\hline 16. (EF) & .09 & .12 & .06 & -.01 & $.22^{*}$ & .20 & .11 & $.32 *$ & $.41^{*}$ & $.44^{*}$ \\
\hline 18. (EF) & .14 & .16 & .14 & .11 & $.21^{*}$ & .18 & .11 & $.29^{*}$ & $.28 *$ & $.43^{*}$ \\
\hline 19. (EF) & .11 & .16 & .16 & .06 & $.26^{*}$ & .16 & .15 & $.38^{*}$ & $.32^{*}$ & $.44^{*}$ \\
\hline 5. (AV) & .13 & .15 & .06 & .18 & $.20^{*}$ & .08 & .13 & -.09 & -.01 & -.08 \\
\hline 8. (AV) & $.22^{*}$ & .15 & .17 & .07 & .09 & .05 & .10 & -.02 & -.06 & -.07 \\
\hline 12. (AV) & $.23^{*}$ & .19 & $.29 *$ & .17 & .16 & -.01 & .07 & -.03 & .11 & .02 \\
\hline 17. (AV) & .15 & .10 & -.01 & $.23^{*}$ & .17 & .04 & .07 & -.06 & -.10 & .00 \\
\hline
\end{tabular}


Table 2.8 (continued)

\begin{tabular}{|c|c|c|c|c|c|c|c|c|c|}
\hline Item & 10. & 14. & 16. & 18. & 19. & 5. & 8. & 12. & 17. \\
\hline 1. (PF) & .10 & -.14 & .09 & .14 & .11 & .13 & $.22^{*}$ & $.23^{*}$ & .15 \\
\hline 3. (PF) & .06 & -.05 & .12 & .16 & .16 & .15 & .15 & .19 & .10 \\
\hline 6. (PF) & .01 & .04 & .06 & .14 & .16 & .06 & .17 & $.29 *$ & -.01 \\
\hline 9. (PF) & -.02 & -.09 & -.01 & .11 & .06 & .18 & .07 & .17 & $.23^{*}$ \\
\hline 11. (PF) & .09 & -.03 & $.22^{*}$ & $.2 \mathrm{I}^{*}$ & $.26^{*}$ & $.20^{*}$ & .09 & .16 & .17 \\
\hline 13. (PF) & $.69^{*}$ & .05 & .20 & .18 & .16 & .08 & .05 & -.01 & .04 \\
\hline 15. (PF) & -.01 & -.12 & .11 & .11 & .15 & .13 & .10 & .07 & .07 \\
\hline 2. (EF) & .17 & $.24^{*}$ & $.32^{*}$ & $.29 *$ & $.38^{*}$ & -.09 & -.02 & -.03 & -.06 \\
\hline 4. (EF) & $.30^{*}$ & $.29 *$ & $.41^{*}$ & $.28^{*}$ & $.32^{*}$ & -.01 & -.06 & .11 & -.10 \\
\hline 7. (EF) & $.25^{*}$ & $.41^{*}$ & $.44^{*}$ & $.43^{*}$ & $.44^{*}$ & -.08 & -.07 & .02 & .00 \\
\hline 10. (EF) & - & $.25^{*}$ & $.36^{*}$ & $.36^{*}$ & .15 & -.02 & -.11 & -.07 & -.03 \\
\hline 14. (EF) & $.25^{*}$ & - & $.22^{*}$ & .17 & $.26^{*}$ & .03 & $-.38^{*}$ & $-.22 *$ & -.20 \\
\hline 16. (EF) & $.36^{*}$ & $.22^{*}$ & - & $.53^{*}$ & $.29 *$ & -.08 & .03 & .10 & .09 \\
\hline 18. (EF) & $.36^{*}$ & .17 & $.53^{*}$ & - & $.38 *$ & -.18 & .04 & .06 & -.11 \\
\hline 19. (EF) & .15 & $.26^{*}$ & $.29 *$ & $.38 *$ & - & -.04 & .02 & -.08 & -.04 \\
\hline 5. (AV) & -.02 & .03 & -.08 & -.18 & -.04 & - & .14 & .14 & $.39 *$ \\
\hline 8. (AV) & -.11 & $-.38 *$ & .03 & .05 & .02 & .14 & - & $.71^{*}$ & $.22^{*}$ \\
\hline 12. (AV) & -.07 & $-.22^{*}$ & .10 & .06 & -.08 & .14 & $.7 \mathrm{I}^{*}$ & $\ldots$ & .14 \\
\hline 17. (AV) & -.03 & -.20 & .09 & -.11 & -.04 & $.39 *$ & $.22^{*}$ & .14 & - \\
\hline
\end{tabular}

Note. Correlation matrix is based on pair-wise comparisons and the $\mathbf{n}$ values range from 94 to 97. Note. $\mathrm{PF}=$ problem-focused coping; $\mathrm{EF}=$ emotion-focused coping; $\mathrm{AV}=$ avoidance coping. " $<$.05 (two tail significance) 
Table 2.9

Zero-order Correlations Among Items on the Perceived Control Measure for Study 1.

\begin{tabular}{|c|c|c|c|c|c|c|c|c|c|c|c|c|}
\hline Item & 1. & 3. & 10. & 11. & 2. & 4. & 7. & 9. & 5. & 6. & 8. & 12. \\
\hline 1. $(\mathrm{CH})$ & - & $.57^{*}$ & $.59 *$ & $.61^{*}$ & $.31^{*}$ & $.24^{*}$ & .18 & .10 & $.36^{*}$ & $.25^{*}$ & $.50^{*}$ & .20 \\
\hline 3. (CH) & $.57^{*}$ & $\ldots$ & $.62^{*}$ & $.63^{*}$ & $.33^{*}$ & $.29 *$ & $.25^{*}$ & .15 & $.43^{*}$ & .19 & $.38 *$ & .11 \\
\hline 10. $(\mathrm{CH})$ & $.59 *$ & $.62^{*}$ & - & $.73^{*}$ & .19 & .09 & .13 & .04 & $.51^{*}$ & .13 & $.47^{*}$ & $.22^{*}$ \\
\hline 11. $(\mathrm{CH})$ & $.6 \mathrm{I}^{*}$ & $.63^{*}$ & $.73^{*}$ & - & $.25^{*}$ & $.21^{*}$ & .14 & .13 & $.38 *$ & $.38^{*}$ & $.44^{*}$ & $.36^{*}$ \\
\hline 2. (E) & $.32^{*}$ & $.33^{*}$ & $.19^{*}$ & $.25^{*}$ & - & $.45^{*}$ & $.60^{*}$ & $.43^{*}$ & $.22^{*}$ & .06 & $.25^{*}$ & .05 \\
\hline 4. (E) & $.24^{*}$ & $.29^{*}$ & .09 & $.21^{*}$ & $.45^{*}$ & - & $.50^{*}$ & $.65^{*}$ & .14 & $.22^{*}$ & .16 & .14 \\
\hline 7. (E) & .18 & $.25^{*}$ & .13 & .14 & $.60^{*}$ & $.50^{*}$ & - & $.49^{*}$ & $.22^{*}$ & .14 & .19 & .17 \\
\hline 9. (E) & .10 & .15 & .04 & .13 & $.43^{*}$ & $.65^{*}$ & $.49^{*}$ & $\cdots$ & .05 & .09 & .10 & .12 \\
\hline 5. (A) & $.36^{*}$ & $.43^{*}$ & $.51^{*}$ & $.38^{*}$ & $.22^{*}$ & .14 & $.22^{*}$ & .05 & - & $.26^{*}$ & $.42^{*}$ & $.46^{*}$ \\
\hline 6. (A) & $.25^{*}$ & .19 & .13 & $.38^{*}$ & .06 & $.22^{*}$ & .14 & .09 & $.26^{*}$ & - & $.33^{*}$ & $.65^{*}$ \\
\hline 8. (A) & $.50^{*}$ & $.38 *$ & $.47^{*}$ & $.44^{*}$ & $.25^{*}$ & .16 & .19 & .10 & $.42^{*}$ & $.33^{*}$ & $\ldots$ & $.30^{*}$ \\
\hline 12. (A) & .20 & .11 & $.22^{*}$ & $.36^{*}$ & .05 & .14 & .17 & .12 & $.46^{*}$ & $.65^{*}$ & $.30^{*}$ & - \\
\hline
\end{tabular}

Note. Correlation matrix is based on pair-wise comparisons and the n values range from 96 to 98 . Note. $\mathrm{CH}=$ perceived control over changing the situation; $\mathrm{E}=$ perceived control over emotions; $\mathrm{A}$ $=$ perceived control over avoiding the situation.

${ }^{*} \mathrm{p}<.05$ (two tail significance) 
problem-focused coping item (I talked to someone who could help me solve the problem), which was not significantly related to a number of other problem-focused coping items, but was moderately related $(r=.69, p<.05)$ to item 10 , an emotion-focused item (I talked to someone who could help me feel better). It was not surprising given the similar item content that these two social support items were inter-correlated. It indicates, however, that item 13 may need to be reworded to capture a greater range of coping strategies for the problem-focussed coping function it was intended to assess. It appeared that item 6, a problem-focused item (I tried to use problem-solving strategies to make things better), also needed to be improved to reflect more of a problem-focused coping function. Item 5 , an avoidance coping item (I got out of the situation as soon as I could), was related to only one other item on the avoidance coping scale, suggesting revisions in the wording of the item were required.

On the perceived control measure, the perceptions of control over changing the situation items had higher correlations with each other than with items on other scales. Similar results were found for the perceptions of control over emotions items. On the perceptions of avoidance scale, the items had similar correlations with the perceptions of control over changing the situation as among themselves, suggesting modifications to the scale were required.

Internal consistency values for each of the CFQ and perceived control scales are presented in Table 2.10. Intermal consistency values for the scales were greater than .70 except for the avoidance coping scale (alpha $=.61$ ). The avoidance coping scale may need to be modified slightly or an additional item added to improve the reliability of the scale. Additionally, the internal consistency values on the problem-focused coping scale could be improved with the removal of item 13 (I talked to someone who could help me solve the problem), suggesting that this item needed to be improved or removed.

2.1.2.5.3 Frequency, duration, and efiort of coping functions. One purpose of Study 1 was to evaluate the usefulness of the response format on the CFQ which asked students to 
Table 2.10

Internal Consistency Values for the CFO and the Perceived Control Measure for Studv 1.

\begin{tabular}{llc}
\hline Scale & n & Alpha \\
\hline Problem-focused coping (7 items) & 97 & .78 \\
Emotion-focused coping (8 items) & 96 & .80 \\
Avoidance coping (4 items) & 94 & .61 \\
Control over changing situation (4 items) & 98 & .87 \\
Control over emotions (4 items) & 97 & .81 \\
Control over avoiding situation (4 items) & 97 & .73 \\
\end{tabular}


break down use of coping strategies into frequency, duration, and effort. Correlations among coping scales for frequency, duration, and effort are presented in Table 2.11. Correlations among rating dimensions ranged from $\underline{r}=.89$ to .96 . These results suggest that the subject burden required to discriminate among frequency, duration, and effort of coping strategy usage is not warranted. The high response format correlations suggest that students might not be able to discriminate adequately among these response dimensions, or the dimensions are so highly related that the use of one scale provides the same information as all three. Using only one response format would also allow the length of the CFQ to be significantly reduced.

2.1.2.5.4 Relationships among scales. Examining the relationships among constructs was not the primary purpose of Study 1 , and therefore, results should be considered exploratory. The relationships among constructs were examined more fully in Study 2. Correlations among scales are presented in Table 2.12. Problem-focused coping was positively related to emotion-focused coping. Avoidance coping had a moderate positive correlation with problem-focused coping. Many of the stressful situations reported occurred over an extended period ( 49 participants reported their stressful situation occurred longer than one week) and it is possible both problem-focused and avoidance strategies were used either in conjunction or sequentially. It is also possible that avoidance may be a coping strategy, not a coping function, and may actually be serving a problem-focused coping function. For example, an athlete might miss a practice, not in an attempt to get away from the stress, but to get the coach to realize how important he or she is to the team and give the athlete a more prominent role. In this example, the true goal was to change the situation, with the chosen means of doing so being temporary withdrawal. The wording of the items, focusing on the function of coping strategies, should help improve this distinction. Relationships among coping functions and relationships with other coping scales examined in Study 2 were expected to provide further evidence for or against the inclusion of avoidance at the functional level. However, the appropriateness of avoidance at the coping 
Table 2.11

Zero-order Correlations Among CFO Frequency. Duration, and Effort Sub-scales.

\begin{tabular}{|c|c|c|c|c|c|c|c|c|c|}
\hline Item & 1. & 2. & 3. & 4. & 5. & 6. & 7. & 8. & 9. \\
\hline 1. PFOften & - & $.96^{*}$ & $.90^{*}$ & & & & & & \\
\hline 2. PFDur & $.96^{*}$ & - & $.93^{*}$ & & & & & & \\
\hline 3. PFEffort & $.90^{*}$ & $.93^{*}$ & - & & & & & & \\
\hline 4. EFOtten & & & & - & $.93^{*}$ & $.90^{*}$ & & & \\
\hline 5. EFDur & & & & $.93^{*}$ & - & $.89^{*}$ & & & \\
\hline 6. EFEffort & & & & $.90^{*}$ & $.89 *$ & - & & & \\
\hline 7. AVOften & & & & & & & - & $.93^{*}$ & $.89 *$ \\
\hline 8. AVDur & . & & & & & & $.93 *$ & - & $.91^{*}$ \\
\hline 9. AVEffort & & & & & & & $.89^{*}$ & $.91^{*}$ & - \\
\hline
\end{tabular}

Note. Correlation matrix is based on pair-wise comparisons and the n values range from 94 to 98 . Note. Only correlations among similar coping function scales is presented to exhibit the most salient correlations.

Note. PFOften $=$ frequency of problem-focused coping; PFDur $=$ duration of problem-focused coping; PFEffort effort of problem-focused coping; EFOften = frequency of emotion-focused coping; EFDur duration of emotion-focused coping; EFEffort = effort of emotion-focused coping: AVOften = frequency of avoidance coping; $\mathrm{AVDur}=$ duration of avoidance coping; $\mathrm{AVEffort}=$ effort of avoidance coping.

" $\mathrm{p}<.05$ (two tail significance) 
Table 2.12

Zero-order Correlations Among Scales for Study 1.

\begin{tabular}{llllllllll}
\hline Item & 1. & 2. & 3. & 4. & 5. & 6. & 7. & 8. & 9. \\
\hline l. Long & - & $.32^{*}$ & $.31^{*}$ & -.09 & -.08 & .06 & -.01 & .09 & .15 \\
2. When & $.32^{*}$ & - & $.27^{*}$ & -.11 & .09 & -.10 & -.05 & .08 & -.05 \\
3. Stress & $.31^{*}$ & $.27^{*}$ & - & .03 & $.27^{*}$ & .01 & -.13 & -.19 & -.11 \\
4. PF & -.09 & -.11 & .03 &.-- & $.24^{*}$ & $.30^{*}$ & $.34^{*}$ & .09 & .12 \\
5. EF & -.08 & .09 & $.27^{*}$ & $.24^{*}$ & -- & -.11 & -.10 & .11 & -.12 \\
6. AV & .06 & -.10 & .01 & $.30^{*}$ & -.11 & - & $.25^{*}$ & -.12 & $.26^{*}$ \\
7. CH & -.01 & -.05 & -.13 & $.34^{*}$ & -.10 & $.25^{*}$ & $-\ldots$ & $.28^{*}$ & $.53^{*}$ \\
8. E & .09 & .08 & -.19 & .09 & .11 & -.12 & $.28^{*}$ & -- & $.24^{*}$ \\
9. A & .15 & -.05 & -.11 & .12 & -.12 & $.26^{*}$ & $.53^{*}$ & $.24^{*}$ & - \\
& & & & & & & & & \\
\hline
\end{tabular}

Note. Correlation matrix is based on pair-wise comparisons and the $\underline{n}$ values range from 94 to 98 . Note. Long = length of time the stressful situation lasted; When = how long ago the stressful situation took place; Stress = stress thermometer scale score; $P F=$ problem-focused coping; EF = emotion-focused coping; $\mathrm{AV}=$ avoidance coping; $\mathrm{CH}=$ perceived control over changing the situation; $E$ = perceived control over emotions; $A$ = perceived control over avoidance. " $\mathrm{p}<.05$ (two tail significance) 
strategy or coping function level might remain primarily a theoretical issue.

As expected, problem-focused coping was moderately related to increased perceived control over changing the situation, and avoidance coping was moderately related to increased control over avoiding the situation. Although emotion-focused coping was not related to perceptions of control over emotions, it was positively related to stressfulness of the situation. The perceptions of control over emotions measure had a relatively high mean value and low standard deviation $\underline{\underline{M}}=3.90, \underline{S D}=.85$; scale was scored from 1 to 5), suggesting that most individuals felt relatively high perceptions of control over emotions in most situations, and actual coping strategies may have been more influenced by perceptions of control over changing the situation and/or perceptions of control over avoidance. The relationships among coping functions and perceived control dimensions were more adequately addressed in Study 2.

T-tests comparing males and female sport participants on coping and perceived control variables showed that females used significantly more emotion-focused coping than males $t(94)=$ $3.46, \mathrm{p}<.05)$. Males had a mean on the emotion-focused coping function scale of $1.47(\underline{\mathrm{SD}}=.87)$ compared to a mean of $2.05(\underline{S D}=.75)$ for females. Gender issues were more adequately examined in Study 2.

2.1.2.5.5 Discussions with students. Students reported that the questionnaires were easy to understand and relevant for their situations. Based on student discussions, as well as from questions asked of research assistants during questionnaire administration, it was apparent that the response format on the CFQ did present some problems. First, some students were unsure how to answer the item responses. Second, one student indicated it was difficult to discriminate among coping frequency, duration, and effort.

The apparent length of the questionnaire (due mainly to the space required for the response format on the CFQ) was intimidating. Based on discussions, the students seemed to enjoy the stress 
thermometer as an assessment tool for stress intensity. Other than questions regarding item 6 on the CFQ(I tried to use problem-solving strategies to make things better), no other concerns regarding item clarity emerged.

2.1.2.5.6 Scale modifications. Based on the results of Study I, a number of CFQ scale items were modified. Five items were reworded, three items were removed, and two new items were included on the instrument. Problem-focused coping item 6 (I tried to use problem-solving strategies to make things better) was reworded (I used strategies to change the situation in order to deal with the stress) to improve the clarity of the item and to capture a greater range of coping strategies for the intended problem-focused function. Problem-focused coping item 13 (I talked to someone who could help me solve the problem) was removed. The internal consistency of the problem-focused scale was higher in Study 1 with item 13 removed. The primary limitation of the item may have been that it was too specific to capture a wide range of coping strategies to achieve the problem-focused function. Similarly, emotion-focused coping function items 10 (I talked to someone who could help me feel better) and 14 (I accepted the situation) were deemed to be too specific and might more accurately represent an actual coping strategy as opposed to coping function. Although these two items were moderately related to most other emotion-focused coping scales, the items were removed and replaced with an additional, more emotion-focused coping function item (I tried to use different strategies that would help me control my emotions).

A number of steps were taken to improve the avoidance coping function scale. Item 5 (I got out of the situation as soon as I could) was slightly modified (I tried to get out of the situation as soon as I could to reduce the stress) to more accurately reflect the avoidance function of the strategy. Item 8 (I left or avoided the situation temporarily to get away from the problem) was modified slightly (I tried to leave or avoid the situation to get away from the problem or reduce the stress) so as to be less restrictive and to reflect coping efforts rather than outcome. Item 12 (I got out of the situation for a 
little while to get away from the stress) was likewise reworded (I tried to get out of the situation to get away from the stress) to be less restrictive and to reflect coping efforts rather than outcome. Item 17 (I tried to get away from the situation) was slightly expanded (I tried to get away from the situation to reduce the stress) to more accurately reflect coping function. An additional avoidance item (In order to reduce the stress, I tried to get myself out of the situation) was added to the CFQ in an attempt to improve the reliability of the avoidance coping scale.

The response format on the CFQ was changed for a number of reasons. First, the high correlations among coping frequency, duration, and effort suggested that either students were unable to discriminate among these three dimensions or that they are so highly interrelated that the addition of all three dimensions is unnecessary. The addition of all three dimensions increases the length of the questionnaire and response burden greatly. Second, discussions with students and questions that were asked during administration of the CFQ indicated the response format was not always clear to the students. Rating coping on one dimension alone would significantly reduce the difficulty of responding in an appropriate format. Third, changing the response format would significantly reduce the number of pages in the questionnaire, making it less intimidating to the students. Fourth, examples of responses, which seemed to confuse students, would no longer be needed. Fifth, a new format could provide a quicker, less complex assessment of coping function, which should make the questionnaire more practical for researchers.

A response format requiring students to respond to "how much" they used a particular coping strategy was selected. This response format has been used on a number of current coping assessment instruments, including the modified COPE and the Life Situations Inventory which were used to assess validity of the CFQ in Study 2. This response format was also expected to be appropriate for a greater range of coping situations, as opposed to the more restrictive ratings of frequency, duration, or effort of coping usage. Changing the response format to assess "how much" was expected to make the 
meaning of the responses in terms of frequency, duration, or effort, unclear (Stone et al., 1992), but based on the results of Study 1 there is considerable overlap among these three dimensions. The choice of a more global measure of coping usage, such as "how much" each coping strategy was used, is likely more appropriate for assessment of general coping function than a more restrictive rating of coping frequency, duration, or effort. Each response format has limitations. Given the benefits of a response format that is appropriate for a wide range of coping, a more general, unidimensional response format was selected.

Slight modifications to the perceived control scale were made based on the results of Study 1. First, "could have" or "couldn't have" was bolded to emphasize the responses should be based on coping options, not actual efforts. Second, two items requiring students to assess control beliefs regarding avoiding the situation (items 5 and 12) were expanded upon to emphasize that the students were to assess avoidance of the stressful situation once they were already in it, as opposed to avoiding the situation before it occurred.

\subsection{STUDY 2}

The purpose of the second study was to further examine the measurement properties of the CFQ, based on scale modifications that were made in Study 1 . More specifically, the factorial validity of the CFQ measurement model, convergent and divergent validity with other coping scales, and relationships between coping and perceived control were examined.

Specific hypotheses for study two were as follows:

(a) It was expected that the CFQ would have acceptable psychometric properties including factor structure, internal consistency, item variability, and approximately normal distributions of scales. Factorial validity of two separate CFQ models were examined; a one factor (coping) and a three factor (problem-focused, emotion-focused, avoidance) model. It was expected that the three factor model would provide acceptable factorial validity for the CFQ, and would be a significantly 
better model than the one factor model. The factorial gender invariance in the three factor CFQ measurement model was also examined.

(b) As evidence of convergent validity, it was expected that coping function scales on the CFQ would be related to theoretically similar coping strategy dimensions from existing coping measures. The evaluation of criterion-related validity may be difficult for coping instruments because an appropriate criterion needs to be selected against which to judge the validity of the test scores. Because of the difficulties in measuring coping strategies, a satisfactory criterion does not exist. Still, it was expected that the CFQ coping functions would be related to theoretically similar dimensions on existing coping measures.

Specific COPE or MCOPE scales were expected to be related to conceptually similar coping function scales on the CFQ. The active coping (taking action or exerting efforts to remove or manage the stressful situation) and planning (thinking about or planning one's coping efforts to deal with the stressful situation) scales on the MCOPE should be related to problem-focused coping on the CFQ. Both MCOPE scales reflect an aftempt to change the stressful situation, either through direct action or making a plan of action, and are conceptually consistent with the problem-focused coping function on the CFQ.

The COPE scales related to emotion-focused coping on the CFQ should be acceptance (accepting the fact that stressful event has occurred and that it is real), restraint coping (coping passively and holding back one's coping attempts until they can be useful), and seeking social support for emotional reasons (getting moral support, sympathy, or understanding from someone). Acceptance should be related to emotion-focused coping function because it consists of two components; acceptance that it is a real situation and that there is an absence of current active coping strategies (Carver et al., 1989). As Carver et al. (1989) suggested, acceptance is likely to be used in situations where the stressor must be accommodated, which is consistent with the emotion-focused coping 
function scale on the CFQ. Restraint coping should be related to emotion-focused coping function because it contains a passive component prior to acting (Carver et al., 1989). Because restraint coping does have an active coping component, it may be related to problem-focused as well as emotionfocused coping. Seeking social support for emotional reasons reflects an aspect of emotion-focused coping (Carver et al., 1989), and may be one of primary strategies individuals use to help them manage emotions.

The avoidance scale on the Life Situations Inventory (LSI) was expected to be related to avoidance coping function on the CFQ because of conceptual similarity in the content of the two scales. Also, the LSI avoidance and LSI resignation scales were positive correlated (Feifel \& Strack, 1989), suggesting that resignation coping should also be positively related to the avoidance coping function scale on the CFQ. A conceptual diagram with hypothesized relations between the CFQ and COPE and LSI scales is presented in Figure 2.1.

(c) The relationships among coping functions is not well established. However, problemfocused, emotion-focused, and avoidance coping function were expected to be relatively independent. Low intercorrelations among coping functions would provide discriminant validity evidence for the CFQ.

(d) As further discriminant validity evidence for the CFQ, social desirability should be unrelated to coping responses. Social desirability has been considered the response tendency towards culturally acceptable and approved behaviours that are unlikely to occur. Social desirability has been shown not to be related to competitive anxiety (Ryska, 1993), classification into ego identity status groups (Jones, Akers, \& White, 1994), or sport involvement (Ryckman \& Hamel, 1995) for high school aged subjects, indicating that social desirability is an appropriate construct to provide divergent validity evidence.

(e) As evidence for construct validity, coping function was expected to be related to the 

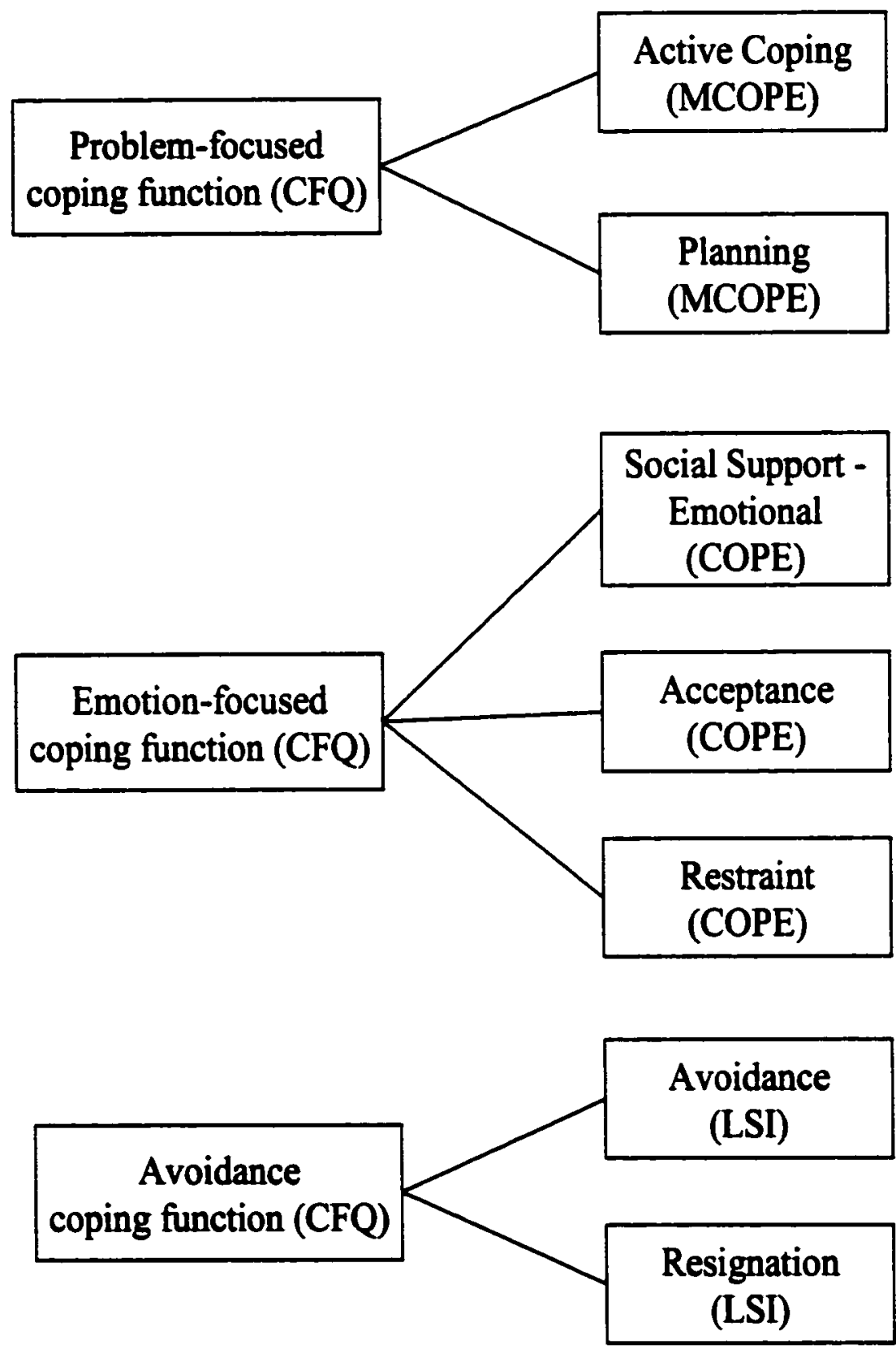

Figure 2.1. Hypothesized relations between the CFQ and COPE and LSI coping scales. Solid lines indicate expected bivariate correlations. Questionnaire source is indicated in parentheses. 
theoretically relevant dimension of perceived control. More specifically, problem-focused coping function was expected to be related to control over changing the situation. Emotion-focused coping function was expected to be related to perceived control over emotions. Avoidance coping function was expected to be related to perceived control over avoidance. Further, at a structural level, avoidance coping function was expected to be determined not only by perceptions that avoidance was possible but also by low perceived control over changing the situation and low perceived control over emotions.

\subsubsection{Participants}

Questionnaires were administered to 871 high school students (grades 9 through 12) from two schools in the Saskatoon Catholic School system and one school in the Saskatoon Public School system. A total of 28 students were removed from the study for a number of reasons. Data from fifteen students were removed from the study for having missed more than one item in the questionnaire package. However, student's data were not removed at that point if they reported they did not experience any stress in the previous 12 months or if a second missing item in the questionnaire package was on the social desirability scale. Social desirability was deemed less important in establishing validity evidence than either coping or perceived control, and therefore eliminating a student from the study for missing an item on social desirability was unnecessary. Data from six students were removed for reporting a situation that occurred beyond the required previous 12 months, three did not report gender, two were removed for obviously not reporting valid information, and two students were excluded from the analysis for being outliers on age (beyond the age of 19). Thus, the final sample consisted of 843 high school students (413 males, 430 females) ranging in age from 13 to 19 years.

\subsubsection{Measures}

2.2.2.1 Demographics and Sport Participation Questionnaire (DSPQ). Same as 
in Study 1.

2.2.2.2 Stress appraisal. Same as in Study 1.

2.2.2.3 Coping Function Questionnaire (CFQ). The CFQ previously described in Study 1 was modified based on the results of that study. The revised CFQ (see Appendix F) contained 18 items which assessed three coping functions; (a) problem-focused coping consisted of six items to assess an effort to actively change and remain in the situation that was causing the stress, (b) emotionfocused coping consisted of seven items and assessed an effort to control thoughts or emotions while remaining in the situation that was causing the stress, and (c) avoidance coping consisted of five items and assessed an effort to remove oneself either permanently or temporarily from the situation that was causing the stress. Items on the revised CFQ are presented Table 2.13.

Students were asked how much they used each coping function to handle the stressful situation they described in the stress appraisal section. Responses for each coping function item were scored on a 5-point scale (not at all, a little, somewhat, quite a bit, very much). Coping function scale scores were determined by taking the mean of all items comprising each scale, with higher scores reflecting greater coping. Scale scores ranged from 1 (not used) to 5 (used very much).

2.2.2.4 Specific MCOPE and COPE coping scales. Specific scales from the COPE (Carver et al., 1989) and sport modifications of the COPE scale (Crocker \& Graham, 1995) were selected to assess coping strategies (see Appendix G). The sport modified COPE (MCOPE) was developed to assess coping in recent stressful performance situations. Nine original COPE scales and three additional sport scales make up the MCOPE. Some items from the original COPE scale were modified to provide greater sport relevance.

Five scales were chosen to provide convergent validity evidence. The scales from the COPE or MCOPE were selected based on psychometric properties and expectations that the scales contained some theoretical relevance to the coping function scales on the CFQ. Two problem-focused (active 
Table 2.13

Items on the CFO Used in Study 2.

\begin{tabular}{|c|c|c|}
\hline Item & & Coping Function \\
\hline 1. & I tried to find a way to change the situation. & Problem-focused \\
\hline 2. & $\begin{array}{l}\text { I stayed in the situation and tried to control my emotions to } \\
\text { better deal with the situation. }\end{array}$ & Emotion-focused \\
\hline 3. & I worked harder to try to change the situation. & Problem-focused \\
\hline 4. & $\begin{array}{l}\text { I tried to change how I thought about the situation so it didn't } \\
\text { seem so stressful. }\end{array}$ & Emotion-focused \\
\hline 5. & $\begin{array}{l}\text { I tried to get out of the situation as soon as I could to reduce } \\
\text { the stress. }\end{array}$ & Avoidance \\
\hline 6. & $\begin{array}{l}\text { I used strategies to change the situation in order to deal with } \\
\text { the stress. }\end{array}$ & Problem-focused \\
\hline 7. & $\begin{array}{l}\text { I tried to view the situation in a way that made it seem less } \\
\text { stressful. }\end{array}$ & Emotion-focused \\
\hline 8. & $\begin{array}{l}\text { I tried to leave or avoid the situation to get away from the } \\
\text { problem or reduce the stress. }\end{array}$ & Avoidance \\
\hline 9. & I did my best to change the situation. & Problem-focused \\
\hline 10. & $\begin{array}{l}\text { I tried to use different strategies that would help me control } \\
\text { my emotions. }\end{array}$ & Emotion-focused \\
\hline 11. & I looked for ways to solve the problem or change the situation. & Problem-focused \\
\hline 12. & I tried to get out of the situation to get away from the stress. & Avoidance \\
\hline 13. & I stayed in the situation and tried to change it. & Problem-focused \\
\hline 14. & I worked through my emotions in order to feel better. & Emotion-focused \\
\hline 15. & I tried to get away from the situation to reduce the stress. & Avoidance \\
\hline 16. & I tried to find ways to control my emotions. & Emotion-focused \\
\hline 17. & $\begin{array}{l}\text { I tried to relax so that I could keep my emotions under } \\
\text { control. }\end{array}$ & Emotion-focused \\
\hline 18. & $\begin{array}{l}\text { In order to reduce the stress I tried to get myself out of the } \\
\text { situation. }\end{array}$ & Avoidance \\
\hline
\end{tabular}


coping, planning) coping scales from the MCOPE and three emotion-focused (acceptance, restraint coping, and seeking social support for emotional reasons) coping scales from the COPE were selected. Scales on the COPE and MCOPE consist of four items, each scored on a 5-point scale ranging from "not used at all" to "used very much". Scale scores are unweighted item composites. Internal consistency values from previous research for the COPE or MCOPE scales used in the present study are presented in Table 2.14. Generally, internal consistency values are adequate, with none of the studies reporting alpha values below .60 . Two of the studies reported in Table 2.14 were with adolescents suggesting that the COPE had adequate reliability for adolescents, a conclusion reached by Phelps and Jarvis (1994). It should be noted, however, that Gould, Udry, Tuffey, and Loehr (1996) eliminated the restraint coping scale on the COPE from their analysis of adolescent's coping with a stressful tennis situation for having an internal consistency value of .54 .

There is some scale validity evidence for the MCOPE, although validation has not been the purpose of most studies (Crocker et al., 1998). Content validity for the MCOPE was strengthened because it has been modified to provide greater sport relevance (Crocker \& Graham, 1995). There is also preliminary construct validity evidence for the instrument. Clustering of types of coping using the MCOPE have been shown to be similar to clustering found in non-sport populations using the original COPE (Carver et al., 1989).

There is some evidence to suggest that the scales used for convergent validity in the present study are related within their coping dimensions. An exploratory principal components analysis used with the original COPE for a group of grade 9 to 12 students found active coping and planning (along with suppression of competing activities and seeking social support for instrumental reasons) loaded on a common active coping factor (Phelps \& Jarvis, 1994). Similarly, restraint coping and acceptance (along with positive re-interpretation and growth and mental disengagement) loaded together on a common acceptance coping factor. Seeking social support for emotional reasons loaded (along with 
Table 2.14

Internal Consistency Values for the COPE and Modified COPE in Previous Research.

\begin{tabular}{lcccccccc}
\hline & \multicolumn{8}{c}{ COPE Study } \\
\cline { 2 - 8 } Scale & $1^{\mathrm{a}}$ & $2^{\mathrm{b}}$ & $3^{\mathrm{c}}$ & $4^{\mathrm{d}}$ & $5^{\mathrm{c}}$ & $6 \mathrm{a}^{\mathrm{f}}$ & $6^{\mathrm{g}}$ \\
\hline Active Coping & .62 & .64 & .66 & $.68-.77$ & .74 & & \\
& & & & & & $.87, .85$ & $.69, .73$ \\
Planning & .80 & .82 & .78 & $.72-.85$ & .80 & & \\
Acceptance & .65 & -- & .74 & - & .75 & $.63, .72$ & - \\
Restraint coping & .72 & - & .69 & - & - & $.65, .67$ & - \\
Seeking Social Support & .85 & .81 & .83 & $.77-.80$ & .88 & $.84, .82$ & - \\
for Emotional Reasons & & & & & & & \\
\end{tabular}

- Carver et al. (1989) used the COPE with 978 undergraduate students.

${ }^{b}$ Crocker and Graham (1995) used the MCOPE with 235 competitive athletes.

' Phelps and Jarvis (1994) used the COPE with 475 students in grades 9 through 12.

${ }^{2}$ Bouffard and Crocker (1992) use the COPE with 30 individuals with physical disabilities over three occasions.

' Crocker and Isaak (1997) used the swimming MCOPE with 25 youth swimmers.

'Eklund et al. (1998) used the COPE with 2 samples (435 athletes in each sample). They combined the active coping and planning scales into one factor.

B Eklund et al. (1998) used the MCOPE with 2 samples (310 and 311 athletes in each sample respectively). They combined the active coping and planning scales into one factor. The internal consistency value for seeking social support for emotional reasons is not reported because they used a combined scale including both seeking social support for emotional and instrumental reasons. 
focus on and venting of emotions) on a factor that was subsequently labelled emotion-focused coping. Eklund et al. (1998) found that a MCOPE model including a combined active coping/ planning factor provided the best model fit in a confirmatory factor analysis for athletes recalling a performance slump, suggesting these two coping strategies are highly related and possibly not independent. They also used a confirmatory factor analysis to examine the COPE model and found that the acceptance latent factor was related to the restraint coping latent factor $(r=.35$, Sample $A ; \underline{r}=.47$, Sample B). The social support for emotional reasons latent factor was moderately related to restraint coping $(r=$ .35 , Sample $A ; \underline{r}=.22$, Sample B) and weakly related to acceptance $(r=.12$, Sample $A ; \underline{r}=.07$, Sample B).

2.2.2.5 Life Situations Inventory (LSI). The LSI (Feifel \& Strack, 1989) was developed to assess coping with life conflict situations. Due to the lack of reliability for the disengagement scales on the COPE, two scales (avoidance and resignation) on the LSI were used to assess convergent validity of the CFQ (see Appendix $\mathrm{H}$ ). The avoidance scale ( 8 items) reflects an attempt to get away from the problem by minimizing, excusing, or ignoring it, which is conceptually similar to the avoidance coping function scale on the CFQ. The resignation scale ( 5 items) reflects resignation to the situation and lack of attempt to modify it.

Students were asked how much they used each strategy to deal with their self-indicated stress situation. One item on the LSI was slightly modified from "How much did you feel that the final decision was beyond your control" to "How much did you feel that the final outcome was beyond your control", in order to be more applicable across a wide range of situations. Items (randomly ordered) on the LSI were scored on a 4-point scale ranging from "not at all" to "very much". Scale composites are unweighted sums of scale items.

The LSI was developed for middle-aged and elderly men, however, the content of the scales appears to be adequate to assess convergent validity of the avoidance coping function scale on the 
CFQ. Feifel and Strack (1989) found the avoidance and resignation scales to have adequate intermal consistency (alpha $=.75$ for both scales).

2.2.2.6 Perceived Control. Refer to Study 1 and see Appendix I.

2.2.2.7 Social Desirability Scale. A short form of the Marlowe-Crowne scale (MCS; Reynolds, 1982) was used to examine divergent validity of the CFQ (see Appendix J). The short form of the MCS scale assesses students' response tendencies towards culturally acceptable and approved behaviours which are unlikely to occur. The MCS has 13 items scaled on a true-false response format. Scores can range from 0 to 13 , with higher scores reflecting a higher need for social approval. The MCS scale is expected to have zero to low correlations with other measures.

Kuder-Richardson Formula 20 reliability of the MCS was .76 for 608 undergraduate student (Reynolds, 1982), and .68 for 399 college aged students (Ballard, 1992). Fischer and Fick (1993) found the MCS to have high intemal consistency (alpha $=.89$ ) and was correlated $\underline{r}=.97$ with the original 33-item version of the Marlowe-Crowne scale for 360 undergraduate students. The MCS was also found to be a good fitting model (adjusted goodness-of-fit index $=.916$; root mean square $=.047$ ).

\subsubsection{Procedure}

A researcher met with teachers from the three schools and explained the purposes and procedures of the study. Teachers then distributed consent forms to their classroom students. One week later a researcher visited the classrooms in the high school and reintroduced the study to the students, handed out additional consent forms, and answered any questions. Consent forms (see Appendix K) were retumed by students to their teachers. Students were allowed to participate only if they retumed a signed consent form. Determining the exact percentage of students who returned consent forms could not have been determined without placing an additional burden on the classroom teachers. Attempts were made by both teachers and researchers to encourage the retum of consent forms. Approximately one week later the questionnaire package was administered during class time 
either in class or in an empty classroom in the school.

Students were instructed to complete the questionnaires in three parts. First, students completed the Demographics and Sport Participation Questionnaire. Second, students began completing the stress appraisal by being asked to recall a stressful situation they had experienced in sport. Verbal instructions to the students were as follows:

Describe the most stressful situation you have experienced in the last 12 months. Just describe one (the most stressful) situation. This situation can be anything related to sport. It could be during competition, or it can be any issue surrounding your sport. If you have not participated in sport in the past 12 months, then you should describe a stressful situation you experienced in a physical activity setting, fitness/dance setting, physical education, or other type of game.

Students then completed the items regarding how long the stressful situation lasted, when the stressful situation occurred, the stress thermometer, and why the situation was important. Third, the instructions for filling out the CFQ were read aloud. The students then completed the rest of the questionnaire package in the following order; CFQ; COPE active coping, planning, seeking social support for emotional reasons, acceptance, and restraint scales; LSI avoidance and resignation scales; perceived control; and social desirability. Following completion, the students were asked to check over their questionnaires for possible missing items. A research assistant was available to answer any questions. Research assistants were required to sign a researcher confidentiality form prior to the study.

\subsubsection{Data analysis}

Correlations among measures were examined for evidence of convergent, divergent, and construct validity. Item distributions, item means, item variances, and inter-item correlations were also examined. Confirmatory factor analysis (CFA) was conducted to test the underlying subscale structure. More specifically, CFA procedures were used to examine whether a one-factor (coping) or a three-factor (problem-focused, emotion-focused, and avoidance) provided an adequate measurement model for the CFQ. Also, CFA was used to evaluate the COPE, LSI, and perceived control 
measurement models separately. Structural equation modelling was conducted to test the proposed theoretical relationships between the CFQ and perceived control. Structural equation modeling analysis was conducted using Amos 3.61 (Arbuckle, 1997). Model estimation was conducted using maximum likelihood estimation, which is the standard method of estimating free parameters in a structural equation model (Hoyle \& Panter, 1995). Analysis was conducted separately for each gender when appropriate.

\subsubsection{Results and Discussion}

2.2.5.1 Descriptive Statistics. Students who reported participation in at least one organized sport in the previous 12 months were classified as "sport participants". Students not reporting participation in organized sport in the previous 12 months were classified as "non-sport participants". Eight students ( 4 male, 4 female) of the final 843 students reported they experienced no stress in the past 12 months. Thus, all subsequent data analysis was conducted with these eight students removed. From the remaining sample of 835 students, 683 were classified as a sport participant (344 males, 339 females) and 152 were classified as a non-sport participant (65 males, 87 females). Mean age of the sport participants was $15.46(\underline{S D}=1.20)$ for males and $15.31(\underline{S D}=1.11)$ for females. Data for non-sport participants is not presented given the small male and female sample size and that validation of the CFQ with non-sport participants was not a primary purpose of the present study. A summary of results for non-sport participants is presented in Appendix L. Frequency statistics for age, grade, how long the stressful situation lasted, and when the stressful situation occurred are provided in Table 2.15. Students reported participation in a wide range of individual and team sports. Sports included a variety of competitive levels from recreational to elite. A wide range of stressful situations were reported by the students. Situations were classified as being stressful due to physical, psychological, environmental, or relationship demands. These categories generally correspond to stress source dimensions identified by Gould, Finch, and Jackson (1993), with three 
Table 2.15

Frequency Statistics for Age. Grade. How Long the Stressful Situation Lasted, and When the Stressful Situation Occurred for Males $(n=344)$ and Females $(n=339)$.

\begin{tabular}{llll}
\hline & & \multicolumn{2}{c}{ Frequency of Participants } \\
\cline { 3 - 4 } Variable & Males & Females \\
\hline Age & & & \\
& 13 & 1 & 3 \\
14 & 88 & 93 \\
15 & 97 & 102 \\
16 & 88 & 85 \\
17 & 52 & 49 \\
18 & 16 & 7 \\
19 & 2 & 0
\end{tabular}

Grade

$106 \quad 107$

10

$96 \quad 103$

11

$77 \quad 78$

12

65

51

Length of time the stressful situation lasted

$\begin{array}{lll}\text { less than I week } & 197 & 143 \\ 1 \text { week to } 1 \text { month } & 85 & 110 \\ 1 \text { month to } 3 \text { months } & 46 & 41 \\ \text { more than } 3 \text { months } & 16 & 44\end{array}$

When the stressful situation took place

$\begin{array}{lll}\text { less than } 1 \text { week ago } & 29 & 31 \\ 1 \text { week to } 1 \text { month ago } & 63 & 56 \\ 1 \text { month to } 3 \text { months ago } & 75 & 48 \\ 3 \text { months to } 12 \text { months ago } & 177 & 200\end{array}$


exceptions. (1) All stressful situations were classified, so there were no uncategorized stress sources, (2)no situations were categorized as life-direction concerns, and (3) the psychological and expectations and pressure to perform dimensions were combined into one psychological demands category. The number of students classified in each of the stress source categories were as follows: 91 (males, 44: females 47) situations were classified as physical demands (e.g. injury, making weight), 314 (males, 155; females, 159) situations were classified as being psychological demands (e.g. competitive stress, pressure to perform), 173 (males, 98; females, 75) were classified as environmental demands (e.g. time management, financial), and 105 (males, 47; females, 58) were classified as relationship demands (e.g. conflict with coaches, parents, teammates, or opponents).

Descriptive statistics for the items on the CFQ and perceived control are presented in Tables 2.16 and 2.17. The means on all items were acceptable, and items had adequate variance. The avoidance item means were relatively low compared to problem- and emotion-focused items, but the variances on the avoidance items were similar to other items. The lower mean on the avoidance items is consistent across both studies and across both genders. Items within scales were quite consistent on both mean and standard deviation values.

Descriptive statistics for the summary variables are presented in Table 2.18. All variables were approximately normally distributed. Although the avoidance scale had skewness values ranging from .80 to 1.12 , this was deemed not to be excessive, and the decision to retain the original distribution was chosen over transformation due to the potential difficulty in interpreting the meaning of a transformed avoidance scale. Also, correlations between the avoidance scale and other coping scales (presented later) varied only slightly for the original avoidance scale compared with the transformed avoidance scale (typical correlation difference was .01 ). Thus, the avoidance scale was retained with its original distribution for all subsequent analysis.

Adequate mean and variance values were found for the three coping function scales. Problem- 
Table 2.16

Descriptive Statistics for Items on the CFO for Study 2 (Males, $n=344$; Females, $n=339$ ).

\begin{tabular}{|c|c|c|c|c|}
\hline \multirow[b]{2}{*}{ Item } & \multicolumn{2}{|c|}{ Males } & \multicolumn{2}{|c|}{ Females } \\
\hline & $\underline{\mathbf{M}}$ & $\underline{\text { SD }}$ & $\underline{\mathbf{M}}$ & $\underline{\mathbf{S D}}$ \\
\hline 1 (Problem-focused) & 2.64 & 1.32 & 2.68 & 1.26 \\
\hline 2 (Emotion-focused) & 3.33 & 1.15 & 3.58 & 1.05 \\
\hline 3 (Problem-focused) & 3.23 & 1.36 & 3.12 & 1.31 \\
\hline 4 (Emotion-focused) & 3.11 & 1.26 & 3.19 & 1.19 \\
\hline 5 (Avoidance) & 2.20 & 1.33 & 2.26 & 1.30 \\
\hline 6 (Problem-focused) & 2.63 & 1.19 & 2.50 & 1.11 \\
\hline 7 (Emotion-focused) & 2.97 & 1.20 & 3.17 & 1.12 \\
\hline 8 (Avoidance) & 1.88 & 1.21 & 2.00 & 1.24 \\
\hline 9 (Problem-focused) & 3.05 & 1.34 & 2.84 & 1.29 \\
\hline 10 (Emotion-focused) & 2.69 & 1.15 & 2.89 & 1.07 \\
\hline 11 (Problem-focused) & 2.99 & 1.25 & 2.89 & 1.23 \\
\hline 12 (Avoidance) & 1.92 & 1.23 & 1.99 & 1.25 \\
\hline 13 (Problem-focused) & 3.09 & 1.35 & 2.91 & 1.19 \\
\hline 14 (Emotion-focused) & 2.84 & 1.20 & 3.06 & 1.08 \\
\hline 15 (Avoidance) & 1.94 & 1.15 & 1.99 & 1.17 \\
\hline 16 (Emotion-focused) & 2.85 & 1.19 & 3.01 & 1.05 \\
\hline 17 (Emotion-focused) & 3.36 & 1.24 & 3.59 & 1.14 \\
\hline 18 (Avoidance) & 1.86 & 1.17 & 1.96 & 1.21 \\
\hline
\end{tabular}

Note. Items ranged from 1 (not used) to 5 (used very much). 
Table 2.17

Descriptive Statistics for Items on the Perceived Control Measure for Study 2 (Males, $n=344$;

Females, $n=339$ ).

\begin{tabular}{|c|c|c|c|c|}
\hline \multirow[b]{2}{*}{ Item } & \multicolumn{2}{|c|}{ Males } & \multicolumn{2}{|c|}{ Females } \\
\hline & $\underline{\mathbf{M}}$ & $\underline{\text { SD }}$ & $\underline{\mathbf{M}}$ & $\underline{\mathrm{SD}}$ \\
\hline I (Change situation) & 3.00 & 1.33 & 2.71 & 1.18 \\
\hline 2 (Control emotion) & 3.72 & .97 & 3.58 & .99 \\
\hline 3 (Change situation) & 3.24 & 1.33 & 2.95 & 1.23 \\
\hline 4 (Control emotion) & 3.84 & 1.01 & 3.65 & .97 \\
\hline 5 (Avoid situation) & 2.61 & 1.09 & 2.50 & 1.19 \\
\hline 6 (Avoid situation) & 3.17 & 1.31 & 3.00 & 1.28 \\
\hline 7 (Control emotion) & 3.80 & .92 & 3.63 & .91 \\
\hline 8 (Avoid situation) & 3.14 & 1.31 & 2.98 & 1.25 \\
\hline 9 (Control emotion) & 3.74 & 1.05 & 3.65 & .98 \\
\hline 10 (Change situation) & 3.09 & 1.21 & 2.85 & 1.15 \\
\hline 11 (Change situation) & 3.20 & 1.25 & 2.93 & 1.20 \\
\hline 12 (Avoid situation) & 3.10 & 1.26 & 2.96 & 1.16 \\
\hline
\end{tabular}

Note. Items ranged from I (strongly disagree) to 5 (strongly agree). 
Table 2.18

Summary Variable Descriptive Statistics for Studv 2 (Males, $\mathrm{n}=344 ;$ Females, $\mathrm{n}=339$ ).

\begin{tabular}{|c|c|c|c|c|}
\hline \multirow[b]{2}{*}{ Variable } & \multicolumn{2}{|c|}{ Males } & \multicolumn{2}{|c|}{ Females } \\
\hline & $\underline{\mathbf{M}}$ & $\underline{\underline{S D}}$ & $\underline{\mathbf{M}}$ & $\underline{\text { SD }}$ \\
\hline Stress Thermometer (scale range, $0-100$ ) & 53.69 & 23.55 & 53.66 & 22.05 \\
\hline \multicolumn{5}{|l|}{ CFQ (scale range $1-5$ ) } \\
\hline Problem-focused coping & 2.94 & .97 & 2.82 & .91 \\
\hline Emotion-focused coping & 3.02 & .81 & 3.21 & .79 \\
\hline Avoidance coping & 1.96 & 1.12 & 2.04 & 1.07 \\
\hline \multicolumn{5}{|l|}{ COPE (scale range 4-20) } \\
\hline Active Coping & 12.14 & 3.74 & 12.07 & 3.37 \\
\hline Planning & 11.62 & 4.16 & 12.14 & 3.89 \\
\hline Social Support Emotional & 9.70 & 4.52 & 12.10 & 5.01 \\
\hline Acceptance & 13.92 & 4.28 & 13.78 & 4.17 \\
\hline Restraint & 10.17 & 3.97 & 10.60 & 3.77 \\
\hline \multicolumn{5}{|l|}{ LSI } \\
\hline Avoidance (scale range 8-32) & 16.61 & 4.47 & 17.63 & 4.16 \\
\hline Resignation (scale range 5-20) & 10.52 & 3.42 & 11.32 & 3.57 \\
\hline \multicolumn{5}{|l|}{ Perceived Control (scale range 1-5) } \\
\hline Control over changing situation & 3.13 & 1.07 & 2.86 & .97 \\
\hline Control over emotions & 3.77 & .80 & 3.63 & .81 \\
\hline Control over avoiding situation & 3.00 & .98 & 2.86 & .93 \\
\hline Social Desriability (scale range 0-13) & 5.02 & 2.86 & 5.27 & 2.77 \\
\hline
\end{tabular}


focused $\underline{M}=2.94$, males; 2.82, females $)$ and emotion-focused $\underline{M}=3.02$, males; 3.21 , females) coping function scale mean values were near the midpoint of the scale. The avoidance coping means were 1.96 for males and 2.04 for females. The avoidance coping mean value was closer to the midpoint of the scale compared to Study $\mathrm{l}$. There was also increased variance on the avoidance scale compared with Study I. Means and variances on the perceived control measure were similar to those found in Study $\mathrm{l}$.

Mean and standard deviation values for the COPE and LSI found in the present study were similar to previous studies using these instruments, although there were slight differences in some instances. Mean and standard deviation values for COPE scales were generally similar to means and standard deviations found for the COPE and MCOPE in previous research (e.g. Carver et al., 1989; Crocker \& Graham, 1995; Crocker \& Isaak, 1997; Phelps \& Jarvis, 1994). Although there were differences in mean values (either higher or lower) in the present study compared with other studies, these differences were relatively small in magnitude considering the variety of populations examined and situations that were recalled in various studies. LSI scores on the avoidance and resignation scales in the present study generally fell withing the range of mean and standard deviation values found on the LSI for middle-aged and elderly populations across a variety of situations (Feifel \& Strack, 1989). Based on these comparisons, it was concluded that scores on the COPE and LSI represented acceptable means and standard deviations.

A multivariate analysis of variance (MANOVA) was conducted to look at gender differences on coping and perceived control scales. Males and females were compared for significant multivariate effects on CFQ, COPE, LSI, and perceived control scales simultaneously. A significant multivariate effect for gender was found (Wilks Lambda $=.90 ; \mathrm{F}(13,669)=5.83, \mathrm{p}<.05$ ). Prior to examining follow-up univariate effects, the significance level was corrected to $\mathrm{g}<.004$ for multiple comparison error inflation using the Bonferroni adjustment (Stevens, 1992). Females had significantly higher 
means on the CFQ emotion-focused coping function, COPE social support for emotional reasons, LSI avoidance, and LSI resignation scales than males. Males had a significantly higher mean on the perceived control over changing the situation scale than females (see Table 2.18).

2.2.5.2 Relationships among items and scale reliability. Pearson correlations among the items within the CFQ and perceived control scales are presented in Tables 2.19 and 2.20. Consistent with expectations, items within each scale were generally more highly related to each other compared to correlations with items on other scales. Correlations among problem-focused coping function iterns ranged from $\underline{\underline{r}}=.33$ to .63 for males and $\underline{\underline{r}}=.25$ to .58 for females. All but one $\underline{r}=.25$ between item 3 and item 6) problem-focused inter-item correlation was higher than the maximum correlation between problem-focused items and items on other scales for females. All problem-focused inter-item correlations for males were higher than the maximum correlation between problem-focused items and items on other scales. All avoidance function scale inter-item correlations $(r=.55$ to .78 for males and $\underline{r}=.49$ to .82 for females) were higher than correlations between avoidance items and either problem- or emotion-focused items for both males and females. The pattem is generally similar for emotion-focused coping function, with 16 of 21 for males and 19 of 21 for females emotionfocused coping scale inter-item correlations being equal to or higher than correlations between emotion-focused items and either problem-focused or avoidance items.

On the perceived control measure, the perceptions of control over changing the situation items had higher correlations with each other than with items on other scales for males, and were equal to or higher for females than all but one correlation (between items 6 and 11). Perceptions of control over emotion items had higher correlations with each other than with items on other scales for both males and females. Similar to Study $l$, the perceptions of avoidance scale items had similar correlations with the perceptions of control over changing the situation as with avoidance scale items, suggesting control over avoidance may have a questionable factor structure. 
Table 2.19

Zero-order Correlations Among Items on the CFO for Studv 2 (Males above diagonal, $n=344$;

Females below diagonal, $n=339$.

\begin{tabular}{|c|c|c|c|c|c|c|c|c|c|c|}
\hline Item & 1. & 3. & 6. & 9. & 11. & 13. & 2. & 4. & 7. & 10. \\
\hline 1. (PF) & - & $.53^{*}$ & $.33^{*}$ & $.53^{*}$ & $.53^{*}$ & $.41^{*}$ & -.01 & .06 & .06 & $.13^{*}$ \\
\hline 3. (PF) & $.49 *$ & - & $.35^{*}$ & $.63^{*}$ & $.45^{*}$ & $.50^{*}$ & .01 & .05 & .02 & .10 \\
\hline 6. (PF) & $.37 *$ & $.25^{*}$ & - & $.36^{*}$ & $.38^{*}$ & $.39 *$ & .07 & $.17^{*}$ & $.19^{*}$ & $.31^{*}$ \\
\hline 9. (PF) & $.56^{\star}$ & $.52^{*}$ & $.36^{\star}$ & - & $.55^{*}$ & $.52^{*}$ & .02 & -.02 & .03 & $.18^{*}$ \\
\hline 11. (PF) & $.52^{*}$ & $.45^{*}$ & $.38 *$ & $.58^{*}$ & - & $.50^{*}$ & $.11^{*}$ & .09 & .07 & $.30^{*}$ \\
\hline 13. (PF) & $.42^{*}$ & $.45^{*}$ & $.33^{*}$ & $.53^{*}$ & $.47^{*}$ & - & $.12^{*}$ & .05 & .04 & $.21^{*}$ \\
\hline 2. (EF) & -.08 & -.02 & .05 & -.09 & .00 & $.12^{*}$ & - & $.16^{*}$ & .05 & $.37^{*}$ \\
\hline 4. (EF) &. .01 & .02 & $.16^{*}$ & -.08 & -.02 & .08 & $.25^{*}$ & - & $.54^{*}$ & $.30^{*}$ \\
\hline 7. (EF) & -.01 & -.03 & .10 & -.02 & .03 & $.11^{*}$ & $.25^{*}$ & $.61^{*}$ & - & $.29 *$ \\
\hline 10. (EF) & $.13^{*}$ & $.14^{*}$ & $.24^{\star}$ & $.15^{*}$ & $.24^{*}$ & $.15^{*}$ & $.37^{*}$ & $.39 *$ & $.45^{*}$ & - \\
\hline 14. (EF) & -.03 & .02 & $.19^{*}$ & .05 & $.16^{*}$ & $.14^{*}$ & $.35^{*}$ & $.36^{*}$ & $.44^{*}$ & $.45^{*}$ \\
\hline 16. (EF) & .01 & .05 & $.16^{*}$ & .08 & $.22^{*}$ & $.12^{*}$ & $.43^{*}$ & $.42^{*}$ & $.47^{*}$ & $.63^{*}$ \\
\hline 17. (EF) & -.08 & .00 & $.17^{*}$ & -.03 & .03 & .14 & $.30^{*}$ & $.39^{*}$ & $.43^{*}$ & $.40^{*}$ \\
\hline 5. (AV) & $.26^{*}$ & $.18^{*}$ & $.23^{*}$ & $.16^{*}$ & $.21^{*}$ & -.08 & $-.18 *$ & -.06 & -.07 & .09 \\
\hline 8. (AV) & $.28 *$ & .08 & $.15^{*}$ & $.14^{*}$ & $.21^{*}$ & $-.19^{*}$ & -.21 & -.04 & -.04 & .05 \\
\hline 12. (AV) & $.28 *$ & .10 & $.23^{*}$ & $.23^{*}$ & $.21^{*}$ & $-.15^{*}$ & $-.26^{*}$ & -.06 & -.08 & .05 \\
\hline 15. (AV) & $.24^{*}$ & .06 & $.18 *$ & $.18^{*}$ & $.24^{*}$ & $-.21^{*}$ & $-.20^{*}$ & -.07 & -.07 & .05 \\
\hline 18. (AV) & $.29 *$ & $.13^{*}$ & $.19^{*}$ & $.21^{*}$ & $.27^{*}$ & $-.13^{*}$ & $-.26^{*}$ & -.09 & $-.11 *$ & .04 \\
\hline
\end{tabular}


Table 2.19 (continued)

\begin{tabular}{|c|c|c|c|c|c|c|c|c|}
\hline Item & 14. & 16. & 17. & 5. & 8. & 12. & 15. & 18. \\
\hline 1. (PF) & .00 & .06 & -.02 & $.18^{*}$ & $.22^{*}$ & $.18^{*}$ & $.16^{*}$ & $.18^{*}$ \\
\hline 3. (PF) & .10 & $.11^{*}$ & .03 & $.12^{*}$ & .03 & .11 & .06 & .09 \\
\hline 6. (PF) & $.24^{*}$ & $.26^{*}$ & $.18^{*}$ & $.11^{*}$ & $.13^{*}$ & $.13^{*}$ & $.11^{*}$ & $.15^{*}$ \\
\hline 9. (PF) & $.11^{*}$ & .08 & .05 & $.19^{*}$ & .08 & $.17^{*}$ & $.13^{*}$ & $.17^{*}$ \\
\hline 11. (PF) & $.16^{*}$ & $.21^{*}$ & .09 & $.14^{*}$ & $.14^{*}$ & $.24^{*}$ & $.14^{*}$ & $.22^{*}$ \\
\hline 13. (PF) & $.14^{*}$ & $.17^{*}$ & $.16^{*}$ & -.05 & $-.19^{*}$ & $-.11^{*}$ & $-.18^{*}$ & -.09 \\
\hline 2. (EF) & $.31^{*}$ & $.35^{*}$ & $.33^{*}$ & -.05 & -.03 & -.07 & -.05 & -.08 \\
\hline 4. (EF) & $.32^{*}$ & $.34^{*}$ & $.34^{*}$ & .01 & .02 & .00 & .00 & -.04 \\
\hline 7. (EF) & $.36^{*}$ & $.26^{*}$ & $.31^{*}$ & .05 & .05 & .05 & .02 & .01 \\
\hline 10. (EF) & $.56^{*}$ & $.61^{*}$ & $.37^{*}$ & .08 & $.14^{*}$ & $.13^{*}$ & $.11^{*}$ & $.11^{*}$ \\
\hline 14. (EF) & - & $.69 *$ & $.40^{*}$ & .05 & .03 & .08 & .08 & .01 \\
\hline 16. (EF) & $.63^{*}$ & - & $.46^{*}$ & .10 & .09 & $.13^{*}$ & $.13^{*}$ & .09 \\
\hline 17. (EF) & $.42^{*}$ & $.53^{*}$ & - & .07 & -.01 & -.01 & $.11^{*}$ & .05 \\
\hline 5. (AV) & -.09 & .06 & $-.11^{*}$ & - & $.55^{*}$ & $.59^{*}$ & $.60^{*}$ & $.61^{*}$ \\
\hline 8. (AV) & $-.15^{*}$ & -.03 & $-.19^{*}$ & $.49^{*}$ & - & $.68^{*}$ & $.73^{*}$ & $.71^{*}$ \\
\hline 12. (AV) & -.09 & -.04 & $-.19^{\star}$ & $.63^{*}$ & $.72^{*}$ & $\infty$ & $.74^{*}$ & $.78^{*}$ \\
\hline 15. (AV) & -.05 & .01 & $-.14^{*}$ & $.60^{*}$ & $.78^{*}$ & $.79^{*}$ & - & $.78^{*}$ \\
\hline 18. (AV) & -.07 & .00 & $-.14^{*}$ & $.65^{*}$ & $.73^{*}$ & $.81^{*}$ & $.82^{*}$ & - \\
\hline
\end{tabular}

Note. PF = problem-focused coping; $E F=$ emotion-focused coping; $A V=$ avoidance coping. * $\mathrm{p}<$.05 (two tail significance) 
Table 2.20

Zero-order Correlations Among Items on the Perceived Control Measure for Study 2 (Males above diagonal, $n=344$; Females below diagonal, $n=339$ ).

\begin{tabular}{|c|c|c|c|c|c|c|c|c|c|c|c|c|}
\hline Item & 1. & 3. & 10. & 11. & 2. & 4. & 7. & 9. & 5. & 6. & 8. & 12. \\
\hline 1. (CH) & - & $.63^{*}$ & $.59 *$ & $.53^{*}$ & $.18^{*}$ & $.23^{*}$ & $.21^{*}$ & $.11^{*}$ & $.20^{*}$ & $.24^{*}$ & $.30^{*}$ & $.24^{*}$ \\
\hline 3. (CH) & $.58^{*}$ & - & $.52^{*}$ & $.59 *$ & $.2 \mathrm{~L}^{*}$ & $.34^{*}$ & $.20^{*}$ & $.22^{*}$ & .08 & $.31^{*}$ & $.24^{*}$ & $.29 *$ \\
\hline 10. (CH) & $.60^{*}$ & $.48^{*}$ & $\infty$ & $.71^{*}$ & $.20^{*}$ & $.21^{*}$ & $.27^{*}$ & $.16^{*}$ & $.37 *$ & $.36^{*}$ & $.48^{*}$ & $.36^{*}$ \\
\hline 11. (CH) & $.44^{*}$ & $.55^{*}$ & $.70^{*}$ & - & $.17^{*}$ & $.24^{*}$ & $.18^{*}$ & $.25^{*}$ & $.2 \mathrm{I}^{*}$ & $.38^{*}$ & $.33^{*}$ & $.39 *$ \\
\hline 2. (E) & .08 & $.11^{*}$ & $.11^{*}$ & $.13^{*}$ & - & $.63^{*}$ & $.60^{*}$ & $.49^{*}$ & .09 & $.13^{*}$ & $.12^{*}$ & .09 \\
\hline 4. (E) & .09 & $.25^{*}$ & .05 & $.19^{*}$ & $.59^{*}$ & - & $.55^{*}$ & $.57^{*}$ & .03 & $.19^{*}$ & .07 & $.14^{*}$ \\
\hline 7. (E) & .11 & $.14^{*}$ & $.20^{*}$ & $.23^{*}$ & $.68^{*}$ & $.57^{*}$ & - & $.46^{*}$ & $.12^{*}$ & $.13^{*}$ & $.17^{*}$ & .07 \\
\hline 9. (E) & .07 & .17 & .11 & $.26^{*}$ & $.51^{*}$ & $.64^{*}$ & $.65^{*}$ & - & .04 & $.21^{*}$ & .10 & $.20^{*}$ \\
\hline 5. (A) & $.12^{*}$ & $.12^{*}$ & $.19^{*}$ & $.16^{*}$ & $.11^{*}$ & .01 & .10 & -.01 & - & $.36^{*}$ & $.51^{*}$ & $.35^{*}$ \\
\hline 6. (A) & $.27 *$ & .33 & $.40^{*}$ & $.49^{*}$ & $.20^{*}$ & $.21^{*}$ & $.22^{*}$ & $.25^{*}$ & $.38^{*}$ & - & $.46^{*}$ & $.41^{*}$ \\
\hline 8. (A) & $.28^{*}$ & $.19^{*}$ & $.44^{*}$ & $.36^{*}$ & $.21^{*}$ & $.12^{*}$ & $.24^{*}$ & $.15^{*}$ & $.41^{*}$ & $.60^{*}$ & - & $.46^{*}$ \\
\hline 12. (A) & $.19^{*}$ & $.26^{*}$ & $.32^{*}$ & $.52^{*}$ & $.16^{*}$ & $.17^{*}$ & $.15^{*}$ & $.23 *$ & $.26^{*}$ & $.5 \mathrm{I}^{*}$ & $.48^{*}$ & - \\
\hline
\end{tabular}

Note. $\mathbf{C H}=$ perceived control over changing the situation; $\mathrm{E}=$ perceived control over emotions; $\mathrm{A}$ $=$ perceived control over avoiding the situation.

* $<$ <.05 (two tail significance) 
Intemal consistency values for coping and perceived control scales for both males and females are presented in Table 2.21. Internal consistency values for all CFQ subscales were greater than .80, suggesting acceptable reliability for the scales. Of note is that the change in format and items on the CFQ improved the internal consistency on the CFQ avoidance coping function scale from a combined gender alpha of .61 in the first study to alpha $=.91$ for males and alpha $=.92$ for females in the present study. Internal consistency values were greater than .75 on the perceived control measure for all subscales. All COPE subscales with the exception of active coping (alpha $=.64$ ) had internal consistency values greater than .70 . The COPE active coping subscale reliability is similar to what has been found in previous studies, but values for the acceptance scale and restraint coping subscales were higher in the present study compared to previous research (see Table 2.15). The LSI had intemal consistency values greater than .70 on the resignation scale for both males and females, similar to previous research using the LSI with a sample of middle-aged and elderly men (Feifel \& Strack, 1989). Altematively, the LSI avoidance scale had internal consistency values ranging from .66 to .71 on the avoidance scale, which is slighly lower compared with results found in the Feifel and Strack study.

2.2.5.3 Structural equation modeling. Structural equation modelling can be used to examine both measurement and structural models of interest to researchers. A confirmatory factor analysis measurement model specifies relations of measured variables to their hypothesized underlying constructs with the constructs allowed to intercorrelate freely (Anderson \& Gerbing, 1988). A structural model, on the other hand, specifies causal relations among constructs based on theory. As has been suggested (Anderson \& Gerbing, 1988), measurement modeis were examined prior to simultaneous estimation of measurement and structural models. A confirmatory factor analysis of the CFQ is an example of evaluation of a measurement model. An example of a structural model is the examination of the relationships among coping and perceived control latent variables.

A number of indexes evaluating model fit should be reported when examining structural 
Table 2.21

Internal Consistency Values for the CFO. Perceived Control Measure, COPE, and LSI (Males, $\mathfrak{n}=$ 344; Females, $n=339$ ).

\begin{tabular}{lll}
\hline Scale & Males & Females \\
\hline CFQ & & \\
Problem-focused coping (6 items) & .84 & .83 \\
Emotion-focused coping (7 items) & .80 & .84 \\
Avoidance coping (5 items) & .91 & .92 \\
Perceived Control & & \\
Control over changing situation (4 items) & .85 & .83 \\
Control over emotions (4 items) & .83 & .86 \\
Control over avoiding situation (4 items) & .75 & .76 \\
COPE & .71 & \\
Active Coping (4 items) & .71 & .64 \\
Planning (4 items) & .80 & .76 \\
Social Support Emotional (4 items) & .86 & .90 \\
Acceptance (4 items) & .82 & .83 \\
Restraint Coping (4 items) & .74 & .72 \\
LSI & .74 \\
Avoidance (8 items) & & \\
Resignation (5 items) & .76 \\
\hline & & \\
\hline & & .71 \\
\hline
\end{tabular}


equation models because there is little consensus as to the best index of fit (Hoyle \& Panter, 1995). The chi-square test can be used as an overall test of model fit to assess the discrepancy between the sample and fitted covariance matrices (Hu \& Bentler, 1995), given the assumption of multivariate normality. Chi-square is an absolute index of fit that assesses how well an a priori model reproduces the sample data. Chi-square also forms the basis for nested model analysis (Hoyle \& Panter, 1995), which was important for simultaneous gender analysis (presented later). The chi-square estimate divided by its degrees of freedom can also be used as an estimate of how many times larger the chisquare value is than its expected value. However, there is no consensus on what represents a good fit for this ratio (Bollen, 1989). The chi-square test is limited in that with large samples even trivial differences between the sample and fitted models will result in rejection of the proposed model due to high power in the analysis. Also, the chi-square test cannot be used to quantify degree of fit along a continuum with a specified boundary, making interpretation difficult(Hu \& Bentler, 1995). Therefore, along with an absolute index of fit, incremental fit indexes should also be used.

Incremental fit indexes assess the proportionate implvivement in fit by comparing a target model with a more restrictive baseline model. Hoyle and Panter (1995) recommended using an absolute index, such as chi-square, as well as at least one type-2 and type-3 incremental fit index to evaluate the proposed model. The primary difference between incremental fit indexes is that a type-2 index is based on a central chi-square distribution of a target model versus a baseline model, whereas a type-3 index is estimated by the noncentral chi-square. Hoyle and Panter suggested using an index such as the Tucker and Lewis Index (TLI) as a type-2 index and the comparative fit index (CFI) as a type-3 index. Even when distributions are nonnormal, there is a only a modest underestimation of TLI and CFI when using maximum likelihood estimation (West, Finch, \& Curran, 1995).

There is also debate as to the value of incremental fit indexes which represents an adequate model. Hu and Bentler (1995) suggested the cutoff of .90 is an inadequate rule to consider models 
acceptable because the criteria for model acceptance will differ depending on the fit index, sample size, estimation method, and distribution. However, .90 is generally agreed upon as a cutoff for overall fit indexes (Hoyle \& Panter, 1995). More important than absolute value of fit indexes is the contribution of the model to a field of study (Bollen, 1989). Therefore, even if a model is not a great fit for the data, it can still be a useful model if little is known in the field or the model is an improvement over existing models.

MacCallum (1995) argued for the use of the root mean square error of approximation (RMSEA) because it is a measure of lack of fit of a model per degrees of freedom. Thus, RMSEA takes into account the disconfirmability of a model. In order for a model to be disconfirmable the number of parameters must be less than the number of measured variable variances/covariances. A model can be considered highly disconfirmable when there is a low number of parameters relative to the number of measured variable variances/covariances. When a model is found to be a good fit and highly disconfirmable (a high degrees of freedom), the researcher can be more confident that the data can plausibly be explained by the model (MacCallum, 1995).

A strength of using a chi-square statistic to estimate model fit is that chi-square change can be used to compare nested models and determine which model best accounts for observed data (Hoyle, 1995). For example, a chi-square difference test can be used to look at the adequacy of a three factor structure on the CFQ compared with a one factor model. Also, the chi-square change was used to look at the factorial invariance in the structure of the CFQ between genders. Hoyle and Panter (1995) recommended against using incremental fit indexes as a basis for making decisions between different models, although these can supplement information that the chi-square difference test provides when looking at competing models.

\subsubsection{Confirmatory Factor Analysis (CFA) for CFQ and other measurement}

models. Confirmatory factor analysis (CFA) was conducted to examine the adequacy of the CFQ. 
COPE, LSI, and perceived control measurement models separately (see Table 2.22). The appropriateness of using CFA for assessing measurement instruments depends on the ability to a priori specify factors for items (Byme, 1994). The CFA measurement models hypothesized that (a) responses on each questionnaire could be explained by the proposed number of factors on each questionnaire, (b) each item would have a nonzero loading on the factor it was intended to measure, and a zero loading on all other factors, (c) covariances among factor scores were free parameters, and (d) measurement error would be uncorrelated. The measurement models for the CFQ, COPE, LSI, and perceived control are presented in Figures 2.2 to 2.6 .

CFA was conducted for a one factor (coping) and three factor (problem-focused, emotionfocused, avoidance) CFQ measurement model. The one factor measurement model for the CFQ was not an adequate model. This lack of model fit for the one factor model provided evidence that the CFQ items do not assess a unidimensional coping construct. As expected, the three factor coping function model was a significant improvement over the one factor coping model. The change in chi-square for the three factor model was significant in relation to the change in degrees of freedom $(\mathfrak{p}<.05)$ for males and females. The TLI and CFI values supported the adequacy of the three factor model. Although acceptable, these fit indexes suggest that improvements to the measurement model may be possible.

The combination of measured problem-focused, emotion-focused, and avoidance scales were also checked for multivariate normality using Amos 3.61. There was no evidence for multivariate kurtosis on the measured coping function scales. However, at an item level, with problem-focused, emotion-focused, and avoidance function as latent variables and CFQ items as measured variables, multivariate kurtosis was significant for males (Mardia's coefficient $=45.45$ ) and females (Mardia's coefficient $=52.95$ ). Although a measure of multivariate skewness is unavailable in Amos 3.61, it is the absence of multivariate kurtosis, as opposed to skewness, that is particularly important for 
Table 2.22

Scale Confirmatory Factor Analysis Results (Males, $n=344$; Females, $n=339$ ).

\begin{tabular}{|c|c|c|c|c|c|c|}
\hline Scale & Chi-square & df & $\mathbf{Q}$ & TLI & CFI & RMSEA \\
\hline \multicolumn{7}{|l|}{$\operatorname{CFQ}(18,1)$} \\
\hline Males & 1684.03 & 135 & 12.47 & .372 & .446 & .183 \\
\hline Females & 1734.64 & 135 & 12.85 & .406 & .476 & .187 \\
\hline \multicolumn{7}{|l|}{$\operatorname{CFQ}(18,3)$} \\
\hline Males & 378.71 & 132 & 2.87 & .898 & .912 & .074 \\
\hline Females & 442.76 & 132 & 3.35 & .882 & .898 & .083 \\
\hline \multicolumn{7}{|l|}{$\operatorname{COPE}(20,5)$} \\
\hline Males & 279.50 & 160 & 1.75 & .946 & .954 & .047 \\
\hline Females & 432.81 & 160 & 2.71 & .883 & .902 & .071 \\
\hline \multicolumn{7}{|l|}{$\operatorname{LSI}(13,2)$} \\
\hline Males & 125.43 & 64 & 1.96 & .900 & .918 & .053 \\
\hline Females & 249.17 & 64 & 3.89 & .755 & .799 & .093 \\
\hline \multicolumn{7}{|c|}{ Perceived Control $(12,3)$} \\
\hline Males & 183.76 & 51 & 3.60 & .895 & .919 & .087 \\
\hline Females & 264.50 & 51 & 5.19 & .846 & .881 & .111 \\
\hline
\end{tabular}

Note. Values in parentheses represent number of items in scale and number of factors in the model.

Note. $Q=$ chi-square divided by degrees of freedom in the model; TLI = Tucker-Lewis index; CFI = comparative fit index; RMSEA = root mean square error of approximation. 


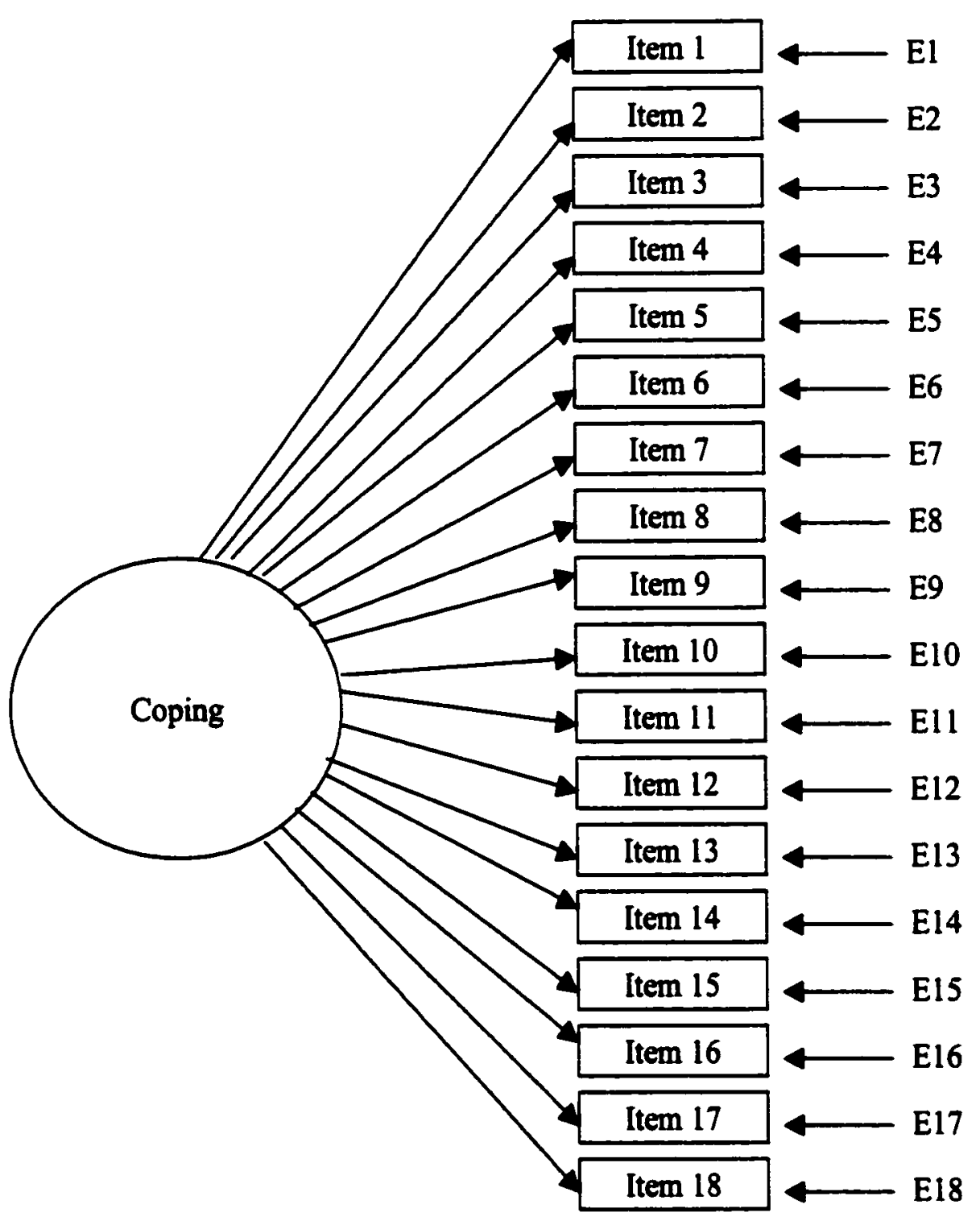

Figure 2.2. Hypothesized one-factor model of factorial structure for the CFQ. 


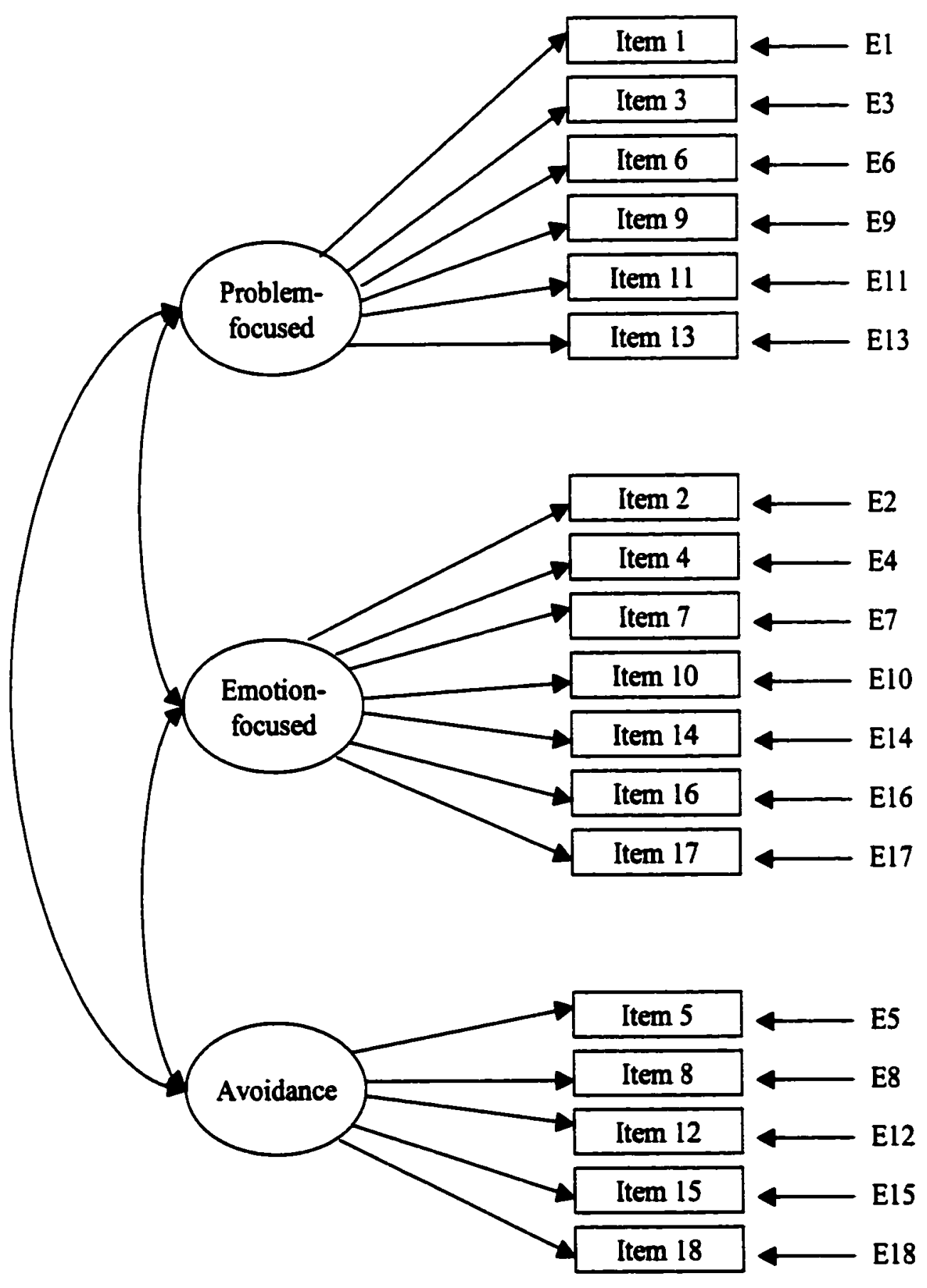

Figure 2.3. Hypothesized three-factor model of factorial structure for the CFQ. 


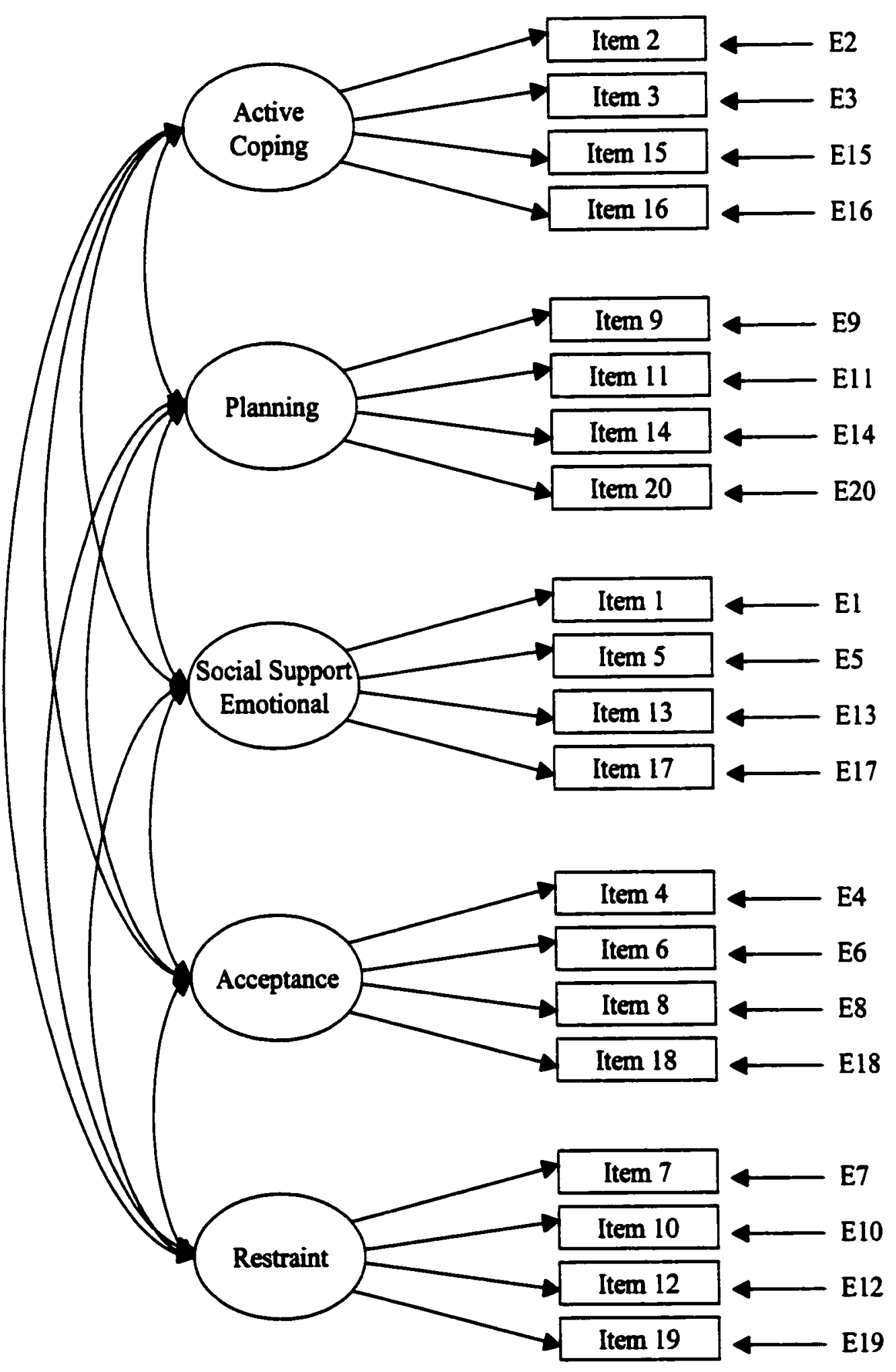

Figure 2.4. Hypothesized five-factor model of factorial structure for the COPE. 


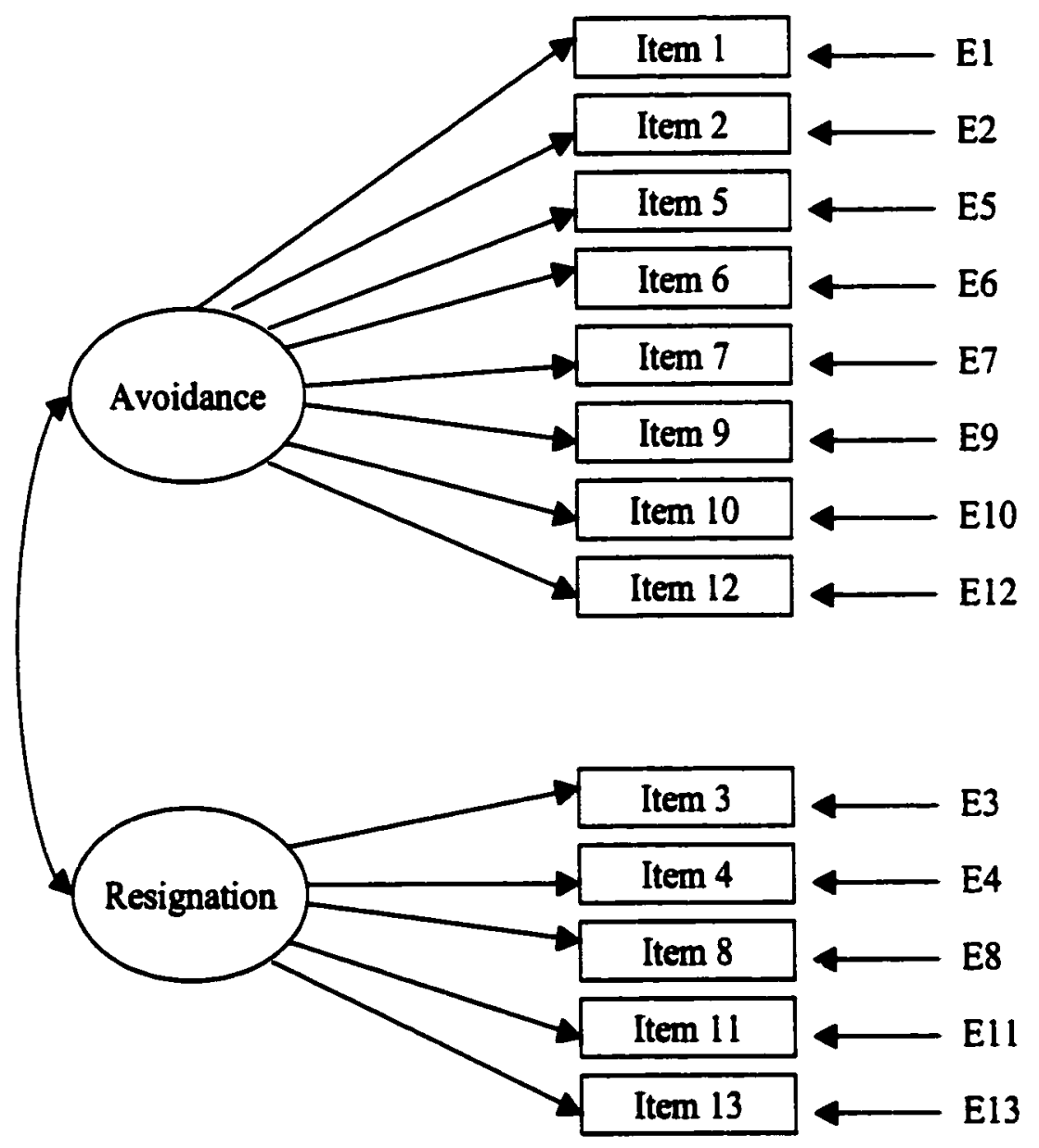

Figure 2.5. Hypothesized two-factor model of factorial structure for the LSI. 


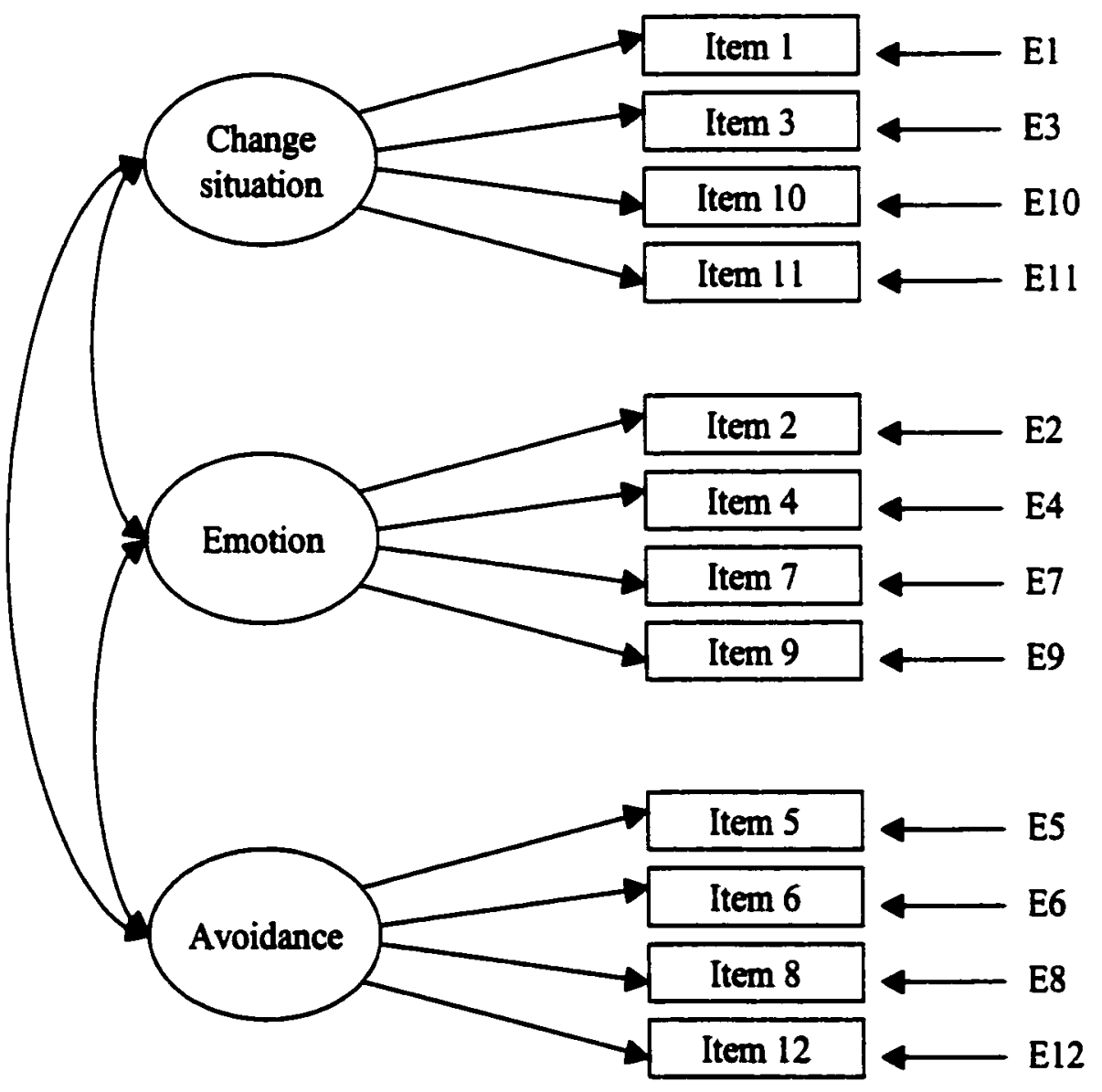

Figure 2.6. Hypothesized three-factor model of factorial structure for the perceived control measure. 
structural equation modeling (West et al., 1995). Although there was evidence of multivariate kurtosis for the CFQ model at the item level, CFI has only a small downward bias even under conditions of severe nonnormality (West et al., 1995). However, due to the presence of multivariate kurtosis for the CFQ measurement model, there may be inflated chi-square values and modest underestimation of fit indexes (West et al., 1995). Given that at a univariate level kurtosis values were acceptable for CFQ items and that transformation of the scales would make interpretation of the scale variables more difficult, the decision was made to conduct subsequent analysis with the unmodified CFQ measurement model.

Standardized factor loading for CFQ items for the three factor model are presented in Table 2.23. All factor loadings were greater than .40 for males and females, demonstrating that all items had acceptable factor loadings on their hypothesized factor. All factor loadings were significant (greater than twice their standard errors), providing evidence for convergent validity of the scale (Anderson \& Gerbing, 1988). Factor loadings appeared to be consistent across gender (a more stringent test than visual inspection of factor loading invariance between males and females will be discussed in section 2.2.5.5)

Following CFA, models can be modified to provide a better fit to the observed data, however, model modification is not without limitations. A modification index (MI) can be used to evaluate how much a model could be improved by adding a parameter to the hypothesized model (e.g. a correlated error term). The danger in using a MI to respecify a model is that the research moves from a confirmatory level of analysis to an exploratory level of analysis (Bollen, 1989). Model modification should be used with caution for a number of reasons (Bollen, 1989). First, other parameters may be affected when modifications are made to a model. Second, because one is engaging in exploratory work at this stage, cross-validation with an independent sample is required. Third, a MI reflects changes that will occur in chi-square, not parameter estimates. It is possible that small parameter 
Table 2.23

Factor Loading from CFO Confirmatory Factor Analysis Results (Males, $n=344$; Females, $n=$ 339).

\begin{tabular}{|c|c|c|c|}
\hline \multirow[b]{2}{*}{ Function } & \multicolumn{2}{|c|}{ Factor Loading } & \multirow[b]{2}{*}{ Item } \\
\hline & Males & Females & \\
\hline \multicolumn{4}{|c|}{ Problem-focused } \\
\hline & .68 & .72 & I tried to find a way to change the situation (1). \\
\hline & .74 & .65 & I worked harder to try to change the situation (3). \\
\hline & .51 & .49 & $\begin{array}{l}\text { I used strategies to change the situation in order to deal } \\
\text { with the stress (6). }\end{array}$ \\
\hline & .79 & .79 & I did my best to change the situation (9). \\
\hline & .71 & .73 & $\begin{array}{l}\text { I looked for ways to solve the problem or change the } \\
\text { situation (11). }\end{array}$ \\
\hline & .66 & .63 & I stayed in the situation and tried to change it (13). \\
\hline \multicolumn{4}{|c|}{ Emotion-focused } \\
\hline & .42 & .49 & $\begin{array}{l}\text { I stayed in the situation and tried to control my emotions } \\
\text { to better deal with the situation (2). }\end{array}$ \\
\hline & .45 & .58 & $\begin{array}{l}\text { I tried to change how I thought about the situation so it } \\
\text { didn't seem so stressful (4). }\end{array}$ \\
\hline & .42 & .64 & $\begin{array}{l}\text { I tried to view the situation in a way that made it seem } \\
\text { less stressful ( } 7) \text {. }\end{array}$ \\
\hline & .72 & .71 & $\begin{array}{l}\text { I tried to use different strategies that would help me } \\
\text { control my emotions (10). }\end{array}$ \\
\hline & .79 & .70 & I worked through my emotions in order to feel better (14). \\
\hline
\end{tabular}


Table 2.23 (continued)

$.83 \quad$ I tried to find ways to control my emotions (16).

$.55 \quad 62$ I tried to relax so that I could keep my emotions under control (17).

\section{Avoidance}

$69 \quad 68 \quad$ I tried to get out of the situation as soon as I could to reduce the stress $(5)$.

$.80 \quad .82$ I tried to leave or avoid the situation to get away from the problem or reduce the stress (8).

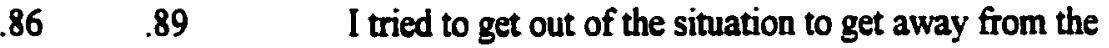
stress (12).

$.88 \quad .90$

I tried to get away from the situation to reduce the stress (15).

$.89 \quad 91 \quad$ In order to reduce the stress I tried to get myself out of the situation (18).

Note. Items number are in parentheses. 
changes are associated with large changes in chi-square or large parameter changes are associated with small changes in chi-square. Fourth, the parameter that was freed in model respecification may not alway be the one that should be freed because a MI for a single restriction may be a function of several parameters. Fifth, a MI is most useful when model misspecification is minor. Finally, the freed parameter may not be interpretable and should be based on substantive grounds.

Since initial analysis and fit indexes indicated the original CFQ model was acceptable, subsequent analysis examining relationships among latent variables and factorial invariance was conducted with the original CFQ three factor measurement model intact, followed by analysis looking at possible model respecification. Doing so allowed the analysis to remain at a confirmatory rather than exploratory level, because once the model is modified it loses its status as a hypothesis (Cliff, 1983). Also, since errors are common in initial models (MacCallum, 1986), and that initially specified measurement models almost invariably fail to provide adequate fit (Anderson \& Gerbing, 1988), the acceptable fit found for the initial CFQ measurement model may be an important step forward.

Confirmatory factor analysis fit indexes for the COPE scales suggested the five factor model was acceptable for males and females. The two factor model for the LSI was acceptable for males, but not a good fitting model for females. The three factor perceived control model was acceptable for males, but borderline for females. Taken together, these results suggest that the measurement models were acceptable fitting models for males, but some models may not be adequate for females.

2.2.5.5 Factorial gender invariance analysis for CFQ. Given the gender differences in various coping model fit indexes and differences in coping mean values found between males and females, tests of factorial gender invariance on the CFQ was critical to determine the appropriateness of the scale across groups. Factorial invariance analysis can be used as a powerful test of the equivalence of a solution across multiple groups because it allows a researcher to specify equality constraints in parameters across the groups (Marsh, Hey, Johnson, \& Perry, 1997). A chi-square 
difference test can be used to evaluate the change in model fit by adding equality constraints when fitting the CFQ model simultaneously for males and females (MacCallum, 1995). A procedure similar to that used by Marsh et al. (1997) was followed to examine the gender invariance on the CFQ. First, a simultaneous group analysis was conducted for the three factor CFQ model with no restrictions. The goodness of fit with more constrained models was then compared with the unconstrained model. A non-significant chi-square change test would indicate an invariance in the CFQ across gender on the parameters that were constrained. The minimal condition for factorial invariance is equivalence of factor loadings (Marsh et al., 1997), which was the first model restriction. This was followed by test for the invariance of (a) factor loadings and factor variance, (b) factor loadings and factor covariance, (c) factor loadings, factor variance, and factor covariance, and (d) factor loadings, factor variance, factor covariance, and error variance.

Results for the simultaneous group analysis indicated the three factor unrestricted CFQ model provided an adequate representation of the data (see Table 2.24). The chi-square difference test was not significant when factor loadings were held invariant and when factor loadings and factor variance were constrained to be equivalent. The chi-square change $(851.01-821.48=29.53)$ for invariance of factor loadings and factor covariance was significant $(\boldsymbol{p}<.05)$ in relation to the change in degrees of freedom $(282-264=18)$, suggesting lack of invariance in factor covariance (the latent factor correlations differed) between genders. However, despite this significant chi-square difference test, examination of other fit indexes indicated even when factor loadings and factor covariance was constrained, the model was still adequate $(T L I=.894, C F I=.903)$. The fit indexes for the constrained factor loadings and factor covariance model were similar to the model fit indexes for the unconstrained model $(T L I=.890, C F I=.905)$. When factor loadings, factor variance, and factor covariance were constrained to be invariant, the chi-square difference test was again not significant. The chi-square difference test (chi-square change $=82.98$, df change $=40$ ) fit for the most restrictive total invariance 
Table 2.24

Simultaneous Group Analvsis for Males $(n=344)$ and Females ( $n=339$ ): Test of Factorial

Invariance on the CFO.

\begin{tabular}{lllllllll}
\hline Model & Chi-square & df & Chi-Ch & R & Q & TLI & CFI & RMSEA \\
\hline M1 & & & & & & & & \\
\multicolumn{1}{c}{ Males } & 378.71 & 132 & - & & 2.87 & .898 & .912 & .074 \\
Females & 442.76 & 132 & - & & 3.35 & .882 & .898 & .083 \\
M2 & 821.48 & 264 & - & & 3.11 & .890 & .905 & .056 \\
M3 & 844.02 & 279 & 22.54 & n.s. & 3.03 & .894 & .903 & .055 \\
M4 & 846.44 & 282 & 24.96 & n.s. & 3.00 & .895 & .903 & .054 \\
M5 & 851.01 & 282 & 29.53 & $<.05$ & 3.02 & .894 & .903 & .054 \\
M6 & 852.97 & 285 & 31.49 & n.s. & 2.99 & .896 & .903 & .054 \\
M7 & 904.46 & 304 & 82.98 & $<.05$ & 2.98 & .897 & .897 & .054 \\
& & & & & & & & \\
\hline
\end{tabular}

Note. $\mathrm{Ml}=$ original model analysed for males and females separately; $M 2=$ simultaneous group analysis with no restrictions; M3 = M2 with factor loading (FL) invariance; M4 = M2 with FL and Factor Variance (FV) invariance; M5 = M2 with FL and Factor Covariance (FC) invariance; M6 $=M 2$ with FL, FV, and FC invariance; $M 7=M 2$ with total invariance (FL, FV, FC, and Error Variance invariant); $\mathrm{Chi}-\mathrm{Ch}=$ change in chi-square from indicated model to $\mathrm{M} 2 ; \mathrm{Q}=$ chi-square divided by degrees of freedom in the model; TLI = Tucker-Lewis index; CFI = comparative fit index; RMSEA = root mean square error of approximation. 
model was significant $(\mathfrak{Q}<.05)$, but the most constrained model still seemed to fit the data adequately $(\mathrm{TLI}=.897, \mathrm{CFI}=.897)$. These results provided support for the invariance of the CFQ model across gender. Lack of gender invariance in covariance among factors suggested that relationships among coping function factors differs for males and females. An examination of correlations among coping function latent variables (discussed in section 2.2.5.7) indicates that a source of difference is in the strength of the relationship between problem- and emotion-focused coping. For males, problemfocused coping was more strongly related to avoidance coping than emotion-focused coping. The opposite was found for females. It should be noted, however, that the correlations among all coping functions were relatively weak for both males and females. Although the correlations between emotion-focused and avoidance coping function were not significant, the directions of the correlations were opposite for males and females. Overall the gender differences in latent variable covariances were relatively small, and the invariance in factor loadings and factor variances provided strong evidence for the equivalence in the three-factor CFQ measurement model structure for males and females.

\subsubsection{Relations between CFQ and other coping scales: Convergent validity}

evidence. The relationship between the CFQ coping function scales and other coping measures were examined to provide convergent validity evidence. Correlations among measured variable scales are presented in Table 2.25. Relationships among latent coping variables were examined by entering the CFQ, COPE, and LSI coping scales into one measurement model and freeing all factor covariance parameters. The relationships among latent variables is considered a more powerful test of the relationships among variables than examining correlations among measured variables because latent variables are unobserved variables which are free of random error and uniqueness associated with their indicators (Hoyle, 1995). Correlations among latent variables are reported in Table 2.26.

As expected, the CFQ problem-focused coping function scale was related to active coping and 
Table 2.25

Zero-order Correlations Among Scales for Study 2 (Males above diagonal, $n=344$; Females below diagonal, $n=339$ ).

\begin{tabular}{|c|c|c|c|c|c|c|c|c|c|c|}
\hline Scale & 1. & 2. & 3. & 4. & 5. & 6. & 7. & 8. & 9. & 10. \\
\hline 1. Long & - & .09 & $.24^{*}$ & .06 & .03 & .05 & .01 & .08 & $.15^{*}$ & -.06 \\
\hline 2. When & .10 & - & $.15^{*}$ & -.06 & .09 & -.02 & .02 & .06 & .04 & -.02 \\
\hline 3. Stress & $.37^{*}$ & $.12^{*}$ & - & $.14^{*}$ & $.29 *$ & $.15^{*}$ & $.20^{*}$ & $.26^{*}$ & $.20^{*}$ & .00 \\
\hline 4. PF & $.25^{*}$ & -.02 & $.14^{*}$ & $\cdots$ & $.20^{*}$ & $.15^{*}$ & $.65^{\star}$ & $.48^{*}$ & $.25^{*}$ & -.08 \\
\hline 5. EF & -.03 & .00 & $.18^{*}$ & $.12^{*}$ & - & .07 & $.38 *$ & $.42^{*}$ & $.18^{*}$ & $.14^{*}$ \\
\hline 6. AV & $.22^{*}$ & -.02 & $.18^{*}$ & $.22^{*}$ & $-.13^{*}$ & - & $.13^{*}$ & .10 & $.19^{*}$ & -.04 \\
\hline 7. Active & $.15^{*}$ & .02 & $.24^{*}$ & $.61^{*}$ & $.32^{*}$ & .10 & $\cdots$ & $.65^{*}$ & $.32^{*}$ & .03 \\
\hline 8. Plan & $.16^{*}$ & .02 & $.20^{*}$ & $.38 *$ & $.42^{*}$ & .05 & $.65^{*}$ & - & $.30^{*}$ & .07 \\
\hline 9. SS & $.19^{*}$ & -.01 & $.25^{*}$ & $.19^{*}$ & $.25^{*}$ & $.11^{*}$ & $.30^{*}$ & $.35^{*}$ & - & .06 \\
\hline 10. Accept & -.07 & -.03 & .02 & -.06 & $.31^{*}$ & $-.12^{*}$ & .07 & $.12^{*}$ & .10 & - \\
\hline I1. Restraint & $.14^{*}$ & -.06 & $.14^{*}$ & $.24^{*}$ & $.26^{*}$ & $.15^{*}$ & $.29^{*}$ & $.38^{*}$ & $.24^{*}$ & $.27^{*}$ \\
\hline 12. LSLA & $.16^{*}$ & -.01 & $.15^{*}$ & $.11^{*}$ & $.13^{*}$ & $.38 *$ & .02 & .09 & $.15^{*}$ & $.12^{*}$ \\
\hline 13. LSIR & $.17^{*}$ & -.05 & $.28^{*}$ & .00 & .03 & $.25^{*}$ & -.08 & -.01 & .10 & $.17^{*}$ \\
\hline 14. $\mathrm{CH}$ & -.05 & .03 & $-.16^{*}$ & $.15^{*}$ & -.06 & -.06 & $.12^{*}$ & $.12^{*}$ & -.02 & -.10 \\
\hline 15. E & $-.14^{*}$ & .04 & $-.20^{*}$ & -.10 & .08 & $-.23^{*}$ & -.05 & .01 & $-.12^{*}$ & .06 \\
\hline 16. A & $-.11^{*}$ & $.15^{*}$ & $-.15^{*}$ & -.01 & .07 & .01 & .01 & .01 & -.02 & -.04 \\
\hline 17. SD & -.04 & -.06 & $-.17^{*}$ & .10 & .04 & .00 & $.11^{*}$ & .05 & -.01 & -.03 \\
\hline
\end{tabular}


Table 2.25 (continued)

\begin{tabular}{|c|c|c|c|c|c|c|c|}
\hline Scale & 11. & 12. & 13. & 14. & 15. & 16. & 17. \\
\hline 1. Long & .01 & $.13^{*}$ & .09 & -.06 & -.02 & .04 & -.05 \\
\hline 2. When & .04 & -.03 & .07 & -.07 & .00 & .02 & -.08 \\
\hline 3. Stress & $.22^{*}$ & $.21^{*}$ & $.20^{*}$ & -.06 & $-.11^{*}$ & -.02 & $-.15^{*}$ \\
\hline 4. PF & $.19^{*}$ & .06 & -.09 & $.22^{*}$ & .07 & .06 & .01 \\
\hline 5. EF & $.26^{*}$ & $.25^{*}$ & .06 & .00 & $.18^{*}$ & -.01 & .07 \\
\hline 6. AV & $.14^{*}$ & $.45^{*}$ & $.23^{*}$ & -.01 & -.06 & $.12^{*}$ & .00 \\
\hline 7. Active & $.27^{*}$ & .06 & -.08 & $.19 *$ & $.13^{*}$ & .03 & -.02 \\
\hline 8. Plan & $.44^{*}$ & .09 & -.09 & $.17^{*}$ & $.16^{*}$ & .02 & -.01 \\
\hline 9. SS & $.22^{\star}$ & $.18 *$ & $.13^{*}$ & .02 & .05 & .05 & -.01 \\
\hline 10. Accept & $.14^{*}$ & .07 & $.21^{*}$ & -.07 & .02 & -.01 & .09 \\
\hline 11. Restraint & - & $.18^{*}$ & $.13^{*}$ & -.06 & -.05 & -.04 & -.04 \\
\hline 12. LSLA & $.27 *$ & - & $.38 *$ & -.09 & $-.19^{*}$ & .08 & -.04 \\
\hline 13. LSIR & $.25^{*}$ & $.48^{*}$ & - & $-.45^{*}$ & $-.20^{*}$ & -.08 & -.10 \\
\hline 14. $\mathrm{CH}$ & -.02 & -.10 & $-.33^{*}$ & - & $.31^{*}$ & $.47^{*}$ & .09 \\
\hline 15. E & -.10 & $-.21^{\star}$ & $-.31^{\star}$ & $.21^{*}$ & - & $.19^{*}$ & $.12^{*}$ \\
\hline 16. A & -.06 & -.03 & $-.17^{*}$ & $.46^{*}$ & $.25^{*}$ & - & .02 \\
\hline 17. SD & .00 & -.06 & $-.13^{*}$ & -.07 & .08 & -.04 & - \\
\hline
\end{tabular}

Note. Long = length of time the stressful situation lasted; When = how long ago the stressful situation took place; Stress = stress thermometer scale score; $P F=$ problem-focused coping; $E F=$ emotion-focused coping; $\mathrm{AV}=$ avoidance coping; Active = active coping on the COPE; $\mathrm{Plan}=$ planning on the COPE; SS = social support for emotional reasons coping on the COPE; $A$ ccept = acceptance coping on the COPE; Restraint = restraint coping on the COPE; LSIA = avoidance coping on the LSI; LSIR = resignation on the LSI; $\mathrm{CH}=$ perceived control over changing the situation; $E=$ perceived control over emotions; $A=$ perceived control over avoidance; $S D=$ desirability $\mathbf{N}=337$ for all correlations).

* $\mathrm{p}<05$ (two tail significance) 
Table 2.26

Correlations Among Coping Latent Variables (Males above diagonal, $n=344$; Females below diagonal, $n=339$.

\begin{tabular}{lllllllllll}
\hline Scale & 1. & 2. & 3. & 4. & 5. & 6. & 7. & 8. & 9. & 10. \\
\hline 1. PF &.- & .24 & .17 & .87 & .54 & .25 & -.08 & .23 & .06 & -.10 \\
2. EF & .15 & - & .12 & .45 & .51 & .22 & .13 & .37 & .33 & .08 \\
3. AV & .26 & -.09 & - & .17 & .12 & .21 & -.05 & .16 & .54 & .32 \\
4. Active & .87 & .31 & .20 & - & .79 & .37 & .00 & .32 & .07 & -.10 \\
5. Plan & .45 & .54 & .06 & .76 & - & .30 & .10 & .55 & .14 & -.09 \\
6. SS & .21 & .28 & .17 & .35 & .38 &.- & .05 & .22 & .23 & .19 \\
7. Accept & -.07 & .36 & -.13 & .01 & .17 & .08 & - & .18 & .08 & .24 \\
8. Restraint & .27 & .33 & .13 & .33 & .53 & .23 & .32 & - & .20 & .11 \\
9. LSLA & .12 & .17 & .47 & .07 & .14 & .23 & .13 & .33 & - & .50 \\
10. LSIR & .05 & -.01 & .36 & -.05 & .01 & .13 & .09 & .26 & .58 & - \\
& & & & & & & & & & \\
\hline
\end{tabular}

Note. $\mathrm{PF}=$ problem-focused coping; $E F=$ emotion-focused coping; $A V=$ avoidance coping; Active $=$ active coping on the COPE; Plan = planning on the COPE; SS = social support for emotional reasons coping on the COPE; Accept = acceptance coping on the COPE; Restraint = restraint coping on the COPE; LSIA = avoidance coping on the LSI; LSIR = resignation coping on the LSI. Significance level of $p<.05$ occurs at coefficient value of approximately .13 . 
planning on the COPE. As evidence for divergent validity, these relationships were stronger than relationships between problem-focused coping function and any other coping strategy on any scale. Avoidance coping function was moderately related to the LSI avoidance and resignation coping scales. As evidence for divergent validity, this relationship was higher than the relationships between the avoidance coping function scale and any other problem- or emotion-focused coping strategy scale on the COPE. Also as expected, the emotion-focused coping function scale was positively related to theoretically proposed emotion-focused scales (Carver et al., 1989) on the COPE. However, the magnitude of these correlations was moderate to low, and the social support for emotional reasons and restraint emotion-focused scales on the COPE also had moderate relationships with the problemfocused coping function scale. Although suggesting evidence somewhat against the validity of the emotion-focused coping function scale on the CFQ, the interrelationships among social-support for emotional reasons, acceptance, and restraint subscales on the COPE were either not significant or low, which one would not expect if they are all measures of emotion-focused coping. These low correlations among emotion-focused scales is consistent with previous research using the COPE (e.g. Carver et al., 1989), as well as the Ways of Coping Checklist that attempts to assess a variety of emotion-focused coping strategies (e.g. Folkman \& Lazarus, 1985). In sporting research, low correlations among emotion-focused coping scales has also been found using the MCOPE (Crocker \& Graham, 1995). However, the relationship between these emotion-focused COPE subscales and the emotion-focused coping function subscale on the CFQ suggests these strategies do serve, at least partially, an emotion-focused coping function.

2.2.5.7 Additional evidence of divergent validity. As evidence for divergent validity, the coping function scales on the CFQ were expected to be relatively independent. Problemfocused coping function was positively related to emotion-focused coping function, although the relationship was weak (see Table 2.26). Similar to Study l, avoidance coping function was positively 
related to problem-focused coping, although the magnitude of the correlation was small. Emotionfocused coping function was not related to avoidance coping. As mentioned previously, despite small differences in these relationships between males and females, these results were consistent across gender. Taken together, these results suggest weak to no relationships among the three coping function subscales on the CFQ. These low correlations among coping function provide discriminant validity evidence for the CFQ (Anderson \& Gerbing, 1988). Given the response format on the CFQ and the potential for response bias, the relative orthogonal nature of these three functions is clearly a strength of the scale and provides support for the distinction among problem-focused, emotion-focused, and avoidance coping functions at a conceptual level.

Low correlations among coping functions was not surprising given the little knowledge and empirical work regarding coping at the functional level, especially with high school aged students. Folkman and Lazarus (1985) have suggested that some forms of emotion-focused coping may facilitate problem-focused efforts, while others may impede problem-focused coping. Therefore, the relationship between problem- and emotion-focused coping appears to be quite complex and there may be moderator variables that help understand this relation. At the coping strategy level multiple strategies may be interrelated, but based on the results of the present study, the goals of the strategies (coping function) seem to be relatively independent for a given stressful situation.

Social desirability was used to further examine the divergent validity of the CFQ. As expected, no significant relationship between social desirability and coping function was found.

2.2.5.8 CFQ model respecification. Given that the CFQ model was acceptable, but that improvements to the model were likely possible (as indicated by the TLI and CFI fit indexes and that it was a new measurement instrument), attempts to modify the original CFQ model were made. There is no formula for model respecification, but modifications to a model must depend on a researcher's substantive knowledge and will be specific to each theoretical question (Bollen, 1989). 
Empirical means were chosen as the primary basis for model modification since there was no predetermined hypotheses for potential model modifications prior to testing the original model. As well, empirical means work best for minor model respecifications, but these should be based on theory (Bollen, 1989; MacCallum, 1995).

Examination of MIs revealed the CFQ could be modified in a number of ways to improve model fit. Confirmatory factor analyses for four modified CFQ measurement models are presented in Table 2.27. MIs indicated that allowing the errors to correlate between emotion-focused coping function items 4 (I tried to change how I thought about the situation so it didn't seem so stressful) and 7 (I tried to view the situation in a way that made it seem less stressful) would improve the CFQ model significantly. MI values for inclusion of a covariance term between the errors of items 4 and 7 were 69.03 for males and 58.35 for females. An alternative to allowing correlated uniqueness was to remove item 4 or 7 as indicators of the emotion-focused coping function latent variable. The choice in removing items 4 or 7 seemed to make little difference in overall model fit. In addition to the MI values for items 4 and 7, the largest MIs involved freeing pathways between the problem-focused coping function item 13 (I stayed in the situation and tried to change it) and the avoidance latent variable and avoidance items. MIs for freeing the pathway from item 13 and the avoidance latent variable, once item 4 was removed, were 44.43 for males and 68.49 for females. Therefore, a CFA was conducted with the removal of item 4 and item 13. Results showed that all of the model modifications significantly improved the CFQ measurement model.

Since these MIs are based on purely statistical criteria, they must be substantiated by sound theoretical rationale (Byme, 1994). Items 4 and 7 appear to reflect a thought control component of emotion-focused coping function. The unique content common to these two scales may provide adequate justification for the expectation of correlated error, or the removal of one of the two items may be warranted since recundant content across items may be the cause of correlated error (Byme, 
Table 2.27

Scale Confirmatory Factor Analysis Results for Modified CFO Models (Males, n=344: Females. $\underline{n=339)}$

\begin{tabular}{|c|c|c|c|c|c|c|}
\hline Scale & Chi-square & $\mathrm{df}$ & $\mathbf{Q}$ & TLI & CFI & RMSEA \\
\hline \multicolumn{7}{|c|}{ CFQ (18, 3: Original Scale) } \\
\hline Males & 378.71 & 132 & 2.87 & .898 & .912 & .074 \\
\hline Females & 442.76 & 132 & 3.35 & .882 & .898 & .083 \\
\hline \multicolumn{7}{|c|}{ CFQ (18, 3: I Correlated Uniqueness) } \\
\hline Males & 302.83 & 131 & 2.31 & .928 & .939 & .062 \\
\hline Females & 378.41 & 131 & 2.89 & .905 & .919 & .075 \\
\hline \multicolumn{7}{|c|}{ CFQ (17, 3: Item 4 Removed) } \\
\hline Males & 287.02 & 116 & 2.47 & .925 & .936 & .066 \\
\hline Females & 357.46 & 116 & 3.08 & .902 & .916 & .078 \\
\hline \multicolumn{7}{|c|}{ CFQ (17, 3: Item 7 Removed) } \\
\hline Males & 273.54 & 116 & 2.35 & .930 & .941 & .063 \\
\hline Females & 359.36 & 116 & 3.10 & .900 & .915 & .079 \\
\hline \multicolumn{7}{|c|}{ CFQ (16, 3: Item 4 and Item 13 Removed) } \\
\hline Males & 212.36 & 101 & 2.10 & .946 & .954 & .057 \\
\hline Females & 252.88 & 101 & 2.50 & .932 & .943 & .067 \\
\hline
\end{tabular}

Note. Values in parentheses represent number of items in scale and number of factors in the model.

Note. $Q=$ chi-square divided by degrees of freedom in the model; $T L I=$ Tucker-Lewis index; CFI = comparative fit index; RMSEA = root mean square error of approximation. 
1994).

It is also important that respecified models be cross-validated with independent samples (Bollen, 1989). Although the present study did not directly cross-validate the model modifications, the strongest evidence for the model modifications was the results showing model modification improved the model fit indexes for both males and females. The modifications to the CFQ measurement model were not gender specific.

The choice of the most appropriate modified model to choose may not always be clear. A strength of CFA procedures is that they allow correlated errors to be specified (Bollen, 1989). There is a debate in the literature regarding the use of correlated error for model modification. Correlating error may be justified if it is based on substantive knowledge (Bollen, 1989). Relevant to the present study, Sobel (1997) suggested that often in the social and behavioural sciences the assumption of error independency may not be plausible when measurements are different items on the same latent construct. However, as Byme (1994) noted, error is composed of random error and systematic error which cannot be separated in cross-sectional studies. Correlating error may be more appropriate when you have the same variable measured on two or more occasions (Bentler, 1995). On a similar note, Joreskog (1993) stated that in cross-sectional studies, the error terms should be uncorrelated from one indicator to another, and that it is a misuse of structural equation modelling to correlate error simply to obtain a better model fit, without strong theoretical rationale. Further, Anderson and Gerbing (1988) stated that deleting an indicator from a model is preferable to allowing correlated error because it preserves the potential for scale to have unidimensional measurement. They also suggested that the use of correlated error is only justified when it is specified a priori. There were no correlated errors expected a priori in the present study.

Given the debate regarding the use of correlating measurement error, and because it is preferable to have a shorter questionnaire if possible, the modified model that eliminated item 4 was 
deemed most appropriate. Not only did the elimination of item 4 shorten the questionnaire, but correlations among coping latent variables remained relatively unchanged with the removal of the item. Although the elimination of items 4 and 13 provided the best model fit of those presented in Table 2.27 , the elimination of item 13 from the problem-focused coping function scale influenced the relationships among coping latent variables to a much greater extent than did the removal of item 4 from the emotion-focused coping function scale. The best fitting model may not necessarily be the best model to use, especially when one enters the model generation stage. It may be necessary to sacrifice a little goodness of fit in order to gain interpretability (Cudeck \& Browne, 1983). Based on these considerations, the model with item 4 removed was selected as preferable over the model with items 4 and 13 removed.

Subsequently, simultaneous group analysis was conducted for the CFQ with item 4 removed (see Table 2.28). The procedure for testing the factorial invariance of the modified CFQ was the same as with the original CFQ model described earlier. The only significant chi-square difference test was for the total invariance model $(\mathrm{p}<.05)$, but again similar to analysis with the original model the modified model was still adequate even with the restriction of total invariance (TLI $=.918, C F I=$ 919). Thus, modifying the CFQ by removing item 4 does not weaken the factorial invariance of the scale.

The internal consistency of the emotion-focused coping function scale with item 4 removed was alpha $=.79$ for males and alpha $=.82$ for females, compared with alpha $=.80$ for males and alpha $=.84$ for females in the original model. Therefore, a gain in model fit is at a some expense of reliability for the emotion-focused coping function scale.

\subsubsection{Relations between coping function and perceived control: Construct}

validity evidence. As further evidence for construct validity, the coping function scales on the CFQ were expected to be positively related to theoretically relevant subscales on the perceived control 
Table 2.28

Simultaneous Group Analysis for Males $(n=344)$ and Females $(n=339)$ : Test of Factorial

Invariance on the Modified CFO (Item 4 Removed).

\begin{tabular}{lllllllll}
\hline Model & Chi-square & df & Chi-ch & p & Q & TLI & CFI & RMSEA \\
\hline M1 & & & & & & & & \\
Males & 287.02 & 116 & - & & 2.47 & .925 & .936 & .066 \\
Females & 357.46 & 116 & - & & 3.08 & .902 & .916 & .078 \\
M2 & 644.48 & 232 & - & & 2.78 & .913 & .925 & .051 \\
M3 & 663.90 & 246 & 19.42 & n.s. & 2.70 & .916 & .924 & .050 \\
M4 & 666.86 & 249 & 22.38 & n.s. & 2.68 & .917 & .924 & .050 \\
M5 & 670.79 & 249 & 26.31 & n.s. & 2.69 & .917 & .924 & .050 \\
M6 & 673.23 & 252 & 28.75 & n.s. & 2.67 & .918 & .924 & .050 \\
M7 & 716.02 & 269 & 71.54 & $<.05$ & 2.66 & .918 & .919 & .049 \\
& & & & & & & & \\
\hline
\end{tabular}

Note. $\mathrm{Ml}=$ original model analysed for males and females separately; $\mathrm{M} 2=$ simultaneous group analysis with no restrictions; $M 3=M 2$ with factor loading (FL) invariance; $M 4=M 2$ with $F L$ and Factor Variance (FV) invariance; $\mathbf{M 5}=\mathbf{M} 2$ with FL and Factor Covariance (FC) invariance; $M 6$ $=M 2$ with FL, FV, and FC invariance; $M 7=M 2$ with total invariance (FL, FV, FC, and Error Variance invariant); $\mathrm{Chi}-\mathrm{Ch}=$ change in chi-square from indicated model to $\mathrm{M} 2 ; \mathrm{Q}=$ chi-square divided by degrees of freedom in the model; TLI = Tucker-Lewis index; CFI = comparative fit index; RMSEA = root mean square error of approximation. 
measure. Although these relationships were significant for males, and the relationship between problem-focused coping function and control over changing the situation was significant for females, the magnitude of these relationships was small (see Table 2.25).

As evidence for validity of the perceived control scale, it was expected that the LSI resignation scale would be moderately negatively related to perceived control. The LSI resignation scale was related to perceived control over changing the situation and control over emotions for both males and females, with correlations ranging from low to moderate (see Table 2.25). The LSI resignation scale had a small negative relationship with perceived control over avoidance for females, but was unrelated for males.

2.2.5.10 Structural model for coping function and perceived control. A confirmatory structural model tests a proposed theoretical model that specifies the causal relations among constructs (Anderson \& Gerbing, 1988), and was used to further examine the relationships between perceived control and coping function. The hypothesized structural model is presented in Figure 2.7. It was expected that perceptions of control over a particular coping function dimension would lead to increased efforts on that coping function. More specifically, it was hypothesized that control over changing the situation would lead to problem-focused coping function attempts, control over emotions would lead to emotion-focused coping function attempts, and perceptions over changing the situation, controlling emotions, and avoidance would lead to avoidance function attempts. Avoidance was expected to be influenced by a number of factors. Avoidance was expected when an individual had low perceptions of overall control in the situation but also perceived avoidance was possible. Perceived control covariances were freed parameters in the model since dimensions of perceived control were expected to be related.

Results for the confimatory structural model for the original CFQ and three modified CFQ measurement models are presented in Table 2.29. The proposed structural model appeared to be 


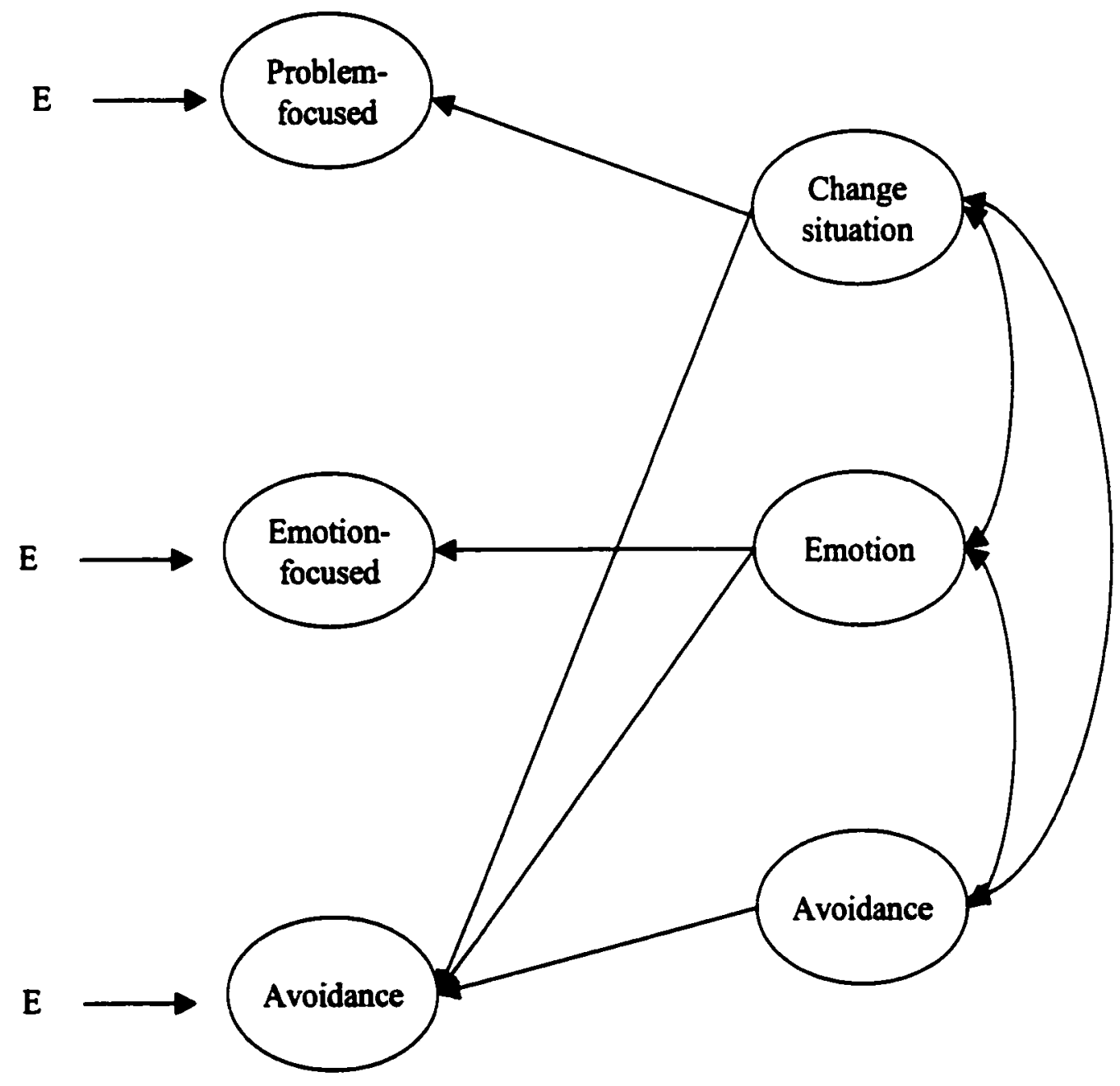

Figure 2.7. Hypothesized structural model for the relationship between coping function and perceived control. 
Table 2.29

Structural Model for Perceived Control Predicting Coping Function (Males, $n=344 ;$ Females, $n=$ 339).

\begin{tabular}{|c|c|c|c|c|c|c|}
\hline Model & Chi-square & df & $\mathbf{Q}$ & TLI & CFI & RMSEA \\
\hline \multicolumn{7}{|c|}{ CFQ Original Scale } \\
\hline Males & 870.28 & 397 & 2.19 & .886 & .896 & .059 \\
\hline Females & 1001.16 & 397 & 2.52 & .866 & .877 & .067 \\
\hline \multicolumn{7}{|c|}{ CFQ 1 Correlated Uniqueness } \\
\hline Males & 794.94 & 396 & 2.01 & .903 & .912 & .054 \\
\hline Females & 936.82 & 396 & 2.37 & .879 & .890 & .064 \\
\hline \multicolumn{7}{|c|}{ CFQ Item 4 Removed } \\
\hline Males & 762.21 & 369 & 2.07 & .901 & .910 & .056 \\
\hline Females & 905.06 & 369 & 2.45 & .876 & .887 & .066 \\
\hline \multicolumn{7}{|c|}{ CFQ Item 4 and Item I3 Removed } \\
\hline Males & 677.93 & 342 & 1.98 & .911 & .919 & .054 \\
\hline Females & 799.43 & 342 & 2.34 & .888 & .899 & .063 \\
\hline
\end{tabular}

Note. $Q=$ chi-square divided by degrees of freedom in the model; TLI = Tucker-Lewis index; CFI = comparative fit index; RMSEA = root mean square error of approximation. 
acceptable for males, but borderline for females for various versions of the CFQ. Structural path coefficients for the original CFQ measurement model are presented in Figure 2.8. Path coefficients were in the hypothesized direction; however, the path from perceived control over changing the situation to problem-focused coping function was the only path consistently significant across males and females. Path coefficients varied only slightly for the modified CFQ structural models, and therefore are not presented. Of importance to the models is the amount of variance explained in coping function by the perceived control latent variables. Although the fit indexes indicated the structural model may be adequate, the amount of variance explained in the three coping functions was relatively small. Perceived control explained $5.5 \%$ and $1.6 \%$ variance in problem-focused coping function for males and females respectively. Perceived control explained $3.6 \%$ and $1 \%$ variance in emotionfocused coping function for males and females respectively. Finally, perceived control explained $3.9 \%$ and $8.1 \%$ variance in the avoidance coping function for males and females respectively. Various modified CFQ models had little effect on the amount of variance explained in coping function. Thus, although the structural model predicting coping function based on perceived control may be adequate, the amount of variance explained by the model in coping function was small.

A more stringent test of theoretically proposed structural model was presented by Anderson and Gerbing (1988) in their two-step modeling approach to assessing a structural model. The two-step approach allows a researcher to consider the strength of the theoretical model over the CFA measurement model, and also allows rival hypotheses to be tested within the same study. Based on this two-step approach, a researcher must estimate a series of five nested structural models. These five models include (a) a saturated structural submodel $\left(\mathbf{M}_{\mathbf{3}}\right)$, in which all parameters relating constructs to one another are estimated (all covariances among latent variables are freed), (b) a null model $\left(\mathbf{M}_{n}\right)$, in which parameters relating constructs are fixed at zero (no covariances among latent variables), (c) the hypothesized theoretical model $\left(\mathrm{M}_{i}\right.$ see Figure 2.7$)$, (d) the next most likely constrained altemative 


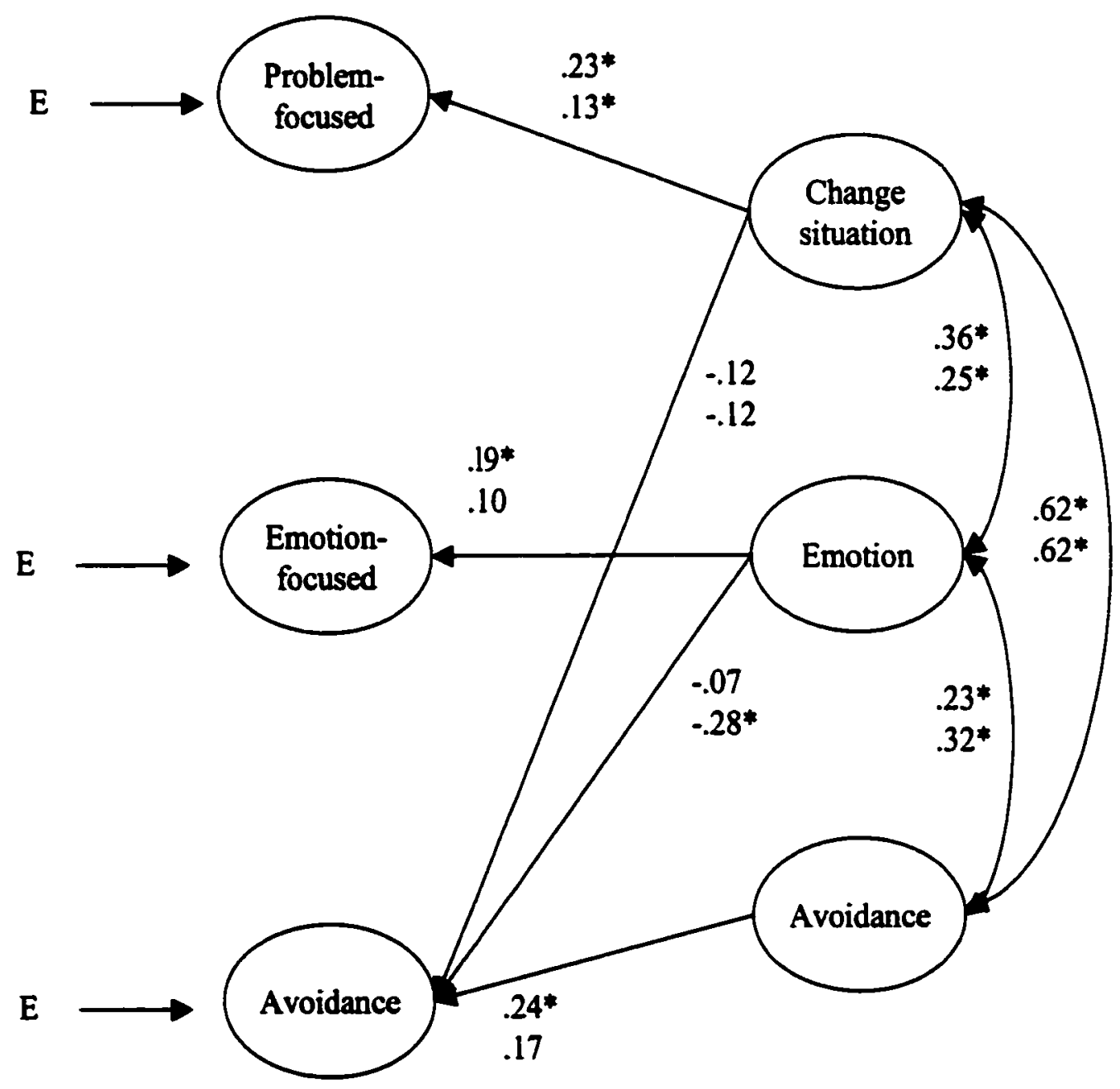

Figure 2.8. Male (top) and female (bottom) standardized path coefficients and perceived control latent factor correlations for the hypothesized structural model for the relationship between coping function and perceived control. Pathways and correlations indicated with an * are significant at $\mathrm{p}<.05$. 
model $\left(M_{c}\right)$, and (e) the next most likely unconstrained alternative model $\left(M_{\psi}\right)$. These five models are nested in sequence $\left(M_{n}<M_{\varepsilon}<M_{t}<M_{u}<M_{s}\right) . M_{\varepsilon}$ in the present study was equivalent to $M_{t}$ with the removal of the pathways from control over changing the situation and control over emotions to the avoidance coping function, such that perceived control would only be related to its particular coping function dimension. $M_{u}$ in the present study was equivalent to $M_{i}$ with the addition of pathways to the problem- and emotion-coping functions from other dimensions of perceived control in addition to its particular perceived control dimension. Model fit indexes for these five nested models are presented in Table 2.30.

Using the two-step approach, a researcher uses a series of chi-square difference tests to examine the adequacy of the proposed theoretical model (and other alternative models) over the unconstrained measurement model (Anderson \& Gerbing, 1988). The first test $M_{t}-M_{3}$ had a chisquare change $=55.87$ with an associated change in degrees of freedom $=7$, which was significant $(\mathrm{p}$ $<.05$ ), indicating the saturated model provides a better fit for the data than the proposed theoretical model. According to the decision-tree framework presented by Anderson and Gerbing, this indicated the theoretical model may not be the best model for the data. Following rejection of the null hypothesis of $M_{t}-M_{3}=0$, the next step was to test $M_{c}-M_{t}$. This chi-square change test resulted in rejection of the null hypothesis $(\mathfrak{D}<.05)$ indicating that the proposed theoretical model provided a better fit for the data than a more constrained altemative model. Next, $\mathbf{M}_{\mathbf{t}}-\mathbf{M}_{\mathrm{u}}$ was examined, which resulted in a nonsignificant chi-square change test, indicating that the more unconstrained altemative model was not better than the proposed theoretically model. The next step would have been to find an alternative unconstrained model that was more adequate than the theoretical model, but not significantly different from the saturated model. However, as Anderson and Gerbing stated, this process would only occur until it was no longer theoretically meaningful to relax additional constrained parameters. Thus, no altemative models were sought beyond $\mathrm{M}_{\mathrm{u}}$ because relaxing additional constraints would only be 
Table 2.30

Nested Structural Models for Perceived Control Predicting Coping Function ( $n=683$ )

\begin{tabular}{lllllll}
\hline Model & Chi-square & df & $\mathbf{Q}$ & TLI & CFI & RMSEA \\
\hline $\mathbf{M}_{s}$ & 1360.79 & 390 & 3.49 & .885 & .897 & .060 \\
$\mathbf{M}_{u}$ & 1410.65 & 393 & 3.59 & .880 & .892 & .062 \\
$\mathbf{M}_{\mathbf{l}}$ & 1416.66 & 397 & 3.57 & .881 & .892 & .061 \\
$\mathbf{M}_{c}$ & 1437.48 & 399 & 3.60 & .880 & .890 & .062 \\
$\mathbf{M}_{n}$ & 1730.70 & 405 & 4.27 & .849 & .859 & .069 \\
& & & & & & \\
\hline
\end{tabular}

Note. $Q=$ chi-square divided by degrees of freedom in the model; TLI = Tucker-Lewis index; CFI = comparative fit index; RMSEA = root mean square error of approximation; $M_{3}=$ saturated structural submodel with covariances freed; $\mathbf{M}_{\mathbf{u}}=$ next most likely unconstrained alternative to the theoretical model; $\mathbf{M}_{\mathrm{l}}=$ is the theoretical model; $\mathbf{M}_{\mathrm{c}}=$ next most likely constrained alternative to the theoretical model; $=M_{n}=$ the null model with factor covariances fixed at zero. 
possible by adding causal pathways within the coping function scale, which could not be adequately supported theoretically. Taken together this two-step approach to assessing CFA structural models indicated the proposed theoretical model was not the best model to describe the relations between perceived control and coping function, despite having adequate model fit index values. However, the theoretical model provided only a slight decrease in TLI and CFI fit indexes compared to the saturated model. Thus, the theoretical model provided a fit to the data similar to the saturated model. Improvements in fit most likely need to be made at the measurement level.

The tests of the structural relations between perceived control and coping function would seem to demonstrate limited convergent validity support for the three coping functions on the CFQ. However, a number of issues need to be addressed prior to rejection of the CFQ model. First, the measurement properties of the perceived control measure may be questioned. Although steps were taken to develop a perceived control measure based on Skinner's $(1995,1996)$ conceptualization of control beliefs, the measurement properties of the instrument were not strong, indicating improvements in the instrument can be made. A better measure of perceived control may be needed. Altematively, the perceived control model did appear to be adequate and did demonstrate convergent validity by its moderate relationship with the LSI resignation scale. Also, since the LSI resignation scale also had low to zero correlations with the coping function scales, and the COPE scales had similar relationships with the perceived control scales as did the coping function scales, these low relations between perceptions of control and coping were consistent across measures of coping and control.

A second explanation for the lack of convergent validity between perceived control and coping function, is that researchers do not understand the relationships among these variables very well. Given the support for convergent and divergent validity of the CFQ within the scale and with other measures of coping, the low relations between coping and perceived control appears most likely a result of faulty theory as opposed to faulty measures. This is not to say that the measures cannot be 
improved, as they clearly can be, but that much more work needs to be done to understand the relationships among coping and appraisal (e.g. perceived control) constructs. It is not entirely surprising that a complex construct like coping function cannot be adequately explained by knowing one appraisal component in a stressful situation. Perceived control is only one aspect of secondary appraisal that goes into determining stress and coping (Folkman, 1984). It is also possible that feelings of control may be more important in positive emotions than negative emotions, as control has been found to be a significant predictor of challenge and benefit emotions, but not threat and harm emotions (Folkman \& Lazarus, 1985). Examination of emotions, as opposed to the more global category of stress, may help sort out the importance of perceived control in stress and coping research. Other potential appraisal components identified by Lazarus' (1991, 1993a, 1993b) cognitive-motivationalrelational theory of emotion and coping include primary appraisals such as goal relevance, goal congruence, and type of ego-involvement and secondary appraisals such as who is to blame or credit, coping potential, and future expectations. If appraisal variables are examined in isolation, it is likely that only a limited amount of variance in either coping or emotion will be accounted for in future research studies.

The small amount of variance explained in coping by perceived control is consistent with previous research. Folkman and Lazanus (1985) found that problem-focused coping had only a low relationship with perceived control for threat and challenge emotions $(r=.20)$ and harm and benefit emotions $(r=.16)$. Further, emotion-focused coping had low to zero correlations with perceived control across a range of more specific emotion-focused coping strategy scales. Likewise, Forsythe and Compas (1987) found major events appraised as controllable were associated with increased problem-focused coping, but emotion-focused coping did not differ as a function of control appraisals. There was no difference for either problem- or emotion-focused coping as a function of perceived control for daily events. Similarly, Carver et al. (1989) found perceived control to have only a weak 
relationship with active coping $(r=.21)$ and planning $(r=.14)$ using a dispositional version of the COPE. Perceived control was not related to social support for emotional reasons, acceptance, and restraint coping, and had a weak negative relationship with behavioural disengagement $(r=-.20)$ and mental disengagement $(r=-.12)$. Low correlations between perceived control and coping were also shown by Amirkhan (1990) who found an external locus of control was related to problem-solving coping $(r=-.27)$, but not to seeking social support or avoidance. In the same study, locus of control was unrelated to problem-focused coping, seeking social support, and avoidance on the Ways of Coping Checklist. In a sample of junior high school students, Compas et al. (1988) found differences in coping related to perceived control for problem-focused coping, but not emotion-focused coping, a result consistent with the current study. Problem-focused coping appears to be more strongly related to perceptions of control than emotion-focused coping. 


\section{CHAPTER 3}

\subsection{General Discussion}

The purpose of this research was to develop a coping function questionnaire appropriate for adolescent sport participants based on theory. Overall the results of the two studies supported a three coping function (problem-focused, emotion-focused, avoidance) measure for assessing coping with stressful situations experienced in sport. The Coping Function Questionnaire (CFQ) demonstrated adequate measurement properties including item means and variances, and convergent and divergent validity with other coping measures. Likely the greatest strength of the CFQ is that its validity was demonstrated for an adolescent sporting population. Most existing coping measures used in sport were originally developed for non-sport adult populations. However, the CFQ was designed specifically with and for adolescent sport participants. The CFQ appears to be a promising step towards assessing coping function in adolescent sport samples.

The final 18-item CFQ was developed through a multi-step process. Steps included item development, interviews with athletes, content specialist review, and three questionnaire administration studies including a pilot study, a study to evaluate preliminary item analysis, and a larger study to examine the CFQ measurement model and relations with other coping measures and perceived control. Item content for some items went from being specific to more global in nature in order to be relevant for a greater range of coping strategies. More global worded items were likely more appropriate given the level of analysis when measuring coping at a functional level. 
A strength of the CFQ was that it was developed from a theoretical framework. Decisions made in item development, modification, and deletion were based on the theoretical distinction among problem-focused, emotion-focused, and avoidance coping function. This approach differs from most previous work in coping scale development which used exploratory factor analysis as the primary basis for item selection. Rather than using exploratory factor analysis to develop empirically based coping dimensions, the three coping function dimensions in the present study were developed from theory and confirmatory factor analysis was used to examine the proposed measurement model. Empirical data was used to supplement scale development, however, revisions to the CFQ were not made without theoretical rational to accompany the empirical information.

The CFQ provides an alternative to other coping measures, such as the WCC and COPE, that have been used previously in sport research. The CFQ, unlike the WCC and COPE, assesses coping function as opposed to specific coping strategies. Researchers may be interested in questions related to the function of coping strategies as opposed to actual coping strategies, and the CFQ would be a more appropriate option than either the WCC or COPE in such a study. A limitation of the CFQ is that does not provide information regarding what specific coping strategies are being used to achieve a function of coping. The CFQ provides measurement of coping at a global, functional level and accounts for a wide range of coping strategies to achieve those functions. If the research questions focus on the stability or effectiveness of specific coping strategies, for example, instruments such as the COPE or MCOPE would be preferable over the CFQ. The choice of coping instrument should depend primarily on the research question of interest.

Another strength of the CFQ is that it is a relatively short questionnaire to complete and its factor structure was supported in the present study. The three coping function dimensions were assessed with 18 items, and the number of items can potentially be reduced further. The CFQ measurement model was also supported for both males and females. In addition, all factor loadings 
were above .40 on each of the coping function scales and internal consistency analysis indicated that the coping function scales were relatively homogenous, a strength of measurement according to domain sampling theory.

The three coping function dimensions were appropriate for an adolescent sporting population. Although the avoidance coping function mean was lower than that of problem- and emotion-focused coping, the mean on the scale was acceptable, and scale variance was similar to variances on other coping function scales. In addition, the low correlations among the three coping functions suggested that these dimensions were relatively independent. The independence among coping functions indicated that avoidance coping did not share a large amount of variance with either problem- or emotionfocused coping function, and may be a distinct coping function in sport.

The format of the CFQ in the present study changed from one in which various dimensions of coping (frequency, duration, effort) were assessed to a more global format regarding how much each coping function was attempted. Stone et al. (1991) suggested that coping extent ratings used in previous research make interpretation of the scales meaning difficult. As a result, one potential solution they proposed was to assess several dimensions of coping within the items. However, results of the first study demonstrated that discrimination among various dimensions of coping on the CFQ was not warranted, at least at a coping function level. The subsequent use of asking "how much" in the second study provided a number of strengths, including shorter questionnaire length and administration time, as well as an easier to understand questionnaire and response format. However, these results should be interpreted with caution since discrimination between dimensions of coping may still be possible at a specific coping strategy, as opposed to a coping function, level. Therefore, the appropriateness of distinguishing among dimensions of coping such as frequency, duration, and effort on coping strategy scales like the WCC or COPE needs to be examined. It is also possible that similar ratings for various dimensions of coping emerged due to method variance. Self-reported ratings of the 
coping dimensions were done following one another for each item. Responses for one dimension may have influenced subsequent ratings on the same item. Thus, the discrimination among dimensions of coping may not be useful only under these conditions.

As support for convergent validity evidence, coping function, as measured on the CFQ, was found to be related to theoretically relevant coping strategies on the COPE and LSI instruments. Problem-focused coping function was related to active coping and planning on the COPE, emotionfocused coping function was related to social support for emotional reasons, acceptance, and restraint coping on the COPE, and avoidance coping function was related to avoidance coping and resignation coping on the LSI. These results were consistent for both males and females. As evidence for divergent validity, in most cases the relationships between coping function and coping strategies were highest for theoretically relevant dimensions. However, a number of coping strategies were related to more than one coping function dimension, especially emotion-focused coping strategies.

Convergent and divergent validity was limited because of the limitations in the criterion scales used. Coping self-reports from other coping instruments used as criterion measures are best described as coping strategies, as opposed to coping function, scales. This presents a limitation if one is trying to look at the convergence of test scores on two different types of instruments. There was evidence that there is a limitation in using various types of emotion-focused coping strategies (e.g. social support for emotional reasons, restraint, acceptance) against which to validate a more global emotionfocused coping dimension. Emotion-focused coping strategy scales taken from the original COPE scale were not related to one another as expected. The low to zero correlations among the proposed emotion-focused coping scales suggested limitations in using these scales as a criterion against which to judge the emotion-focused coping function dimension on the CFQ.

Convergent validity evidence for the CFQ with other coping measure was limited because although both the COPE and MCOPE have been used with adolescent sport participants (e.g. Crocker 
\& Isaak, 1997; Gould, Udry, et al., 1996), validation of the instruments was not the purpose of those studies. Scales from the COPE and MCOPE were chose for use in the present study primarily based on conceptual content within the scale as opposed to strong psychometric properties for this population. The COPE measurement model (which include both COPE and MCOPE scales of interest) was acceptable in the present study providing some support for the validity of the instrument. However, the COPE still only provided and limited criteria against which to gather convergent validity evidence.

Emotion-focused coping may be more complex than previously described in the literature, and examination of the validity of emotion-focused coping function scales may need to rely on alternative methodology or a more appropriate criterion. In the present study the COPE emotion-focused scales (social support for emotional reasons, acceptance, and restraint coping) had low to moderate correlations with the emotion-focused coping function on the CFQ. Also, the proposed emotionfocused coping strategies social support for emotional reasons and restraint coping had similar correlations with problem-focused coping function as with emotion-focused coping function. These results suggest that using specific coping scales as a criteria for emotion-focused coping function is not adequate. A useful way to validate emotion-focused coping function might be to test hypothesized effects of intervention programs. For example, an emotional control intervention would likely result in changes to emotion-focused coping attempts in the future. Methods such as behavioural observation might also be useful to evaluate how sport participants control their emotions during participation in sport and to test whether these observations match the individual's self-reports of coping. Clearly, efforts to control emotion in sport are complex and validation of measures which assess this dimension of coping requires creative and continued effort by researchers.

The low to moderate correlations between problem-focused coping function and both socialsupport for emotional reasons and restraint coping on the COPE, combined with the moderate 
correlations between emotion-focused coping function and both active coping and planning, suggested that most problem- and emotion-focused coping strategies may serve multiple functions. The possibility that strategies serve multiple functions was the rational behind the distinction of seeking social support for instnumental reasons and social support for emotional reasons used on the original COPE (Carver et al., 1989) and for the categorization of seeking social support as being a mixed problem-and emotion-focused coping strategy on the Ways of Coping Checklist (Folkman \& Lazarus, 1985). While strategies may serve multiple functions simultaneously, the functions they serve seem to have low relationships among them.

A strength of the CFQ measurement model is that it was acceptable for both male and female sport participants. Simultaneous gender analysis for the three factor CFQ measurement model demonstrated factor loading and factor variance invariance across gender. This is an important finding because there is evidence that males and females differ in their coping responses to stress in sport. In the present study, females were found to have a higher mean than males on the emotion-focused coping function, as well as used more social support for emotional reasons and more avoidance and resignation coping. The higher mean on the emotion-focused coping function for females compared to males provides evidence for convergent validity of the CFQ because previous research with adolescents has shown females often have higher means than males on emotion-focused coping scales, especially seeking social support (see Boekaerts, 1996).

Not only may males and females be experiencing different types of stressful events, but they may also cope in different ways with similar situations (Ptacek, Smith, \& Dodge, 1994). Goyen \& Anshel (1998) found gender differences in coping for typical coping responses following acute competition stressors. Adolescent males had a preference for using problem-focused strategies to deal with injury, experiencing pain, and parental criticism. Females used more emotion-focused strategies. However, males had a preference for more emotion-focused coping strategies than females to deal with 
a cheating opponent. In support of the idea that coping may differ depending on the type of situation, Goyen \& Anshel found a preference for using more frequent use of problem- or emotion-focused coping depending on the type of stressor. Emotion-focused coping was used to deal with injury and pain, problem-focused coping following a physical error, falling for a sucker move, and when being hassled by teammates. Therefore, the gender invariance found for the CFQ measurement model provides evidence the instrument may be appropriate for both males and females and for a wide range of self-indicated situations.

The CFQ appears to be appropriate for a wide range of self-indicated stress sources that are often reported by sport participants. The sport participants in this research reported a number of different stressful situations. Students reported physical demands on their resources such as being injured, pressure to make weight class, and being sick. They reported psychological demands such as the pressure of an important competition, being angry at self, and feeling that they let their team down. Environmental demands included situations such as time management and not being able to afford to play or afford team apparel. Also, a number of relationship issues were reported including conflict with coaches, parents, teammates, and opponents. In general, the situations reported in the present study reflected the stress source dimensions identified by Gould, Finch, and Jackson (1993) in their study with national champion figure skaters and the sources of acute stress identified by Goyen and Anshel (1998) for adolescent-aged athletes. However, the appropriateness of the CFQ for all stressful situations needs to be examined in future research.

The significant relationships between the CFQ and perceptions of control provided tentative support for construct validity. However, the magnitude of this relationship was weak, which is consistent with the magnitude of the relations between coping and perceived control in previous research. Perceived control may not be a good variable to establish the construct validity of coping instruments as it only accounts for a small amount of variance in coping. This is not entirely 
surprising considering that it is only one ractor in a complex appraisal process leading to the generation of emotions and coping. The present study attempted to distinguish among various dimensions of perceptions of control which were proposed to be more theoretically similar to the three coping function dimensions. However, the validity of breaking perceived control into dimensions when looking at the relations among coping and perceived control variables needs to be evaluated.

A more comprehensive model of coping and perceived control may be needed to explain the relations among perceived control and different dimensions of coping. Compas et al. (1991) presented a model to explain the relations among perceived control and coping. They suggested in their model that problem-focused coping may be related to perceived control, but that emotion-focused coping may be unrelated to control. Emotion-focused coping might instead be related to internal cues of emotional distress. The results of the current study are consistent with this hypothesis. Problem-focused coping was related to perceptions of control, but emotion-focused coping was not related to perceptions of control and was related to stressfulness of the situation. Therefore, although the magnitude of relations found between perceived control, stress, and coping in the present study were weak, they are consistent with the strength and magnitude of relations found in previous research and Compas et al.'s hypothesized model, supporting the convergent validity of the CFQ. Research examining alternative models describing the relationships among perceived control and coping variables, such as the one described by Compas et al., appears warranted.

The validity of the perceived control measure used in the present study should also be further evaluated. Although the perceived control measure had multiple dimensions of control and multiple items per dimension, the factor structure of the instrument was not strong, especially for females. Also, at though some validity evidence was demonstrated by the correlations between perceived control and the LSI resignation scale, which seems to include some elements of perceptions of control, validation of the perceived control scale was not the purpose of the study and needs to be established. 
More specifically, the perceived control over avoidance dimension had items which correlated moderately with the perceived control over changing the situation and had low to zero correlations with other measures, such as the LSI resignation and coping scales, to which it was expected to be related. More research is needed to examine the validity and improve the measure of perceptions of control. However, the multiple item measure is likely an improvement over previous research which has often employed single item measures of perceived control. 


\section{CHAPTER 4}

\subsection{Conclusion}

The Coping Function Questionnaire (CFQ) was developed to assess coping function in adolescent sporting samples. The CFQ is a 18-item measure which assessed three coping functions related to a self-indicated stressful situation in sport: (a) problem-focused coping to assess an effort to actively change and remain in the situation that was causing the stress, (b) emotion-focused coping assessing an effort to control thoughts or emotions while remaining in the situation that was causing the stress, and (c) avoidance coping assessing an effort to remove oneself either permanently or temporarily from the situation that was causing the stress.

The CFQ was found to have a number of desirable measurement properties. The means, variances, and distributions of scale scores were acceptable. Scales were found to have adequate internally consistency. Confirmatory factor analysis results showed that the three coping function CFQ measurement model was acceptable for both males and females. Convergent and divergent validity was supported by latent factor correlations with existing coping instruments. Also, the three coping functions on the CFQ had weak correlations among one another, supporting the distinction between the three coping functions at a conceptual level. Overall, the two studies provided support the CFQ as valid option for assessing coping function in large sample adolescent sport studies.

The multi-step approach in the two studies provided evidence for the appropriateness of using the CFQ with adolescent sport participants. Interviews, pilot testing, and the use of social desirability 
helped establish that the CFQ was understandable and response bias was not a significant factor in participants' responses. Acceptable internal consistency, convergent and divergent validity, and acceptable factor structure for both males and females provided evidence that the CFQ was developmentally appropriate for sport participants between the ages of 13 and 19 . Also, the CFQ appears to be valid for a wide range of stressful physical, psychological, environmental, and relationship situations adolescents experience in sport.

\subsection{Recommendations for Future Research}

Although the results of the present research are encouraging, future research should continue the validation process for the CFQ. More specifically, validity of the CFQ should be examined with methods other than self-report (Messick, 1989). For example, studies examining the correspondence between self-reported coping on the CFQ and behavioural observation may be warranted. However, given that much of coping may not be observable, self-reports may be necessary to understand at least part of the coping process (Ptacek, Smith, \& Dodge, 1994).

The sensitivity of the CFQ to detect changes in coping function should be further examined. Although the problem-focused, emotion-focused, and avoidance coping function scale scores on the CFQ demonstrated adequate variance, and the CFQ was able to detect gender differences in emotionfocused coping, further work needs to determine if the CFQ is able to detect other expected differences or changes in coping. For example, an intervention program designed to influence one or more coping function (e.g. a program designed to increase the use of problem-focused efforts to deal with stressful situations) should be associated with changes in self-reported levels of coping. Also, the CFQ should be sensitive to an experimental manipulation in which individuals are limited to particular coping options or more likely to employ a variety coping possibilities (e.g. situations which vary in degree of perceived stress and/or situations in which avoidance is or is not possible).

Future research should continue to evaluate altemative CFQ models. Although the fit indexes 
suggested acceptable fit for the 18-item three factor model, the model fit was improved by a number of potential scale modifications. It is preferable, for sake of parsimony, to reduce the number of items in the questionnaire if possible. The elimination of item 4 improved model fit, and correlations among variables remained essentially unchanged with the deletion of this item. However, the elimination of this item from the actual questionnaire in the future may have unknown effects on the structure of the scale. Therefore, future work should examine whether the deletion of the item (and/or other items) has an effect on the CFQ measurement model when the item is absent from the questionnaire versus elimination of the item by purely statistical means. Reliability of scales needs to be considered because although model fit may improve with removal of items, reliability may be sacrificed. It is also likely there was modest underestimation in the fit parameters due to significant multivariate kurtosis for the CFQ measurement model (West et al., 1995). The use of a statistic such as the SCALED chisquare statistic (not available in Amos 3.61) may be useful under conditions of nonnormality in future work (West et al., 1995).

A related question to model modifications is the potential for additional or altemative coping functions on the CFQ. Although the three coping function structure on the CFQ was developed from a theoretical framework, and the factor structure of the instrument supported this distinction, it is possible that there may be other functions coping serve that were not included in the present study. For example, although social support was conceptualized to be a coping strategy as opposed to a coping function in the present study, social support may need to be reconsidered as being something unique and deserving of a coping function status. Previous research has generally found social support to form its own coping dimension on various instruments (e.g. Amirkhan, 1990; Ayers, Sandler, West, \& Roosa, 1996; Brodzinsky et al., 1992; Glyshaw, Cohen, \& Towbes, 1989). Is social support a coping domain that does not fall within the problem-focused, emotion-focused, avoidance framework presented in the development of the CFQ? Similarly, other potential coping functions could be 
examined, but should be based on a strong theoretical framework.

Other functions of coping may emerge during stages of stress not assessed in the present study. The CFQ asks for recall of stressful situation during the confrontation stage of a stressful experience. The CFQ tried to break down the stress process by specifying one particular stress stage, however, it may be useful to follow athletes over time to examine whether other coping functions may emerge during other stages of stress. Ingledew et al. (1996) examined health behaviours reported as coping strategies to experienced stressful events in British adults. They suggested that some health behaviours (such as exercise, eating, and self-care) may serve a coping function other than problem-focused. emotion-focused, or avoidance. This additional function was described as serving a preventive function or as a resource for coping. The implication is that other functions of coping may become prominent when looking at stages of stress that were not examined in the present study. For example, the preventive coping function may be important prior to the confrontation of a stressor stage that was assessed on the CFQ. The potential for alternative functions such as preventive coping or seeking social support warrants investigation. The decision to include alternative functions should be based on a strong theoretical framework including the characteristics of these functions, why they should be considered functions not strategies, and how they can be distinguished from other functions of coping such as problem- and emotion-focused coping.

A potential research direction is to assess the strength of the CFQ against other measures with higher-order coping dimensions. For example, the CFQ measurement structure and convergent and divergent validity evidence could be compared to other measures with similar dimensions, such as the Coping Inventory for Stressful Situations (Ender \& Parker, 1990, 1993, 1994). As well, the CFQ could be compared to a measure, such as the Coping Strategy Indicator (Amirkhan, 1990), which has different coping dimensions than the CFQ. It is likely that each instrument will have particular strengths and weaknesses, and different instruments might be more appropriate depending on the 
research question and research methodology. Any comparisons among the various coping instruments should be based on evidence from samples of the same population.

Another question that should be answered is whether certain coping functions are inherently maladaptive. What is the impact of choosing a particular function? There is likely a complex transaction between the environment, the individual's appraisal of the situation, and coping that ultimately determines the adaptive nature of a specific coping response. For example, if a situation is one with important goals at stake, avoidance may be maladaptive, at least in terms of achieving a specific desirable outcome in that domain, unless it prevents burnout. However, if the situation is unimportant to the individual, avoidance may be adaptive because nothing important is really lost. Clearly, there is much yet to understand regarding the consequences for choosing various ways of coping.

Given the format of the CFQ, it would be worthwhile to examine whether the instrument is appropriate for use with non-sport populations, as well as with different age groups. The focus when developing the CFQ was on providing researchers with an instrument that is appropriate for adolescent sport participants. Thus, it had to have the ability to capture a wide range of stressful situations adolescents were reporting, as well as be able to capture a wide range of coping strategies. This focus resulted in a scale with globally worded items that were not necessarily specific to sport or adolescents. Evidence that the CFQ is appropriate for adolescent sport participants was provided, but whether or not the CFQ is specific to adolescent sport participants remains to be tested. The content of the CFQ might be appropriate for populations other than adolescents involved in sport. However, the use of the CFQ with any other group should ultimately depend on the theoretical rationale that the three coping functions identified on the CFQ are appropriate with that group.

An area of future research is understanding the greater context within which one specific stressor occurs. The influence of multiple stressors is not well understood (Lepore \& Evans, 1996), 
but it is quite clear that stressors do not occur in isolation. In order for researchers to understand fully why specific coping strategies are used, it may not be enough to ask about isolated stressors. One of the key aspects in deciding what types of coping options are available to an individual is the future expectancies (Lazarus, 1991). It is quite possible that the most logical coping strategy for one specific stressful situation may not be chosen because of the potential ramifications for the rest of the individual's goal hierarchy. Without understanding how a coping strategy may affect the larger context within which that stressful experience exists, researchers' understanding of the nature of coping may be limited. A solution may be to ask more questions regarding appraisal processes to try to understand why certain strategies were selected, while other, seemingly useful, strategies were not. This may be the most difficult issue quantitative assessment of coping may have to face, and its solution is not easy. At best, quantitative methods may gain some, although limited, insight into the greater context, but it will be difficult to assess. Other methodologies such as qualitative analysis may be more suited to these types of questions. 


\section{REFERENCES}

Aidwin, C. M. (1994). Stress, coping, and development: An integrative perspective. New York: Guildford Press.

Amirkhan, J. H. (1990). A factor analytically derived measure of coping: The Coping Strategy Indicator. Journal of Personality and Social Psychology 59, 1066-1074.

Anderson, J. C., \& Gerbing, D. W. (1988). Structural equation modeling in practice: A review and recommended two-step approach. Psychological Bulletin 103, 411-423.

Arbuckle, J. L. (1997). Amos users' guide version 3.6. Chicago, IL: SmallWaters.

Ayers, T. S., Sandler, I. N., West, S. G., \& Roosa, M. W. (1996). A dispositional and situational assessment of children's coping: Testing altemative models of coping. Joumal of Personality 64, 923-958.

Ballard, R. (1992). Short forms of the Marlowe-Crowne Social Desirability Scale. Psychological Reports, 71, 1155-1160.

Bentler, P.M. (1995). EOS: Structural equations program manual. Encino, CA: Multivariate Sofware Inc.

Boekaerts, M. (1996). Coping with stress in childhood and adolescence. In M. Zeidner \& N. S. Endler (Eds.), Handbook of coping: Theory, research, applications (pp 452-484). New York, NY: Wiley.

Bollen, K. A. (1989). Structural equations with latent variables. New York, NY: Wiley.

Bouffard, M. \& Crocker, P. R. E. (1992). Coping by individuals with physical disabilities with perceived challenge in physical activity: Are people consistent? Research Ouarterly for Exercise and Sport 63, 410-417.

Brewer, W. F. (1994). Autobiographical memory and survey research. In N. Schwartz \& S. 
Sudman (Eds.), Autobiographical memory and the validity of retrospective reports (pp. $11-20$ ). New York, NY: Springer-Verlag.

Brewer, W. F. (1996). What is recollective memory? In D. C. Rubin (Ed.), Remembering our past (pp. 19-66). New York, NY: Cambridge University Press.

Brodzinsky, D. M., Elias, M. J., Steiger, C., Simon, J., Gill, M., \& Hitt, J. C. (1992). Coping scale for children and youth: Scale development and validation. Journal of Applied Developmental Psychology 13, 195-214.

Brustad, R. J. (1998). Developmental considerations in sport and exercise psychology measurement. In J. L. Duda (Ed.), Advances in sport and exercise psychology measurement (pp. 461470). Morgantown, WV: Fitness Information Technology. Byme, B. M. (1994). Structural equation modeling with EOS and EOS/Windows. Thousand Oaks, CA: Sage.

Carpenter, B. N. (1992). Issues and advances in coping research. In B. N. Carpenter (Ed.), Personal coping: Theory, research, and application (pp. 1-13). Westport, CT: Praeger.

Carver, C. S., Scheier, M. F., \& Weintraub, J. K. (1989). Assessing coping strategies: A theoretically based approach. Joumal of Personality and Social Psychology, 56, 267-283.

Christianson, S., \& Safer, M. A. (1996). Emotional events and emotions in autobiographical memories. In D. C. Rubin (Ed.), Remembering our past (pp. 218-243). New York, NY: Cambridge University Press.

Cliff, N. (1983). Some cautions concerning the application of causal modeling methods. Multivariate Behavioral Research, 18, 115-126.

Coakley, J. (1992). Bumout among adolescent athletes: A personal failure or social problem? Sociology of Sport Joumal, 9, 271-285.

Cohen, F. (1995). Measurement of coping. In S. V. Kasl \& C. L. Cooper (Eds.), Research methods in stress and health psychology (pp. 283-305). New York, NY: Wiley. 
Compas, B. E., Banez, G. A., Malcarne, V., \& Worsham, N. (1991). Perceived control and coping with stress: A developmental perspective. Joumal of Social Issues, 47, 23-34.

Compas, B. E., Malcarne, V. L., \& Banez, G. A. (1992). Coping with psychological stress: A developmental perspective. In B. N. Carpenter (Ed.), Personal coping: Theory, research, and application (pp. 47-63). Westport, CT: Praeger.

Compas, B. E., Malcame, V. L., \& Fondacaro, K. M. (1988). Coping with stressful events in older children and young adolescents. Joumal of Consulting and Clinical Psychology, 56, 405-411.

Compas, B. E., Orosan, P. G., \& Grant, K. E. (1993). Adolescent stress and coping: Implications for psychopathology during adolescence. Joumal of Adolescence, 16, 331-349.

Crocker, P.R.E. (1992). Managing stress by competitive athletes: Ways of coping. International Joumal of Sport Psychology, 23, 161-175.

Crocker, P. R. E., \& Graham, T.R. (1995). Coping by competitive athletes with performance stress: Gender differences and relationships with affect. Sport Psychologist, 9, 325-338.

Crocker, P. R. E., \& Isaak, K. (1997). Coping during competitions and training sessions: Are youth swimmers consistent? Intemational Joumal of Sport Psychology, 28, 355-369..

Crocker, P. R. E., Kowalski, K. C., \& Graham, T. R. (1998). Measurement of coping strategies in sport. In J. L. Duda (Ed.), Advances in sport and exercise psychology measurement (pp. 149-161). Morgantown, WV: Fimess Information Technology.

Cudeck, R. \& Browne, M. W. (1983). Cross-validation of covariance structures. Multivariate Behavioral Research, 18, 147-167.

Deaux, K., \& Major, B. (1987). Putting gender into context: An interactive model of genderrelated behavior. Psychological Review, 94, 369-389.

DeVellis, R. F. (1991). Scale development: Theorv and application. London: Sage Publications 
Durante, R., \& Ainsworth, B.E. (1996). The recall of physical activity: Using a cognitive model of question-answering process. Medicine and Science in Sports and Exercise, 28, 1282-1291.

Ebata, A. T., \& Moos, R. H. (1991). Coping and adjustment in distressed and healthy adolescents. Joumal of Applied Developmental Psychology, 12, 33-54.

Endler, N. S., Kantor, L., \& Parker, J. D. A. (1994). State-trait coping, state-trait anxiety and academic performance. Personality and Individual Differences, 16, 663-670.

Endler, N. S., \& Parker, J. D. A. (1990). Multidimensional assessment of coping: A critical evaluation. Joumal of Personality and Social Psychology, 58, 844-854.

Endler, N. S., \& Parker, J. D. A. (1993). The multidimensional assessment of coping: Concepts, issues, and measurement. In G. L. Van Heck, P. Bonaiuto, I. Deary, \& W. Nowack (Eds.), Personality psychology in Europe (Vol. 4) (pp. 309-319). Tilburg, Netherlands: Tilburg University Press.

Endler, N. S., \& Parker, J. D. A. (1994). Assessment of multidimensional coping: Task, emotion, and avoidance strategies. Psychological Assessment 6, 50-60.

Eklund, R. C., Grove, J. R., \& Heard, N. P. (1998). The measurement of slump-related coping: Factorial validity of the COPE and Modified-COPE inventories. Joumal of Sport and Exercise Psychology 20, 157-175.

Feifel, H., \& Strack, S. (1989). Coping with conflict situations: Middle-aged and elderly men. Psychology and Aging, 4, 26-33.

Fischer, D. G., \& Fick, C. (1993). Measuring social desirability: Short forms of the MarloweCrowne Social Desirability Scale. Educational and Psychological Measurement. 53, 417-424.

Folkman, S. (1984). Personal control and stress and coping processes: A theoretical analysis. Joumal of Personalitv and Social Psychology $46,839-852$.

Folkman, S. (1992). Making the case for coping. In B. N. Carpenter (Ed.), Personal coping: 
Theory, research, and application (pp. 31-46). Westport, CT: Praeger.

Folkman, S., \& Lazarus, R. S. (1980). An analysis of coping in a middle-aged community sample. Joumal of Health and Social Behavior, 21, 219-239.

Folkman, S., \& Lazarus, R. S. (1985). If it changes it must be a process: Study of emotion and coping during three stages of a college examination. Jourmal of Personalitv and Social Psvchology, 48, 150-170.

Folkman, S., \& Lazarus, R. S. (1986). Stress processes and depressive symptomatology. Journal of Abnormal Psychology, 95, 107-113.

Folkman, S., \& Lazarus, R. S. (1988). Coping as a mediator of emotion. Joumal of Personality and Social Psychology, 54, 466-475.

Folkman, S., \& Lazarus, R. S., Dunkel-Schetter, C., Delongis, A., \& Gruen, R. J. (1986). Dynamics of a stressful encounter. Cognitive appraisal, coping, and encounter outcomes. Joumal of Personality and Social Psychology, 50, 992-1003.

Forsythe, C. J., \& Compas, B. E. (1987). Interaction of cognitive appraisals of stressful events and coping: Testing the goodness of fit hypothesis. Cognitive Therapy and Research, 11 , 473-485.

Francis, R., \& Stanley, G. (1989). Analogue measurement of dental fear. Australian Psychologist, 24, 55-60.

Frydenberg, E., \& Lewis, R. (1993). Boys play sport and girls turn to others: Age, gender and ethnicity as determinants of coping. Joumal of Adolescence, 16, 253-266.

Ghiselli, E. E., Campbell, J. P., \& Zedeck, S. (1981). Measurement theory for the behavioral sciences. New York: W. H. Freeman and Company.

Glyshaw, K., Cohen, L. H., \& Towbes, L. C. (1989). Coping strategies and psychological distress: Prospective analyses of early and middle adolescents. American Joumal of Community 
Psychology, 17, 607-623.

Gould, D. (1993). Intensive sport participation and the prepubescent athlete: Competitive stress and burnout. In B. R. Cahill \& A. J. Pearl (Eds.), Intensive participation in children's sport (pp. 19-38). Champaign, IL: Human Kinetics.

Gould, D., \& Eklund, R. C. (1996). Emotional stress and anxiety in the child and adolescent athlete. In O. Bar-Or (Ed.), The child and adolescent athlete (pp. 383-398). Oxford: Blackwell Science.

Gould, D., Eklund, R. C., \& Jackson, S. A. (1993). Coping strategies used by U. S. Olympic wrestlers. Research Quarterly for Exercise and Sport 64 , 83-93.

Gould, D., Finch, L. M., \& Jackson, S. A. (1993). Coping strategies used by national champion figure skaters, Research Quarterly for Exercise and Sport 64, 453-468.

Gould, D., Tuffey, S., Udry, E., \& Loehr, J. (1996). Bumout in competitive junior tennis players: II. Qualitative analysis. Sport Psychologist, 10 341-366.

Gould, D., Udry, E., Tuffey, S., \& Loehr, J. (1996). Burnout in competitive junior tennis players: I. A quantitative psychological asessment. Sport Psychologist, 10, 322-340.

Gould, D., Wilson, C. G., Tuffey, S., \& Lochbaum, M. (1993). Stress and the young athlete: The child's perspective. Pediatric Exercise Science, 5, 286-297.

Goyen, M. J., \& Anshel, M. H. (1998). Sources of acute competitive stress and use of coping strategies as a function of age and gender. Joumal of Applied Developmental Psychology, 19, $469-$ 486.

Groer, M. W., Thomas, S. P., \& Shoffiner, D. (1992). Adolescent stress and coping: A longitudinal study. Research in Nursing and Health, 15, 209-217.

Grove, R. J. (1995). Summany data for the athlete coping inventory in a sample of Australian sport performers. Unpublished manuscript. 
Hambleton, R. K. (1984). Validating the test scores. In R. A. Berk (Ed.), A guide to criterion-referenced test construction (pp. 199-230). Baltimore, Maryland: Johns Hopkins University Press.

Haney, C. J., \& Long, B. C. (1995). Coping effectiveness: A path analysis of self-efficacy, control, coping, and performance in sport competitions. Joumal of Applied Social Psychology, 25 , $1726-1746$.

Hauser, S. T., \& Bowlds, M. K. (1990). Stress, coping, and adaptation. In S. S. Feldman \& G. R. Elliott (Eds.), At the threshold: The developing adolescent. (pp. 388-413). Cambridge, MA: Harvard University Press.

Hendren, R. L. (1990). Stress in adolescence. In L. E. Amold (Ed.), Childhood stress (pp. 247-264). New York, NY: Wiley.

Homblow, A. R., \& Kidson, M. A. (1976). The Visual Analogue Scale for Anxiety: A validation study. Australian and New Zealand Joumal of Psvchiatry, 10 339-341.

Hoyle, R. H. (1995). The structural equation modeling approach: Basic concepts and fundamental issues. In R. H. Hoyle (Ed.), Structural equation modeling: Concepts, issues, and applications (pp. 1-15). Thousand Oaks, CA: Sage.

Hoyle, R. H., \& Panter, A. T. (1995). Writing about structural equation models. In R. H. Hoyle (Ed.), Structural equation modeling: Concepts, issues, and applications (pp.158-176). Thousand Oaks, CA: Sage.

Hu, L., \& Bentler, P. M. (1995). Evaluating model fit. In R. H. Hoyle (Ed.), Structural equation modeling: Concepts, issues, and applications (pp.76-99). Thousand Oaks, CA: Sage.

Ingledew, D. K., Hardy, L., Cooper, C. L., Jemal, H. (1996). Health behaviours reported as coping strategies: A factor analytical study. British Jourmal of Health Psychology, 1, 263-281. 
Johnston, B., \& McCabe, M. P. (1993). Cognitive strategies for coping with stress in a simulated golfing task. International Joumal of Sport Psvchology, 24, 30-48.

Jones, R. M., Akers, J. F., \& White, J. M. (1994). Revised classification criteria for the Extended Objective Measure of Ego Identity Status (EOMEIS). Journal of Adolescence, 17, 533-549.

Joreskog, K. G. (1993). Testing structural equation models. In K. A. Bollen \& J. S. Long (Eds.), Testing structurai equation models. Newbury Park, CA: Sage.

Lazarus, R. S. (1990). Theory-based stress measurement. Psychological Inquiry, 1, 3-13. Lazarus, R. S. (1991). Emotion and adaptation. New York, NY: Oxford University Press. Lazanus, R. S. (1993a). Why we should think of stress as a subset of emotion. In L. Goldberger \& S. Breznitz (Eds.), Handbook of stress: Theoretical and clinical aspects (2nd ed.) (pp.21-39). New York, NY: Free Press.

Lazarus, R. S. (1993b). From psychological stress to the emotions: A history of changing outlooks. Annual Review of Psychology 44, 1-21.

Lefcourt, H. M. (1992). Perceived control, personal effectiveness, and emotional states. In B. N. Carpenter (Ed.), Personal coping: Theory, research, and application (pp. 11 l-131). Westport, CT: Praeger.

Lepore, S. J., \& Evans, G. W. (1996). Coping with multiple stressors in the environment. In M. Zeidner \& N. S. Endler (Eds.), Handbook of coping: Theory, research, applications (pp. 350 377). New York, NY: Wiley.

MacCallum, R. C. (1986). Specification searches in covariance structure modeling. Psychological Bulletin 100, 107-120.

MacCallum, R. C. (1995). Model specification: Procedures, strategies, and related issues. In R. H. Hoyle (Ed.), Structural equation modeling: Concepts, issues, and applications (pp. 17-36). Thousand Oaks, CA: Sage. 
Madden, C. C., Kirkby, R. J., \& McDonald, D. (1989). Coping styles of competitive middle distance runners. International Joumal of Sport Psychology, 20, 287-296.

Madden, C. C., Summers, J. J., \& Brown, D. F. (1990). The influence of perceived stress on coping with competitive basketball. International Journal of Sport Psvchology 21, 21-35.

Marsh, H. W., Hey, J., Johnson, S., \& Perry, C. (1997). Elite Athlete Self Description Questionnaire: Hierarchical confirmatory factor analysis of responses by two distinct groups of elite athletes. International Joumal of Sport Psychology, 28, 237-258.

Meichenbaum, D. (1985). Stress inoculation training. New York: Pergamon Press.

Messick, S. (1989). Validity. In R. L. Linn (Ed.), Educational Measurement (3 ${ }^{\text {rd }}$ Ed.) (pp. 13-103). New York, NY: Macmillan.

Parker, J. D. A., \& Endler, N. S. (1992). Coping with coping assessment: A critical review. European Journal of Personality, 6 , 321-344.

Patterson, J. M., \& McCubbin, H. I. (1987). Adolescent coping style and behaviors: Conceptualization and measurement. Joumal of Adolescence, 10, 163-186.

Petlichkoff, L. M. (1996). The drop-out dilemma in youth sports. In O. Bar-Or (Ed.), The child and adolescent athlete (pp. 418-430). Oxford: Blackwell Science.

Phelps, S. B., \& Jarvis, P. A. (1994). Coping in adolescence: Empirical evidence for a theoretically based approach to assessing coping. Joumal of Youth and Adolescence, 23, 359-371.

Ptacek, J. T., Smith, R. E., \& Dodge, K. L. (1994). Gender differences in coping with stress: When stressor and appraisals do not differ. Personality and Social Psychology Bulletin, 20, 421-430.

Ptacek, J. T., Smith, R. E., Espe, K., \& Raffety, B. (1994). Limited correspondence between daily coping reports and retrospective coping recall. Psychological Assessment $6,41-49$.

Rapee, R. M., Craske, M. G., Brown, T. A., \& Barlow, D. H. (1996). Measurement of perceived control over anxiety-related events. Behavior Therapy, 27, 279-293. 
Reynolds, W. M. (1982). Development and reliable and valid short forms of the MarloweCrowne Social Desirability Scale. Joumal of Clinical Psvchology 38 119-125.

Rice, K. G., Herman, M. A., \& Petersen, A. C. (1993). Coping with challenge in adolescence: A conceptual model and psycho-educational intervention. Joumal of Adolescence, $16,235-251$.

Roth, S., \& Cohen, L. J. (1986). Approach, avoidance, and coping with stress. American Psychologist, 41, 813-819.

Ryckman, R. M., \& Hamel, J. (1995). Male and female adolescents' motives related to involvement in organized team sports. International Joumal of Sport Psychology, 26, 383-397.

Ryska, T. A. (1993). The relationship between trait and precompetitive state anxiety among high school athletes. Perceptual and Motor Skills, 76, 413-414.

Scheier, M. F., Weintraub, J. K., \& Carver, C. S. (1986). Coping with stress: Divergent strategies of optimists and pessimists. Journal of Personality and Social Psvchology, 51, 1257-1264.

Scherer, R. F., Drumheller, P. M., \& Owen, C. L. (1993). Evaluating differences in cognitive appraisal and coping over stages of a transaction. Joumal of Psychology, 127, 435-441.

Schmidt, G. W., \& Stein, G. L. (1991). Sport commitment: A model integrating enjoyment, dropout, and burnout. Joumal of Sport and Exercise Psychology $\underline{8}$ 254-265.

Schutz, R. W. (1998). Assessing the stability of psychological traits and measures. In J. L. Duda (Ed.), Advances in sport and exercise psychology measurement (pp. 393-408). Morgantown, WV: Fimess Information Technology.

Seiffge-Krenke, I. (1995). Stress, coping, and relationships in adolescence. Mahwah, NJ: Lawrence Erlbaum Associates.

Skinner, E. A. (1995). Perceived control, motivation, and coping. Thousand Oaks, CA: Sage. Skinner, E. A. (1996). A guide to the constructs of control. Joumal of Personality and Social Psychology, 71, 549-570. 
Smith, R. E. (1980). A cognitive-affective approach to stress management training for athletes. In C. Nadeau, W. Halliwell, K. Newell, \& G. Roberts (Eds.), Psychologv of motor behavior and sport (pp. 54-73). Champaign, IL: Human Kinetics.

Smith, R. E. (1986). Toward a cognitive-affective model of athletic burnout. Joumal of Sport Psychology,, $36-50$.

Sobel, M. E. (1997). Measurement, causation and local independence in latent variable models. In M. Berkane (Ed.), Latent variable modeling and applications to causality. New York, NY: Springer.

Stanton, H. E. (1991). The reduction in secretarial stress. Contemporary Hypnosis, $\underline{8}$ 45-50.

Stevens, J. (1992). Applied multivariate statistics for the social sciences $\left(2^{\text {nd }}\right.$ ed.). Hillsdale, NJ: Lawrence Erlbaum.

Stone, A. A., Greenberg, M. A., Kennedy-Moore, E. \& Newman, M. G. (1991). Self-report, situation-specific coping questionnaire: What are they measuring? Joumal of Personality and Social Psvchology, 61, 648-658.

Stone, A. A., Kennedy-Moore, E., Newman, M. G., Greenberg, M., \& Neale, J. M. (1992). Conceptual and methodological issues in current coping assessments. In B. N. Carpenter (Ed.), Personal coping: Theorv, research, and application (pp. 15-29). Westport, CT: Praeger.

Stone, A. A., \& Neale, J. M. (1984). New measure of daily coping: Development and preliminary results. Journal of Personality and Social Psychology 46 , 892-906.

Thoits, P. A. (1991). Patterns of coping with controllable and uncontrollable events. In E. M. Cummings, A. L. Greene, \& K. H. Karraker (Eds.), Life-span developmental psychology: Perspectives on stress and coping. Hillsdale, NJ: Erlbaum.

Thomas, J. R., and J. K. Nelson. (1990). Research methods in phvsical activity (2nd ed.). Champaign, IL: Human Kinetics. 
Thompson, C. P., Skowronski, J. J., Larsen, S. F., \& Betz, A. L. (1996). Autobiographical memory: Remembering what and remembering when. Mahwah, NJ: Lawrence Eribaum Associates.

Thomdike, R. M., Cunningham, G. K., Thomdike, R. L, \& Hagen, E. P. (1991). Measurement and evaluation in psychology and education (5th ed.). New York, NY: Macmillan Publishing $\mathrm{Co}$, Inc.

Wagenaar, W. A. (1986). My memory: A study of autobiographical memory over six years. Cognitive Psychology, 18, 225-252.

Weiss, M. R. (1993). Psychological effects of intensive sport participation on children and youth: Self-esteem and motivation. In B. R. Cahill \& A. J. Pearl (Eds.), Intensive participation in children's sport (pp. 39-69). Champaign, IL: Human Kinetics.

Weiss, M. R., \& Petlichkoff, L. M. (1989). Children's motivation for participation in and withdrawal from sport: Identifying the missing links. Pediatric Exercise Science, $\underline{1}, 195-211$.

West, S. G., Finch, J. F., \& Curran, P. J. (1995). Structural equation models with nonnormal variables: Problems and remedies. In R. H. Hoyle (Ed.), Structural equation modeling: Concepts, issues, and applications (pp.56-75). Thousand Oaks, CA: Sage. 
Appendix A

Demographics and Sports Participation Questionnaire 
Please fill out the following:

Age:

Grade:

Gender (Circle one): Male Female

Have you participated in any organized sports (teams or clubs with organized leagues or competitions) in the past 12 months?

$$
\begin{aligned}
& \text { Yes No } \\
& \text { (Circle one) }
\end{aligned}
$$

If yes, what sport(s) and level did you play in the past 12 months?

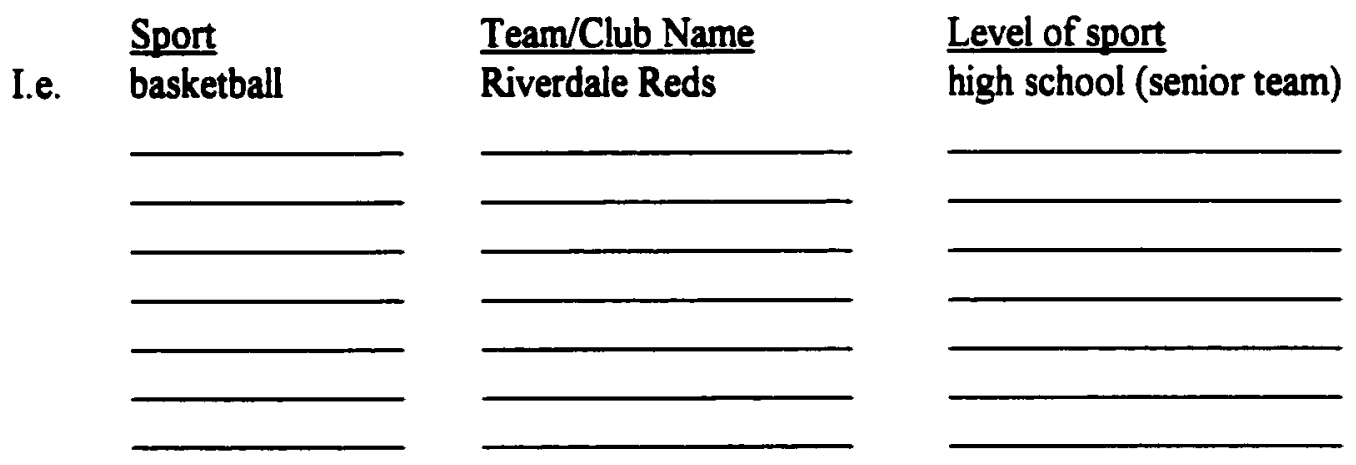




\section{Appendix B}

Stress appraisal and Coping Function Questionnaire (CFQ) used in Study 1. 
How long did the stressful situation last? (Circle one)

less than 1 week 1 week to 1 month 1 to 3 months more than 3 months

When did the stressful situation occur? (Circle one)

$\begin{array}{llll}\text { in the past } & \text { more than } 1 \text { week ago, } & \text { more than } 1 \text { month ago, } & \text { more than } 3 \text { months } \\ \text { week } & \text { but less than } & \text { but less than } & \text { ago, but less than } \\ & 1 \text { month ago } & 3 \text { months ago } & 12 \text { months ago }\end{array}$

Please indicate the amount of stress that you experienced in the situation by marking an ' $X$ ' on the scale within the thermometer:

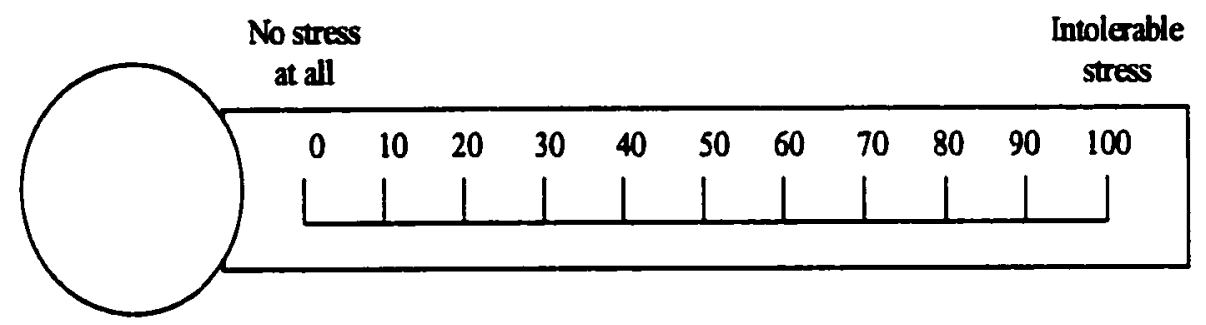

Why was this situation stressful to you?

We are interested in how you tried to handle the stressful situation you described above. We are NOT concemed with what you did before the situation happened or what you did after it was over. We want to know what you did to try to handle the stressful situation when you were actually faced with it.

* Take a minute to think about the types of things you did to try to handle the situation, and then continue.**

Please circle whether or not you used the following strategies to handle the situation you described above.

If yes, then complete Parts A, B, and C. If no, go on to the nert question.

Remember:

A. There are no right and wrong answers - this is not a test.

B. Please answer all the questions as honestly and accurately as you can - this is very important.

Two examples are provided. 
If yes,

\section{Part A}

How OFTEN did you

try this strategy?

(circle one)

seldom sometimes often very

often
Yes or No (Circle one)
Part B

How much TIME did

you spend on this strategy?

(circle one)

little some quite very

\section{Part C}

How much EFFORT was

required by this strategy? (circle one)

\section{Example \#2}

\section{I played basketball.}

If yes,
Part A

How OFTEN did you

try this strategy?

(circle one)

seldom sometimes often very
Yes or No (Circle one)

\section{Part B}

How much TLME did you spend on this strategy? (circle one)

little some quite very little some quite very abit much

1.

I tried to find a way to change the situation.
If yes,

Part A

How OFTEN did you

try this strategy?

(circle one)

seldom sometimes often very
Yes or No (Circle one)

How much TMME did
you spend on this strategy?
(circle one)
little some quite very
a bit much

Part C

How much EFFORT was required by this strategy? (circle one)

little some quite very a bit much
How much EFFORT was required by this strategy? (circle one)

little some quite very a bit much 
2.

I stayed in the situation and tried to control my emotions

to better deal with the situation.

If yes,

Part A

How OFTEN did you

try this strategy?

(circle one)

seldom sometimes often very

often

Yes or No (Circle one)

Part B

How much TIME did

you spend on this strategy?

(circle one)

little some quite very

a bit much
Part C

How much EFTORT was required by this strategy? (circle one)

3.

I worked harder to try to change the situation.

If yes,

Part A

How OFTEN did you

try this strategy?

(circle one)

seldom sometimes often very
Yes or No (Circle one)
Part B

How much TLME did you spend on this strategy?

(circle one)

little some quite very little some quite very a bit much

\section{I tried to change how I thought about the situation} so it didn't seem so stressful.

\section{If yes,}

Part A

How OFTCN did you

try this strategy?

(circle one)

seldom sometimes often very

\section{Yes or No (Circle one)}

\section{Part B}

How much TLME did you spend on this strategy? (circle one)

little some quite very often

\section{Part C}

How much EFFORT was required by this strategy? (circle one)

little some quite very a bit much 
5.

I got out of the situation as soon as I could.

If yes,

Part A

How ORTEN did you

try this strategy?

(circle one)

seldom sometimes often very

often
Yes or No (Circle one)

Part B

How much TIME did you spend on this strategy? (circle one)

little some quite very a bit much

\section{Part C}

How much EFFORT was required by this strategy? (circle one)

6.

I tried to use problem-solving strategies

to make things better.

Part A

How OFTEN did you

try this strategy?

(circle one)

seldom sometimes often very
Part B

How much TIME did you spend on this strategy? (circle one)

little some quite very a bit much
Part C

How much EFFORT was required by this strategy? (circle one)

little some quite very a bit much

7.

I tried to view the situation in a way that made it seem less stressful.

If yes,

Part A

How OFTEN did you

try this strategy?

(circle one)

seldom sometimes often very

often

\section{Yes or No (Circle one)}

\section{Part B}

How much TIME did

you spend on this strategy?

(circle one)

little some quite very

\section{Part C}

How much EFFORT was required by this strategy? (circle one)

litule some quite very a bit much

8.

I left or avoided the situation temporarily to get away from the problem.

If yes,

Part A

How OFTEN did you

try this strategy?

(circle one)

seldom sometimes often very

often

Yes or No (Circle one)

Part B

How much TMES did you spend on this strategy? (circle one)

little some quite very a bit much

\section{Part C}

How much EFFORT was required by this strategy? (circle one)

little some quite very a bit much 
9.

I did my best to change the situation.

Yes or No (Circle one)

If yes,

Part A

How OFTEN did you

try this strategy?

(circle one)

seldom sometimes often very
Part B

How much TLME did you spend on this strategy? (circle one)

little some quite very
Part C

How much EFFORT was required by this strategy? (circle one)

little some quite very a bit much

10.

I talked to someone who could help me feel better.

If yes,

Part A

How OFTEN did you

try this strategy?

(circle one)

Yes or No (Circle one)

seldom sometimes often very

often

\section{Part B}

How much TIME did you spend on this strategy? (circle one)

litule some quite very a bit much

\section{Part C}

How much EFFORT was

required by this strategy?

(circle one)

II.

I looked for ways to solve the problem or change the situation.

If yes,

Part A

How OFTEN did you

try this strategy?

(circle one)

seldom sometimes often very

often

\section{Yes or No (Circle one)}

Part B

How much TIME did

you spend on this strategy?

(circle one)

little some quite very a bit much
Part C

How much EFFORT was required by this strategy? (circle one)

little some quite very a bit much 
12.

I got out of the situation for a little while to get away from the stress.

If yes,

Part A

How OFTEN did you

try this strategy?

(circle one)

seldom sometimes often very

often

Yes or No (Circle one)

\section{Part B}

How much TIME did you spend on this strategy? (circle one)

little some quite very a bit much

\section{Part C}

How much EFFORT was required by this strategy? (circle one)

little some quite very a bit much

13.

I talked to someone who could help me solve the problem.

If yes,

Part A

How OFTEN did you

try this strategy?

(circle one)

seldom sometimes often very

Yes or No (Circle one)

Part B

How much TIME did you spend on this strategy? (circle one)

little some quite very a bit much

\section{Part C}

How much EFFORT was required by this strategy? (circle one)

little some quite very a bit much

14.

If yes,

Part A

How OFTEN did you

try this strategy?

(circle one)

seldom sometimes often very

often

I accepted the situation.

Yes or No (Circle one)

\section{Part B}

How much TLME did you spend on this strategy? (circle one)

little some quite very a bit much

\section{Part C}

How much EFFORT was required by this strategy? (circle one)

little some quite very a bit much 
15.

I stayed in the situation and tried to change it.

If yes,

Part A

How OFTEN did you

try this strategy?

(circle one)

seldom sometimes often very
Yes or No (Circle one)

\section{Part B}

How much TME did

you spend on this strategy?

(circle one)

little some quite very a bit much

\section{Part C}

How much EFFORT was required by this strategy?

(circle one)

little some quite very a bit much

16.

I worked through my emotions in order to feel better.

If yes,

Part A

How OFTEN did you

try this strategy?

(circle one)

seldom sometimes often very

Yes or No (Circle one)

\section{Part B}

How much TIME did

you spend on this strategy?

(circle one)

litule some quite very

\section{Part C}

How much EFFORT was required by this strategy? (circle one)

little some quite very a bit much

17.

I tried to get away from the situation.

If yes,

Part A

How OFTEN did you

try this strategy?

(circle one)

seldom sometimes often very

often

Yes or No (Circle one)

Part B

How much TIME did you spend on this strategy? (circle one)

little some quite very a bit much

\section{Part C}

How much EFFORT was required by this strategy? (circle one)

little some quite very bit much 
18.

I tried to find ways to control my emotions.

If yes,

\section{Part A}

How OFTEN did you

try this strategy?

(circle one)

seldom sometimes often very

often

Yes or No (Circle one)

Part B

How much TIME did

you spend on this strategy?

(circle one)

little some quite very a bit much

\section{Part C}

How much EFFORT was

required by this strategy?

(circle one)

little some quite very a bit much

19.

I tried to relax so that I could keep my emotions under control.

If yes,

Part A

How OFTEN did you

try this strategy?

(circle one)

seldom sometimes often very

Yes or No (Circle one)

Part B

How much TIME did you spend on this strategy? (circle one)

little some quite very a bit much
Part C

How much EFTORT was required by this strategy? (circle one)

little some quite very a bit much 
Appendix C

Perceived control questionnaire used in Study 1 
Please thiak about the stressful situation you described, and respond whether you agree or disagree with the following statements:

1. If I wanted to, I could have changed the situation.

\begin{tabular}{|c|}
\hline $\begin{array}{l}\text { Strongly } \\
\text { disagree }\end{array}$ \\
\hline
\end{tabular}

2. If I wanted to, I could have controlled mv emotions.

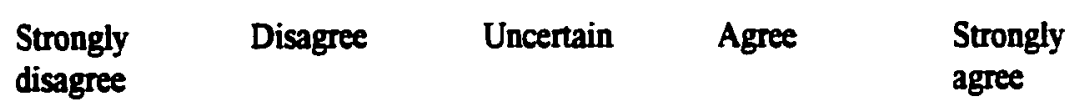

3. No matter how hard I tried, I could not have changed the sinuation.

$\begin{array}{lllll}\begin{array}{l}\text { Strongly } \\ \text { disagree }\end{array} & \text { Disagree } & \text { Uncertain } & \text { Agree } & \begin{array}{l}\text { Strongly } \\ \text { agree }\end{array}\end{array}$

4. No matter how hard I tried, I could not have controlled my emotions.

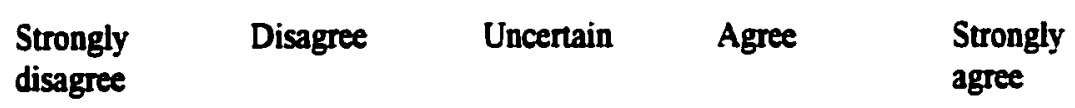

5. I could have avoided the situation.

\begin{tabular}{|c|c|c|}
\hline $\begin{array}{l}\text { Strongly } \\
\text { disagree }\end{array}$ & Disagree & Uncertain \\
\hline
\end{tabular}

6. I couldn't have gotten out of the situation no matter what I did.

$\begin{array}{lllll}\begin{array}{l}\text { Strongly } \\ \text { disagree }\end{array} & \text { Disagree } & \text { Uncertain } & \text { Agree } & \begin{array}{l}\text { Strongly } \\ \text { agree }\end{array}\end{array}$

7. I could have controlled mr emotions.

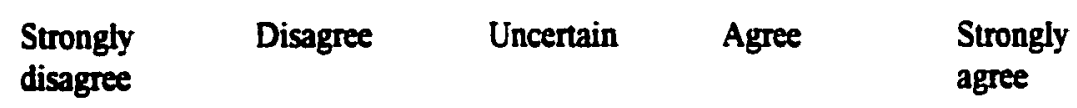

8. I could have got out of the situation if I decided to.

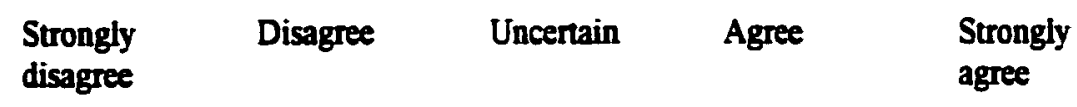

9. I couldn't have controlled my emotions, even if I wanted to.

$\begin{array}{lllll}\begin{array}{l}\text { Strongly } \\ \text { disagree }\end{array} & \text { Disagree } & \text { Uncertain } & \text { Agree } & \begin{array}{l}\text { Strongly } \\ \text { agree }\end{array}\end{array}$


10. I could have changed the situation if I decided to.

$\begin{array}{lllll}\begin{array}{l}\text { Strongly } \\ \text { disagree }\end{array} & \text { Disagree } & \text { Uncertain } & \text { Agree } & \begin{array}{l}\text { Strongly } \\ \text { agree }\end{array}\end{array}$

11. I couldn't have changed the situation, no matter what I did.

$\begin{array}{lllll}\begin{array}{l}\text { Strongly } \\ \text { disagree }\end{array} & \text { Disagree } & \text { Uncertain } & \text { Agree } & \begin{array}{l}\text { Strongly } \\ \text { agree }\end{array}\end{array}$

12. I couldn't have avoided the situation even if I wanted to.

\begin{tabular}{|c|c|c|}
\hline $\begin{array}{l}\text { Strongly } \\
\text { disagree }\end{array}$ & Disagree & Uncertain \\
\hline
\end{tabular}




\section{Appendix D}

Cover letter and consent form used in Study 1 


\section{Cover Letter}

Development and Validation of the Sport Coping Questionnaire for Adolescents

Dear parent or guardian,

We are conducting a study to look at how adolescent's try to manage stress they experience in sport. How individuals manage stress in sport is important because it can affect their participation, fun, satisfaction, as well as performance in sport. The information you give us will hopefully help us better understand adolescents' sporting experiences and provide us a better way to look at stress in sport.

We would like you approve participation of your son or daughter in this research. Participation involves filling out the Sport Coping Questionnaire for Adolescents, a questionnaire that asks about a stress experienced in sport and how it was managed. The questionnaire will take approximately 15-30 minutes to complete, and will occur at school. There are no aspects of physical or psychological risk, and completion of the questionnaires should not cause any more than possibly a mild discomfort in recalling a stressful event.

The results for the study will be used for a doctoral thesis and research publications, but will only be presented as aggregate data, and the identity of individual participants will be kept confidential (only seen by members of the research team). The results will be securely stored for a minimum of five years as required by the University of Saskatchewan guidelines. A summary of the research results will be available upon request.

The students will be advised of any new information that may influence their decision to participate in the study, and they are free to withdraw from this study at any time with absolutely no penalty. The decision to withdraw will NOT result in any loss of services, grades, or other negative consequences at the school or with their athletic team.

If you have any questions, feel free to contact me.

Your respectfully,

Kent Kowalski, M.Sc.

College of Physical Education

University of Saskatchewan

(W) $966-6498$

(H) $343-0536$
Peter Crocker, Ph.D.

College of Physical Education

University of Saskatchewan

966-6510 


\section{Consent Form}

My signature on this sheet indicates that I will allow my son or daughter, to participate in the study Development and Validation of the Sport Coping Questionnaire for Adolescents by Kent Kowalski. It indicates that I understand the following,

l. I received information regarding the nature of the study, its purpose, and procedures.

2. Participation is voluntary, and he/she can withdraw from the study at any time without any fear of penalty. The decision to withdraw will NOT result in any loss of services, grades, or other negative consequences at the school or with his/her athletic team.

3. There are no risks of physical or psychological harm.

4. All individual data that is provided will remain confidential from sources outside of the study.

5. I will receive a summary of the project, upon request, following completion of the project.

6. I have received a copy of the consent for my records.

Signature of parent or guardian

I conditions of my participation in this study.

have read the above statements regarding the study and understand the

Signature of student

Date

Kent Kowalski, M.Sc.

College of Physical Education

University of Saskatchewan

(W) $966-6498$

(H) $343-0536$
Peter Crocker, Ph.D.

College of Physical Education

University of Saskatchewan

966-6510 


\section{Appendix E}

Research assistant confidentiality form 


\section{Research Assistant Confidentiality Form}

I understand that the confidentiality of the participants in the study Development and Validation of the Sport Coping Questionnaire for Adolescents by Kent Kowalski is of utmost importance and agree to treat all information gathered in the study in a confidential manner.

Signature of research assistant

Date

Kent Kowalski, M.Sc.

College of Physical Education

University of Saskatchewan

(W) $966-6498$

(H) $343-0536$
Peter Crocker, Ph.D.

College of Physical Education

University of Saskatchewan

$966-6510$ 


\section{Appendix F}

Stress appraisal and Coping Function Questionnaire (CFQ) used in Study 2. 
Describe the most stressful situation in sport that YOU have faced in the last 12 months?

How long did the stressful situation last? (Circle one)

less than I week I week to 1 month $\quad 1$ to 3 months more than 3 months

When did the stressful situation occur? (Circle one)

$\begin{array}{llll}\text { in the past } & \text { more than } 1 \text { week ago, } & \text { more than } 1 \text { month ago, } & \text { more than } 3 \text { months } \\ \text { week } & \text { but less than } & \text { but less than } & \text { ago, but less than } \\ & 1 \text { month ago } & 3 \text { months ago } & 12 \text { months ago }\end{array}$

Please indicate the amount of stress that you experienced in the situation by marking an ' $X$ ' on the scale within the thermometer:

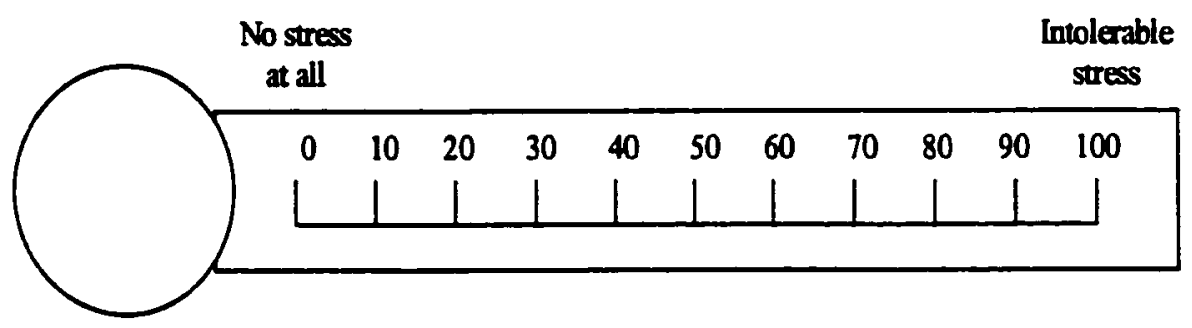

Why was this situation stressfiul to you?

We are interested in how you tried to handle the stressful situation you described above. We are NOT concerned with what you did before the situation happened or what you did after it was over. We want to know what you did to try to handle the stressiul situation when you were actually faced with it.

**Take a minute to think about the types of things you did to try to handle the situation, and then continue.**

Please fill in the circle for how much you used the following strategies to handle the situation you described above.

Remember:

A. There are no right and wrong answers - this is not a test.

B. Please answer all the questions as honestly and accurarely as you can - this is very important. 
How much did you use the following strategies to handle the stressful situation you described on the previous page?

l.

I tried to find a way to change the situation.

$\begin{array}{ccccc}0 & 0 & 0 & 0 & 0 \\ \text { Not at all } & \text { A little } & \text { Somewhat } & \text { Quite a bit } & \text { Very much }\end{array}$

2.

I stayed in the situation and tried to control my emotions to better deal with the situation.

$\begin{array}{lllll}0 & 0 & 0 & 0 & 0\end{array}$

Not at all A little Somewhat Quite a bit Very much

3.

I worked harder to try to change the situation.

O

Not at all
0

A little
0

Somewhat
0

Quite a bit Very much

4.

I tried to change how I thought about the situation so it didn't seem so stressful.

O

Not at all
O

A little
0

Somewhat
0

Quite a bit Very much

5.

I tried to get out of the situation as soon as I could to reduce the stress.

0

Not at all

\section{O}

A little
O

Somewhat
0

Quite a bit
O

Very much

6.

I used strategies to change the situation in order to deal with the stress.

O

Not at all
0

A little
0

Somewhat
O

Quite a bit
O

Very much 
7.

I tried to view the situation in a way that made it seem less stresoful.

$\begin{array}{lllll}0 & 0 & 0 & 0 & 0\end{array}$

Not at all A little Somewhat Quite a bit Very much

8.

I tried to leave or avoid the situation

to get away from the problem or reduce the stress.

O

O

0

O

O

Not at all A litte Somewhat Quite a bit Very much

9.

I did my best to change the situation.

0

O

0

O

O

Not at all A little Somewhat Quite a bit Very much

10.

I tried to use difierent strategies

that would help me control my emotions.

$\begin{array}{lllll}0 & 0 & 0 & 0 & 0\end{array}$

Not at all A little Somewhat Quite a bit Very much

11.

I looked for ways to solve the problem or change the situation.

$\begin{array}{lllll}0 & 0 & 0 & 0 & 0\end{array}$

Not at all A little Somewhat Quite a bit Very much

12.

I tried to get out of the situation to get away from the stress.

$\begin{array}{lllll}0 & 0 & 0 & 0 & 0\end{array}$

Not at all A little Somewhat Quite a bit Very much

13.

I stayed in the situation and tried to change it.

O

O

O

$0 \quad 0$

Not at all A little Somewhat Quite a bit Very much 
14.

I worked through my emotions in order to feel better.

$\begin{array}{lllll}0 & 0 & 0 & 0 & 0\end{array}$

Not at all A little Somewhat Quite a bit Very much

15.

I tried to get away from the situation to reduce the stress.

$\begin{array}{lllll}0 & 0 & 0 & 0 & 0\end{array}$

Not at all A little Somewhat Quite a bit Very much

16.

I tried to find ways to control my emotions.

$\begin{array}{lllll}0 & 0 & 0 & 0 & 0\end{array}$

Not at all A little Somewhat Quite a bit Very much

17.

I tried to relax so that I could keep my emotions under control.

$\begin{array}{lllll}0 & 0 & 0 & 0 & 0\end{array}$

Not at all A litule Somewhat Quite a bit Very much

18.

In order to reduce the stress

I tried to get myself out of the situation.

$\begin{array}{lllll}0 & 0 & 0 & 0 & 0\end{array}$

Not at all A little Somewhat Quite a bit Very much 
Appendix G

COPE questionnaire. 
For each item, indicate how much you used each strategy during the stressful situation.

Use the following scale:

$$
\begin{aligned}
& 1=\text { not used at all } \\
& 2=\text { used a little } \\
& 3=\text { used somewhat } \\
& 4=\text { used much } \\
& 5=\text { used very much }
\end{aligned}
$$

1. I talked to someone about how I felt.

2. I tried real hard to do something about my situation.

3. I did what had to be done, one step at a time.

4. I got used to the idea that it happened.

5. I got support and understanding from someone.

6. I accepted that it had happened and that it couldn't be changed.

7. I forced myself to wait for the right time to do something.

8. I accepted the reality of the fact that it happened.

9. I made a plan of action.

10. I made sure not to make matters worse by acting too soon.

11. I thought hard about what steps to take to manage this situation.

12. I restrained myself from doing anything too quickly.

13. I talked about my feelings with someone.

14. I thought about how I could best handle my situation.

15. I took direct action to overcome the stressful situation.

16. I tried different things to change the situation.

17. I tried to get help from someone to deal with my feelings.

18. I leamed to live with it.

19. I held off doing anything about it until the situation permitted.

20. I tried to think about a plan about what to do. $\begin{array}{lllll}1 & 2 & 3 & 4 & 5\end{array}$

$\begin{array}{lllll}1 & 2 & 3 & 4 & 5\end{array}$

$1 \quad 2 \quad 3 \quad 4 \quad 5$

$\begin{array}{lllll}1 & 2 & 3 & 4 & 5\end{array}$

$\begin{array}{lllll}1 & 2 & 3 & 4 & 5\end{array}$

$1 \quad 2 \quad 3 \quad 4 \quad 5$

12345

12345

12345

$\begin{array}{lllll}1 & 2 & 3 & 4 & 5\end{array}$

$\begin{array}{lllll}1 & 2 & 3 & 4 & 5\end{array}$

12345

12345

12345

12345

12345

12345

12345

12345

12345 
Appendix $\mathrm{H}$

Life Situations Inventory (LSI) questionnaire. 
How much did you use each of the following during your stressful situation?

1. How much did you spend time thinking about

Not A Quite Very

at all little a bit much more pleasant things instead?

2. How much did you try to keep yourself busy - to keep your mind away from the situation?

3. How much did you realize that there was nothing you could do about the situation?

4. How much did you feel that the final outcome was beyond your control?

5. How much did you try to get away from the situation for awhile by doing something else?

6. How much did you try not to think about the situation?

7. How much did you want to just forget about the whole thing?

8. How much did you feel that the worst would probably happen no matter what you did?

9. How much did you try to make yourself feel better about the situation by eating, drinking, smoking, or taking medication?

10. How much did you refuse to take the situation too seriously?

11. How much did you feel that whatever you did wouldn't matter?

12. How much did you prefer to be by yourself during the time that you were trying to resolve the situation?

13. How much did you tell yourself that there was no good solution to the situation? 


\section{Appendix I}

Perceived control questionnaire used in Study 2 
Please think about the stressful situation you described, and respond whether you agree or disagree with the following statements:

1. If I wanted to, I could have changed the situation.

\begin{tabular}{|c|}
\hline $\begin{array}{l}\text { Strongly } \\
\text { disagree }\end{array}$ \\
\hline
\end{tabular}

2. If I wanted to, I could have controlled mv emotions.

$\begin{array}{lllll}\begin{array}{l}\text { Strongly } \\ \text { disagree }\end{array} & \text { Disagree } & \text { Uncertain } & \text { Agree } & \begin{array}{l}\text { Strongly } \\ \text { agree }\end{array}\end{array}$

3. No matter how hard I tried, I could not have changed the situation.

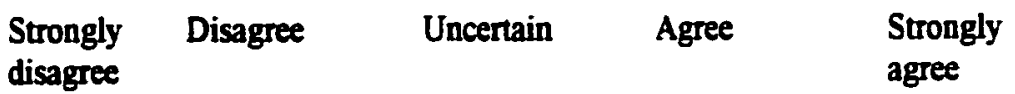

4. No matter how hard I tried, I could not have controlled my emotions.

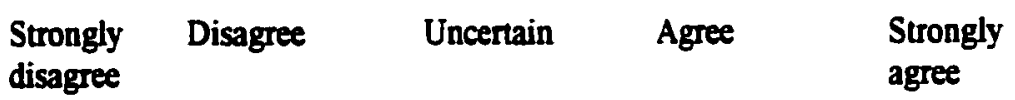

5. I could have avoided the situation to get away from the stress.

$\begin{array}{lllll}\begin{array}{l}\text { Strongly } \\ \text { disagree }\end{array} & \text { Disagree } & \text { Uncertain } & \text { Agree } & \begin{array}{l}\text { Strongly } \\ \text { agree }\end{array}\end{array}$

6. I couldn't have gotten out of the situation, no matter what I did.

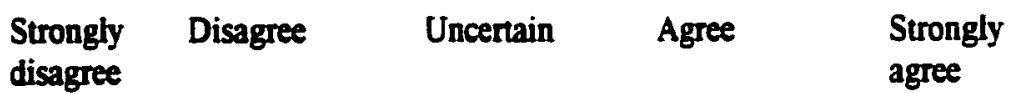

7. I could have controlled my emotions.

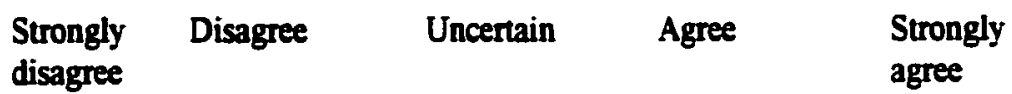

8. I could have gotten out of the situation if I decided to.

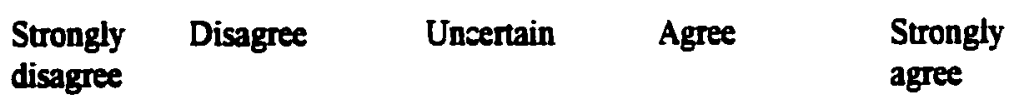

9. I couldn't have controlled my emotions, even if I wanted to.

\begin{tabular}{|c|}
\hline $\begin{array}{l}\text { Strongly } \\
\text { disagree }\end{array}$ \\
\hline
\end{tabular}

10. I could have changed the situation if I decided to.

\begin{tabular}{|c|}
\hline $\begin{array}{l}\text { Strongly } \\
\text { disagree }\end{array}$ \\
\hline
\end{tabular}


11. I couldn't have changed the situation, no matter what I did.

$\begin{array}{lllll}\text { Strongly } & \text { Disagree } & \text { Uncertain } & \text { Agree } & \begin{array}{l}\text { Strongly } \\ \text { agree }\end{array}\end{array}$

12. I coulda't have avoided the situation to get away from the stress, even if I wanted to.

$\begin{array}{lllll}\begin{array}{l}\text { Strongly } \\ \text { disagree }\end{array} & \text { Disagree } & \text { Uncertain } & \text { Agree } & \begin{array}{l}\text { Strongly } \\ \text { agree }\end{array}\end{array}$


Appendix J

Social desirability questionnaire 
Please answer the following questions by circling what you feel is the most appropriate answer.

1. It is sometimes hard for me to go on with my work if I am not encouraged.

True False

2. I sometimes feel resentful when I don't get my way.

True False

3. On a few occasions, I have given up doing something because I thought too little about my ability.

True False

4. There have been times when I felt like rebelling against people in authority even though I knew they were right.

True False

5. No matter who I'm talking to, I'm always a good listener.

True False

6. There have been occasions when I took advantage of someone.

True False

7. I'm always willing to admit it when I make a mistake.

True False

8. I sometimes try to get even rather than forgive and forget.

True False

9. I'm always courteous, even to people who are disagreeable.

True False

10. I have never been irked when people expressed ideas different from my own.

True False

11. There have been times when I was quite jealous of the good fortune of others.

True False

12. I am sometimes irritated by people who ask favors of me.

True False 
13. I have never deliberately said something that hurt someone's feelings.

\section{True False}


Appendix K

Cover letter and consent form used in Study 2 


\section{Cover Letter}

Development and Validation of the Sport Coping Questionnaire for High School Students

Dear parent or guardian,

We are conducting a study to look at how high school students try to manage stress experienced in sport. How individuals manage stress in sport is important because it can affect participation, fun, satisfaction, as well as performance in sport. The information you give us will help us better understand high school students' sporting experiences and provide us with a better way to look at stress in sport.

We would like you to approve participation of your son or daughter in this research. Participation involves filling out a questionnaire package that asks about a stress experienced in sport and how he/she dealt with it. The questionnaire will take approximately 30 minutes to complete, and will occur at school. There is no physical or psychological risk, and completion of the questionnaire should not cause any more than possibly a mild discomfort in recalling a stressful event.

The results of the study will be used for a doctoral thesis and research publications, but will be presented as group data only, and the identity of individual participants will be anonymous. The results will be securely stored for a minimum of five years as required by the University of Saskatchewan guidelines. A summary of the research results will be available upon request.

The students will be advised of any new information that may influence their decision to participate in the study, and they are free to withdraw from this study at any time with absolutely no penalty. The decision to withdraw will NOT result in any loss of services, grades, or other negative consequences at the school or with their athletic team.

If you have any questions, feel free to contact me.

Yours respectfully,

Kent Kowaiski, M.Sc.

College of Kinesiology

University of Saskatchewan

(W) $966-2687$

(H) $343-0536$
Peter Crocker, Ph.D.

College of Kinesiology

University of Saskatchewan

966-6510 


\section{Consent Form}

My signature on this sheet indicates that I will allow my son or daughter, to participate in the study Development and Validation of the Sport Coping Questionnaire for High School Students by Kent Kowalski and Peter Crocker. It indicates that I understand the following,

1. I received information regarding the nature of the study, its purpose, and procedures.

2. Participation is voluntary, and he/she can withdraw from the study at any time without any fear of penalty. The decision to withdraw will NOT result in any loss of services, grades, or other negative consequences at the school or with his/her athletic team.

3. There are no risks of physical or psychological harm.

4. All individual data that is provided will remain confidential from sources outside of the study.

5. I will receive a summary of the project, upon request, following completion of the project.

6. I have received a copy of the consent for my records.

Signature of parent or guardian

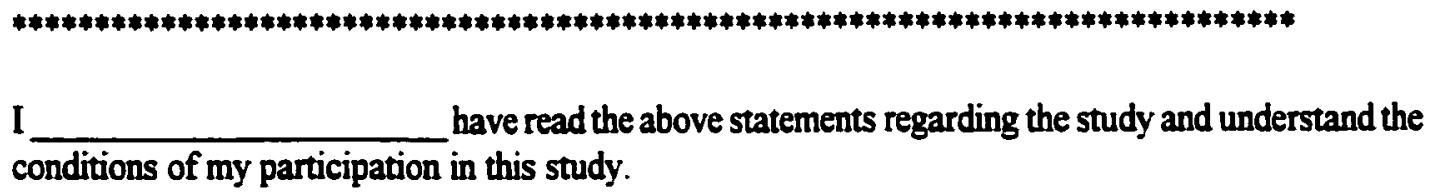

Signature of student

Date

Kent Kowalski, M.Sc.

College of Kinesiology

University of Saskatchewan

(W) $966-2687$

(H) $343-0536$
Peter Crocker, Ph.D.

College of Kinesiology

University of Saskatchewan

966-6510 


\section{Appendix L}

Summary of results for non-sport participants in Study 2 
The CFQ was expected to provide a valid assessment of coping function for a non-sport, as well as sporting sample. No specific differences were expected between sport and non-sport participants, however, differences in relationships among coping and control variables was considered possible given that the two groups were recalling from different classes of stressful situations (sport versus physical activity, fitness/dance, physical education, or other types of games). Validity for non-sport participants would suggest preliminary evidence for the utility of the CFQ in non-sport populations.

The sample size of non-sport participants in Study 2 was 152 (65 males, 87 females). The mean age of the non-sport participants was $16.14(\underline{S D}=1.41)$ for males and $15.83(\underline{S D}=1.14)$ for females.

The mean and standard deviation values for males and females respectively on the CFQ scales were as follows: problem-focused coping function, $\underline{M}=2.83,2.80, \underline{\mathrm{SD}}=.91, .90$ : emotion-focused coping function, $\underline{\mathrm{M}}=2.71,3.03, \underline{\mathrm{SD}}=.80, .83 ;$ and avoidance coping function, $\underline{\mathrm{M}}=2.32,2.34, \underline{\mathrm{SD}}$ $=1.07,1.17$. A multivariate analysis of variance (MANOVA) was conducted to look at gender differences on coping and perceived control scales. The multivariate effect for gender was not significant (Wilks Lambda $=.97 ; \underline{F}(13,138)=1.37$, n.s.), and therefore follow-up univariate analysis was not conducted.

Internal consistency values on the CFQ for male and female non-sport participants respectively were: problem-focused coping function, alpha $=.79, .85$; emotion-focused coping function, alpha $=$ $.78, .85$; and avoidance coping function, alpha $=.87, .92$. Internal consistency values on other scales were above .70 , except for control over avoiding the situation for males (alpha $=.66$ ), and LSI avoidance for both males and females (alpha $=.68$ for both).

The correlations among CFQ and perceived control items for non-sport participants were generally similar as those found for sport participants, although there were a larger number of correlations higher between items on different scales than for items within scales. Notably, item 10 (an emotionfocused item) had similar correlations with problem-focused coping function items as problem-focused 
coping function items had among each other. Also, for females, numerous emotion-focused coping items had relatively similar correlations with problem-focused coping function items as problemfocused coping function items had among each other. The results should be interpreted cautiously considering the relatively small sample sizes used compared to the sport participants. Subsequent work should examine if these relationships hold for other larger non-sport samples, as well as potential reasons for these differences. Results for correlations among items on the perceived control scale were very similar for both sport and non-sport participants.

A confirmatory factor analysis was conducted for a combined sample of non-sport participants $(n=152)$. Males and females were collapsed for non-sport participants because the small sample sizes for males and females separately would be inappropriate for structural equation modeling analysis. Confirmatory factor analysis showed the CFQ three coping function measurement model to be acceptable (chi-square $(132, \underline{\mathrm{n}}=152)=229.10, \mathrm{p}<.05, \mathrm{TLI}=.905, \mathrm{CFI}=.918)$. CFA suggested the COPE measurement model was borderline (chi-square $(160, \underline{\mathrm{n}}=152)=311.99, \mathrm{p}<.05, \mathrm{TLI}=$ $.865, \mathrm{CFI}=.886$ ). The LSI (chi-square $(64, \underline{\mathrm{n}}=152)=128.33, \mathrm{p}<.05, \mathrm{TLI}=.835, \mathrm{CFI}=.865$ ) and perceived control (chi-square $(51, \underline{\mathrm{n}}=152)=144.39, \mathrm{p}<.05, \mathrm{TLI}=.828, \mathrm{CFI}=.867)$ measurement models were likely not acceptable. It is interesting the CFQ measurement model was the only model that was considered acceptable for non-sport participants. In addition, similar to with sport participants, all factor loadings in the CFQ three factor measurement model were significant and above .40. Factorial gender invariance could not be conducted given the small sample sizes for male and female non-sport participants.

Correlations among scale latent variables for non-sport participants were similar to those found with sport participants. A notable exception was the stronger relationship between problem- and emotion-focused coping function on the CFQ for non-sport participants $(r=.45)$, although this relationship was only moderate. Avoidance coping function was not related to either problem-focused 
$(r=.09$, n.s. $)$ or emotion-focused $(r=.05$, n.s. $)$ coping function, providing divergent validity evidence for the coping function scales on the CFQ. As evidence for convergent validity, problem-focused coping function on the CFQ was related to active coping $(r=.87, \mathrm{p}<.05)$ and planning $(r=.60, \mathrm{p}<$ .05 ) on the MCOPE, emotion-focused coping function was related to social support for emotion reasons $(r=.31, \mathrm{p}<.05)$, acceptance $(r=.41, \mathrm{p}<.05)$, and restraint $(r=.42, \mathrm{p}<.05)$ on the COPE, and avoidance coping function was related to avoidance $(r=.48, \mathrm{p}<.05)$ and resignation $(r=.31, \mathrm{p}$ $<.05$ ) on the LSI. Overall, correlations between coping function and coping strategies on the COPE and LSI were similar across sport and non-sport participants, despite non-sport participants reporting from a different class (physical activity, fitness/dance, physical education, or other games) of stressful situations than sport participants who reported sport situations.

Perceived control was more strongly related to coping function for non-sport participants than for sport participants. More specifically, perceptions over changing the situation were correlated $\underline{r}=.32$ for males and $\underline{r}=.40$ for females with problem-focused coping function. The reason for these differences is not clear, but suggests the relationships between coping function and perceived control may be different for non-sport participants compared to sport participants. It should noted that these relationships need to be interpreted with caution given the small sample sizes compared with sport participants. The structural model with perceived control predicting coping function was not acceptable for non-sport participants (chi-square $(397, \underline{\underline{n}}=152)=697.92, \underline{\mathrm{Q}}<.05, \mathrm{TLI}=.835$, CFI $=.849$ ). The only significant path was from perceived control over changing the situation to problemfocused coping (standardized path coefficient $=.40$ ). 